\title{
Political Deepfakes Are As Credible As Other Fake Media And (Sometimes) Real Media*
}

\author{
Soubhik Barari ${ }^{\dagger} \quad$ Christopher Lucas ${ }^{\ddagger} \quad$ Kevin Munger ${ }^{\S}$ \\ First Draft: January 13, 2021 \\ This Draft: April 16, 2021
}

\begin{abstract}
We demonstrate that fabricated videos of public officials synthesized by deep learning ("deepfakes") are credible to a large portion of the American public - up to $50 \%$ of a representative sample of 5,750 subjects - however no more than equivalent misinformation in extant modalities like text headlines or audio recordings. Moreover, there are no meaningful heterogeneities in these credibility perceptions nor greater affective responses relative to other mediums across subgroups. However, when asked to discern real videos from deepfakes, partisanship explains a large gap in viewers' detection accuracy, but only for real videos, not deepfakes. Brief informational messages or accuracy primes only sometimes (and somewhat) attenuate deepfakes' effects. Above all else, broader literacy in politics and digital technology increases discernment between deepfakes and authentic videos of political elites. Our findings come from two experiments testing exposure to a novel collection of deepfakes created in collaboration with tech industry partners.
\end{abstract}

\footnotetext{
${ }^{*}$ For excellent research assistance, we thank Jordan Duffin Wong. We thank the Wiedenbaum Center at Washington University in St. Louis for generously funding this experiment. For helpful comments, we thank the Political Data Science Lab and the Junior Faculty Reading Group at Washington University in St. Louis; the Imai Research Group; the Enos Research Design Happy Hour; the American Politics Research Workshop at Harvard University; the Harvard Experiments Working Group; and Jacob Brown, Andy Guess, Connor Huff, Yphtach Lelkes, Jacob Montgomery, and Steven Webster for helpful comments. We thank Hany Farid for sharing video clips used in this project. We are especially grateful to Sid Gandhi, Rashi Ranka, and the entire Deepfakeblue team for their collaboration on the production of videos used in this project. All replication data and code is publicly available here.

${ }^{\dagger}$ Ph.D. Candidate, Harvard University; URL: soubhikbarari.org, Email: sbarari@g.harvard.edu

¥Assistant Professor, Washington University in St. Louis; URL: christopherlucas.org, Email: christopher.lucas@wustl.edu

${ }^{\S}$ Assistant Professor, Pennsylvania State University; URL: kevinmunger.com, Email: kmm7999@psu.edu
} 


\section{Introduction}

Studies of democratic politics have long emphasized the importance of a well-informed electorate for bolstering democratic accountability (Lippmann, 1922; Berelson, Lazarsfeld and McPhee, 1954; Downs, 1957; Snyder Jr and Strömberg, 2010; Herman and Chomsky, 2010). Information allows voters to accurately judge attributes of electoral candidates such as leadership, expertise, competence, character, and values in order to make principled decisions at the ballot-box (Popkin, 1991; Pierce, 1993; Alexander and Andersen, 1993; Alvarez, 1998; Strömberg, 2004; Caprara et al., 2006). Political misinformation, then, threatens the electorate's ability to credibly evaluate public officials and elect competent leaders (Carpini and Keeter, 1996; Kuklinski et al., 2000; Hollyer, Rosendorff and Vreeland, 2019; Aral and Eckles, 2019; Jerit and Zhao, 2020).

Societal concerns about misinformation have recently centered on novel deep learning technologies capable of synthesizing realistic videos of politicians making statements that they never said, colloquially termed deepfakes. Unlike previously available video manipulation tools, contemporary deepfake tools are open source, and thereby unlicensed, unregulated, and can be harnessed by hobbyists (rather than visual effect specialists) with relatively basic computational skills and resources (Government Accountability Office: Science and Analytics, 2020). Figure 1 graphically summarises the two major technologies for the production of deepfakes, which, by many counts, are responsible for the production of the vast majority of political deepfakes at the time of writing (Lewis, 2018; Davis, 2020; Ajder et al., 2019). Since the advent of open-source deepfake technologies ${ }^{1}$, political elites around the world have been targeted in deepfake video scandals. Notable examples include a 2018 deepfake of Gabon president Ali Bongo, which triggered a coup attempt, and a viral deepfake reporting on a sex scandal involving a Malaysian cabinet minister (Harwell, 2019).

Consequently, legislators (Gazis and Becket, 2019; Brown, 2019; Lum, 2019; Galston, 2020), news outlets (Harwell, 2019; Parkin, 2019; Frum, 2020; Hwang and Watts, 2020; Schick, 2020; Toews, 2020) and civil society groups (Lewis, 2018; Davis, 2020; Ajder et al., 2019; Bateman, 2020) have all emphasized the potential harm that deepfakes may cause to democracy, and legislation exists in more than a dozen states to regulate the production and dissemination of deepfake videos (Prochaska, Grass and West, 2020). Philosophers claim that deepfake technology removes our ability to verify testimony, undercutting the credibility of both honest and dishonest claims (Rini, 2020).

This article evaluates whether or not these concerns are warranted by answering a series of fundamental research questions. First, are deepfake videos of salient public officials more credible (i.e. not appearing fake or doctored) than equivalent information faked in existing media modalities such as textual headlines or audio recordings? We denote this question as

\footnotetext{
${ }^{1}$ According to many reports (Lewis, 2018; Davis, 2020; Ajder et al., 2019), the earliest deep learning faceswap tool to receive popular press was Face2Face in 2016; see also Suwajanakorn, Seitz and KemelmacherShlizerman (2017) in 2017, FakeApp in 2018, Faceswap and DeepFaceLab in 2019.
} 


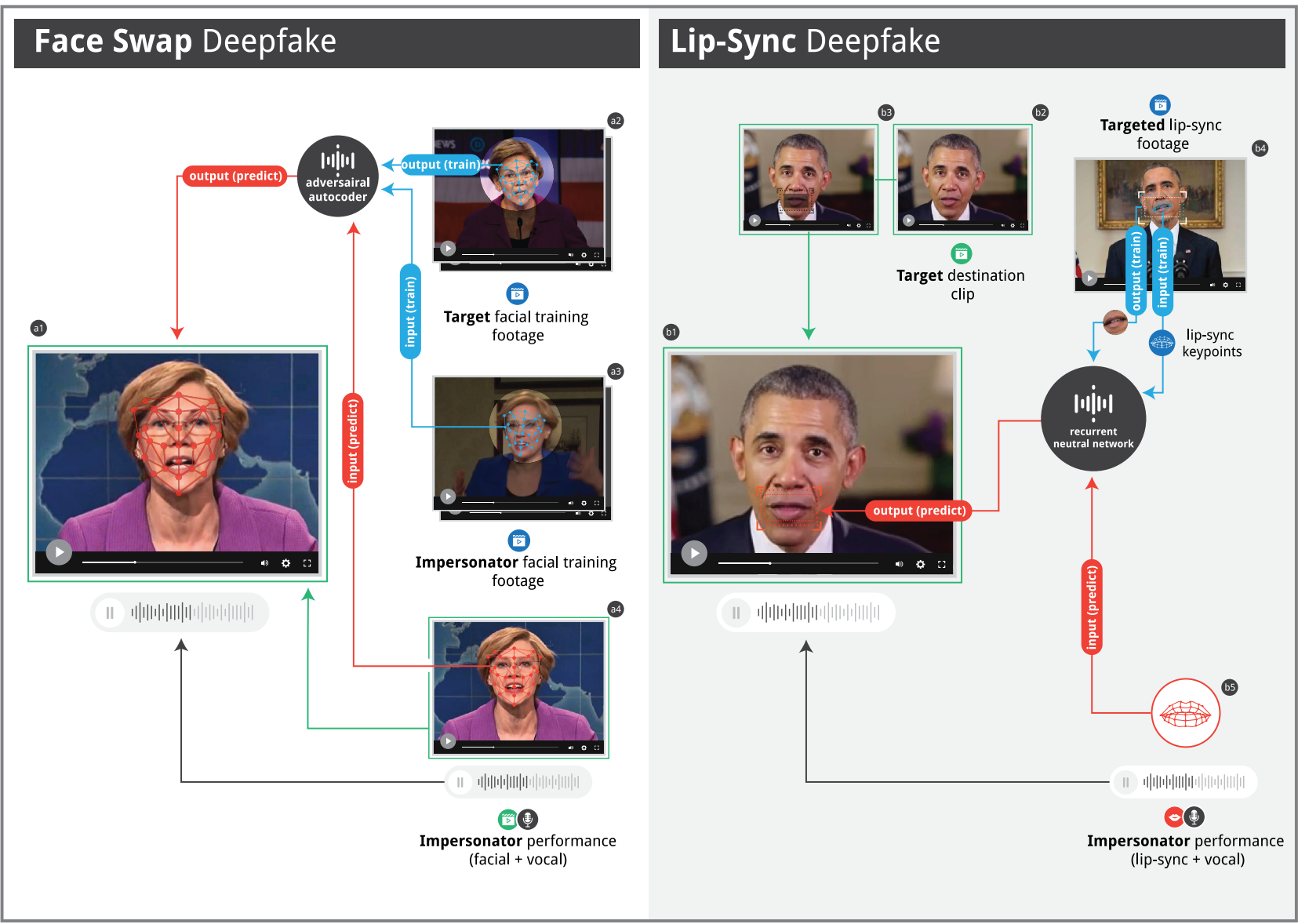

Notes: Shown are two major methods of producing deepfakes. The left illustrates the production of a face-swap deepfake which requires: a full clip featuring the impersonator's performance including the audio (black) and the background context for the clip (green) where the facial features are swapped (red) via a trained (blue) deep learning model called an autoencoder. The right illustrates a lip-sync deepfake which requires a destination clip of the target (green) and a vocal impersonator's performance including their audio (black) and lip sync keypoints (red); these keypoints are transferred into a matching synthetic lip-sync video of the target via a deep convolutional neural network model trained on the target (blue).

Research Question 1 - RQ1 - throughout the text. Second, are deepfakes differentially more credible than other modalities to certain subgroups (RQ2)? Third, are deepfake videos more or less credible than authentic videos of political elites (RQ3)? Although the scope of possible deepfakes, political or non-political, is vast, our questions chiefly concern deepfake scandal videos of political elites, given their attention in contemporary society and imminent election regulations. Before we conducted any research, we pre-registered our hypotheses for these questions, drawing on media effects studies across several disciplines, which we briefly summarise.

On RQ1, we expected that deepfake videos would be deceptively perceived as more credible than equivalent information in text or audio formats. ${ }^{2}$ In addition to the motivating concerns

\footnotetext{
${ }^{2}$ In this article, we elicit direct credibility evaluations of media upon exposure, rather than asking if the
} 
of contemporary political observers, this prediction squares with a literature that documents how audiovisual information is the prima facie format for persuasive communication on a variety of topics, including emotionally charged or traumatic events (Christianson and Loftus, 1987; Kassin and Garfield, 1991), courtroom testimony (Kassin and Garfield, 1991), presidential election campaigns (Grabe and Bucy, 2009), support for medical aid (Yadav et al., 2011), and belief in climate change (Goldberg et al., 2019).

On RQ2, we pre-registered a number of "at-risk" subgroups defined by characteristics previously shown to exacerbate or reduce susceptibility to misinformation in other contexts (Table 1). The first category draws on the observation that older adults, Guess, Nagler and Tucker (2019) report that "users over 65 shared nearly 7 times as many articles from fake news domains as the youngest age group" during the 2016 US Presidential election. Next, we believe that Bayesian reasoning, or the selective acceptance of information based on consistency with prior beliefs, may powerfully shape how at least two groups respond to deepfakes. Thus, we hypothesize that partisan group identity and sexist attitudes will influence credibility perceptions of a deepfake video. A large literature documents how partisan identity - either by way of strong directional motivations to reject new evidence or differing priors about the credibility of new evidence - directs voters' attitudes about events, issues, and candidates (Kahan, 2012; Druckman and McGrath, 2019; Leeper and Slothuus, 2014; Enders and Smallpage, 2019). Moreover, voters' evaluations of candidates or events can be driven by prior negative stereotypes towards sexist attitudes towards women (Jamieson, Hall et al., 1995; Teele, Kalla and Rosenbluth, 2017; Cassese and Holman, 2019). A recent survey finds that, next to partisanship, holding ambivalent sexist views ${ }^{3}$ most strongly predicted support for Donald Trump in the 2016 election (Schaffner, MacWilliams and Nteta, 2018). Another set of subgroups may be especially susceptible to deepfakes due to constraints on cognitive resources or knowledge. Performance in cognitive reflection tasks measures reliance on "gut" intuition which may preclude careful examination of video evidence (Pennycook and Rand, 2019; Pennycook et al., 2019). Similarly, those with little political knowledge may have little prior exposure to the targetted political figure, rendering them unable to discern "uncanny" deepfake artifacts that resemble, but do not perfectly replicate their intended facial features (Mori, MacDorman and Kageki, 2012; Brenton et al., 2005). Finally, the last two categories describe traits that we can intervene on via direct information provision - or raising the salience of deepfakes conceptually or by example - and accuracy priming - or raising the salience or normative value of engaging with accurate news - each of which we expect to reduce deepfakes' credibility (Pennycook et al., 2020, 2019). Echoing our expectations for RQ1, we pre-registered the prediction that all subgroups in Table 1 would be differentially

depicted events truly occurred which may be evaluated on their perceived plausibility independent of the information presented.

${ }^{3}$ Ambivalent sexism describes a bundle of both outright hostile (e.g. "women are physically inferior to men") and deceptively benevolent views about women (e.g. "women are objects of desire") (Glick and Fiske, 1996) 
Table 1: Subgroups Hypothesized to Percieve Deepfakes As Credible

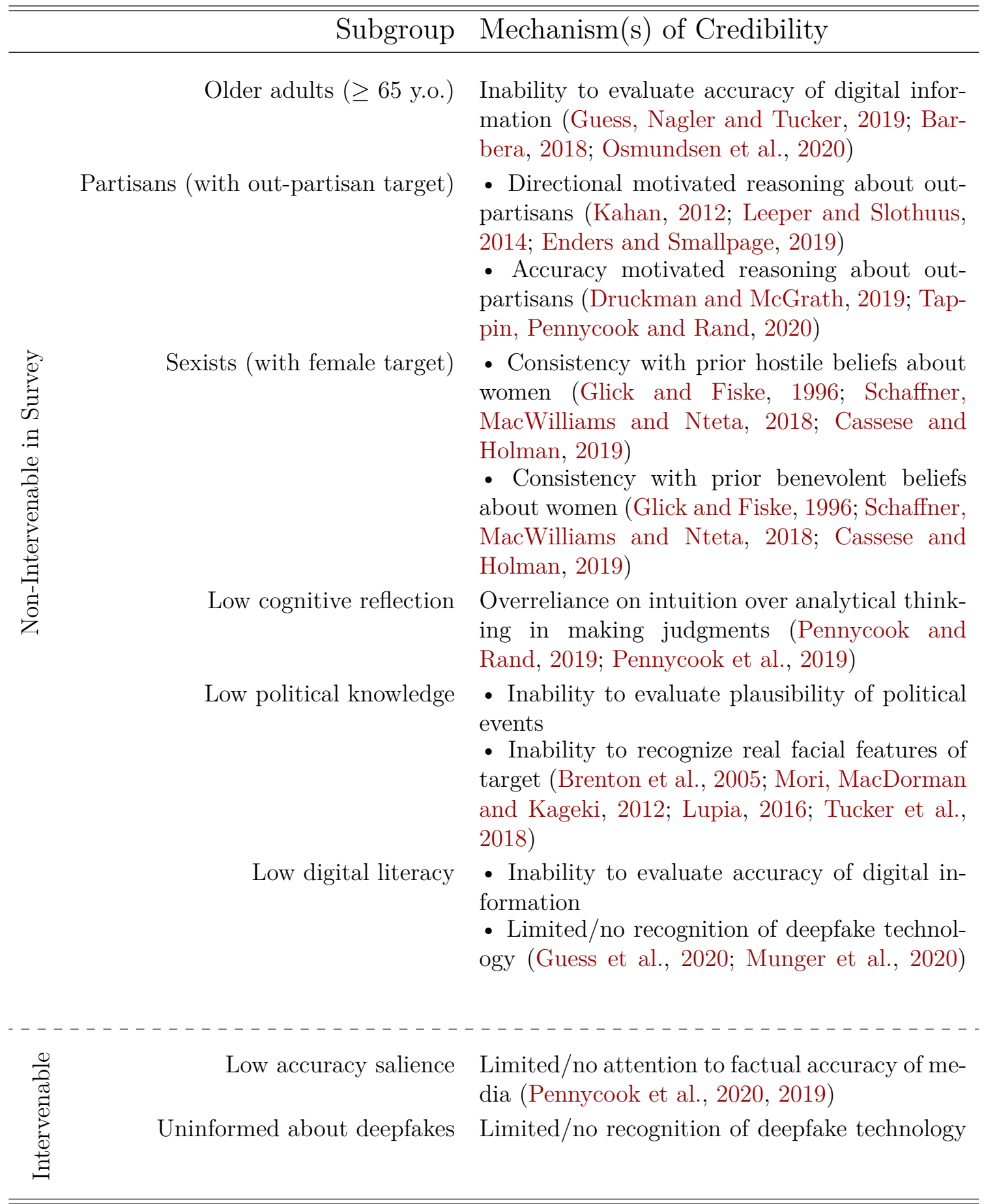

Notes: This list is neither exhaustive nor mutually exclusive. We clarify possible mechanisms for each groups' susceptibility, but proving these and not alternative mechanisms is beyond the scope of this paper.

susceptible to deepfake misinformation over text and audio misinformation.

Lastly, on RQ3 - as with RQ1 - if popular claims about deepfakes are correct, they should be nearly indistinguishable from authentic video clips in a shared context (e.g. a news feed 
about politics). Thus, we expected that deepfakes should be perceived as equally credible as authentic video clips in the same context.

To test our hypotheses, we employed two experiments embedded in a survey fielded to a nationally representative sample of 5,750 respondents on the Lucid survey research platform. ${ }^{4}$ The first experiment (incidental exposure) presents respondents with a news feed of apparently authentic video clips, audio clips, and text headlines about candidates in the 2020 Democratic presidential primary, in which a deepfake video of one of the candidates may or may not be embedded. The second experiment (detection task) asks the same respondents to scroll through a feed of eight news videos - randomized to contain either no deepfakes (dubbed the no-fake feed), two deepfakes (low-fake), or six deepfakes (high-fake) - and discern deepfakes from the authentic video clips. Table 2 describes our overall design and Appendix Figure A6 provides a graphical illustration of the survey flow.

\section{Results}

Figure 2-5 summarise our main results which robustly reject our hypotheses for RQ1 and RQ2, but shed a nuanced light on RQ3. Figure 2 compares baseline and relative subgroup credibility evaluations across all clips in the incidental exposure news feed ${ }^{5}$ alongside baseline and relative subgroup affect towards Warren from respondents in all the Warren clip conditions Figure 3 compares performance in the detection task across environments and subgroups, while Figure 4 and Figure 5 break down performance differences by our pre-registered subgroup traits and by clips respectively. We organize our results into three main findings, each of which we discuss in detail in relation to our original hypotheses, and conclude with a brief discussion of external validity.

For all of results involving multiple group-wise comparisons or estimating multiple substantive coefficients, we adjust $p$-values according to the Benjamini-Hochberg "step-up" procedure which bounds each group of tests' false discovery rate at $\alpha=0.05$ without as strict of a correction as the Bonferroni procedure which assumes no dependence between hypotheses (Benjamini and Hochberg, 1995). Additionally, where we find unexpected null results, we conduct equivalence tests to verify that the estimated null effects are meaningfully null in magnitude (Wellek, 2010). For consistency, we deem an effect "meaningfully null" if it fails to explain half of a standard deviation or more of the outcome, i.e. falls within the equivalence bounds of $\pm 0.5 \sigma$, although we show our null effects are null according to other reasonable interpretations as well.

\footnotetext{
${ }^{4}$ At the time of fielding, Aronow et al. (2020) noted systematic trends in inattentive survey respondents on Lucid. We describe the battery of attention checks we employ to maintain a high-quality sample in Appendix E. All findings are consistent across samples, though slightly smaller in magnitude for less attentive respondents.

${ }^{5}$ Excluded are credibility comparisons with the satirical SNL skit clipping of Bernie Sanders following the randomized stimuli due to the same differential item functioning concerns expressed in the previous section.
} 


\subsection{Deepfake scandal videos are no more credible or emotionally appealing than comparable fake media}

In the incidental exposure experiment, just under half of subjects $(42 \%)$ found our deepfake videos of Warren at least somewhat credible (top left of Figure 2). However, the videos were, on average, less credible than the faked audio (44\%) and comparable in credibility to the fake text $(42 \%)$. Both the fake audio and video clippings not only fail to reject a traditional null hypothesis of no effect relative to the fake text headline, but also reject the null hypothesis of a minimal change of $\pm 0.5 \sigma(\approx 0.64)$ in credibility confidence, let alone a full point step between confidence categories. Appendix Tables F6 and F7 show that these differences are robust to a variety of model-based adjustments. Our best answer to RQ1 is, thus, "no".

Even if deepfakes are not more credible than comparable fake media, are they more emotionally appealing? Relative to no exposure, videos do slightly increase negative affect towards Elizabeth Warren as measured by the 0-100 feeling thermometer, though this still fails to clear our equivalence bounds for a null effect. However, there are demonstrably null effects of the deepfake video on affect when compared to text and audio, as seen in the top-right cell in Figure 2. Deepfake videos are also at least as affectively triggering as negative attack advertisements, a decades-old technology, of the same target. Appendix Table F10 produces this same null effect with model-based controls.

Investigating whether the previous null results mask any credibility or affect heterogeneities for subgroups specified in Table 1 (panels 2-7 in Figure 2), we find few. Verbal information, as intended, provides a targeted, but small reduction of the video stimuli's credibility relative to the text stimuli, which is partially robust to different model-based adjustments (Appendix Tables F8 and F9). The answer we give to RQ2 is then also "no", however with one caveat. Sexist attitudes and out-partisan identification predict increases in the credibility (substantively large in the latter case) of the scandal deepfake (Appendix Figure G25, Tables F17-F18, Tables F20-F21), just not relative to the same information in text or audio format.

\subsection{Digital literacy and political knowledge improve discernment more than information}

Our respondent groups' baseline performance accuracy (Figure 3) in the detection task (53$61 \%$ across all groups) and error rates of less than 50\% suggest that their discernment capabilities are better than random. Though, notably, the false negative rate for our clips is consistently larger than the false positive rate, meaning deepfakes appear to be slightly more credible than authentic videos (more likely to be misclassified as authentic than vice versa). A little more than a third of all deepfakes in our feed are undetected while a little under a third of authentic clips are falsely flagged across all subgroups.

Examining whether Table 1 traits explain performances, we find that neither of our interventions improves discernment accuracy during the detection task (see estimated marginal effects on accuracy in Figure 4). While information and accuracy salience fail, Figure 4 shows 
Figure 2: Minimal Overall and Subgroup Effects of Incidental Exposure to a Deepfake Video
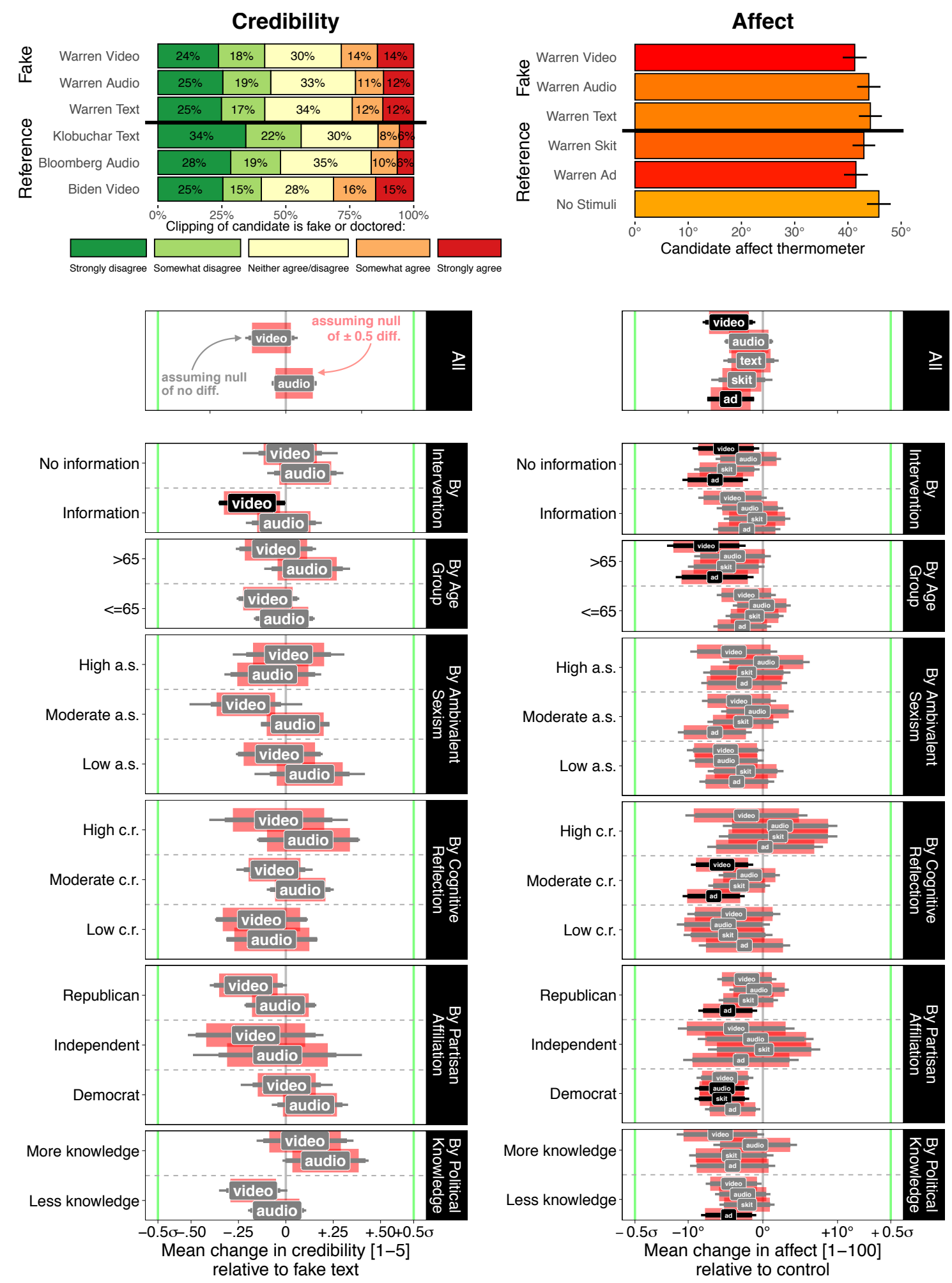

Notes: Categories for ambivalent sexism and cognitive reflection constructed as equal-sized percentiles from sample values. Thicker lines denote $95 \%$ confidence intervals (CIs), thinner lines denote $95 \%$ CIs adjusted for multiple subgroup comparisons (Benjamini and Hochberg, 1995), red blocks indicate 95\% CIs from two one-sided equivalence $t$-tests with equivalence bounds indicated by the vertical red lines (Wellek, 2010). For brevity, the text condition is not shown in the subgroup results for affect, however in no subgroup condition did text produce a significant effect relative to control. 
Figure 3: Performance Comparisons in Deepfake Detection Task
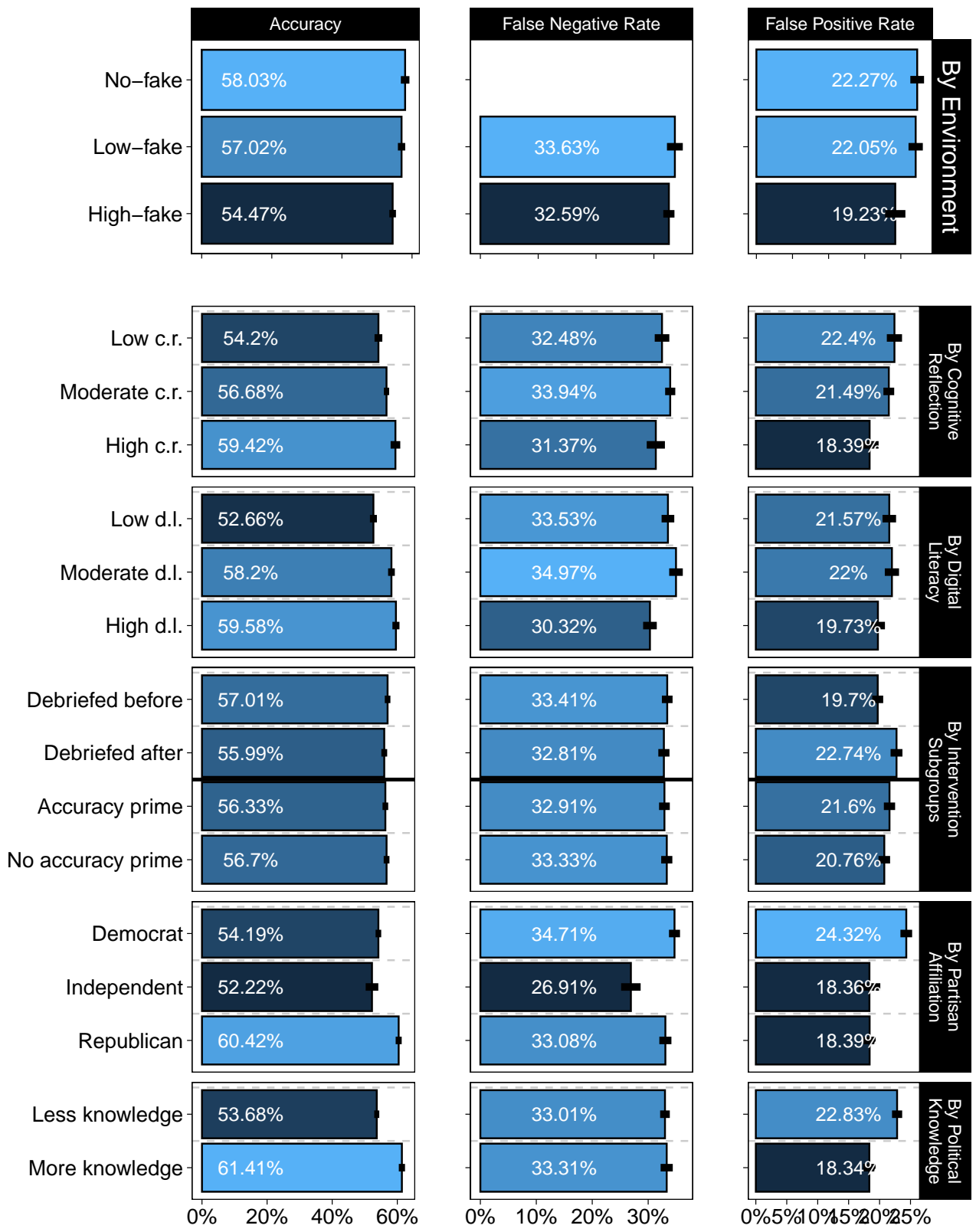

Notes: Shown are three different measures for $n=5,497$ (99\%) of respondents who provide a response to at least one video in the detection experiment task. Coefficient estimates are given in Appendix $\mathrm{F}$ and are robust to the choice of missing-ness threshold. Accuracy is the $\%$ of all videos in the task correctly classified as either fake or real. False negative rate is the \% of deepfakes in the task incorrectly classified as authentic (as such, this quantity is degenerate in the no-fake condition). False positive rate is the $\%$ of authentic videos in the task incorrectly classified as deepfakes.

that respondent traits - specifically digital literacy, political knowledge and, to a lesser extent, cognitive reflection - predict the most substantively meaningful improvements according to our standards of evaluation. A unit increase in digital literacy predicts that a subject will provide $15 \%$ fewer false positives, a reduction of roughly half a standard deviation in the sam- 
ple. Republicans also appear to marginally outperform Democrats and Independents, though scoring little less than a full clip higher in correct classifications than the rest.

\section{Figure 4: Predictors of Detection Task Performance}

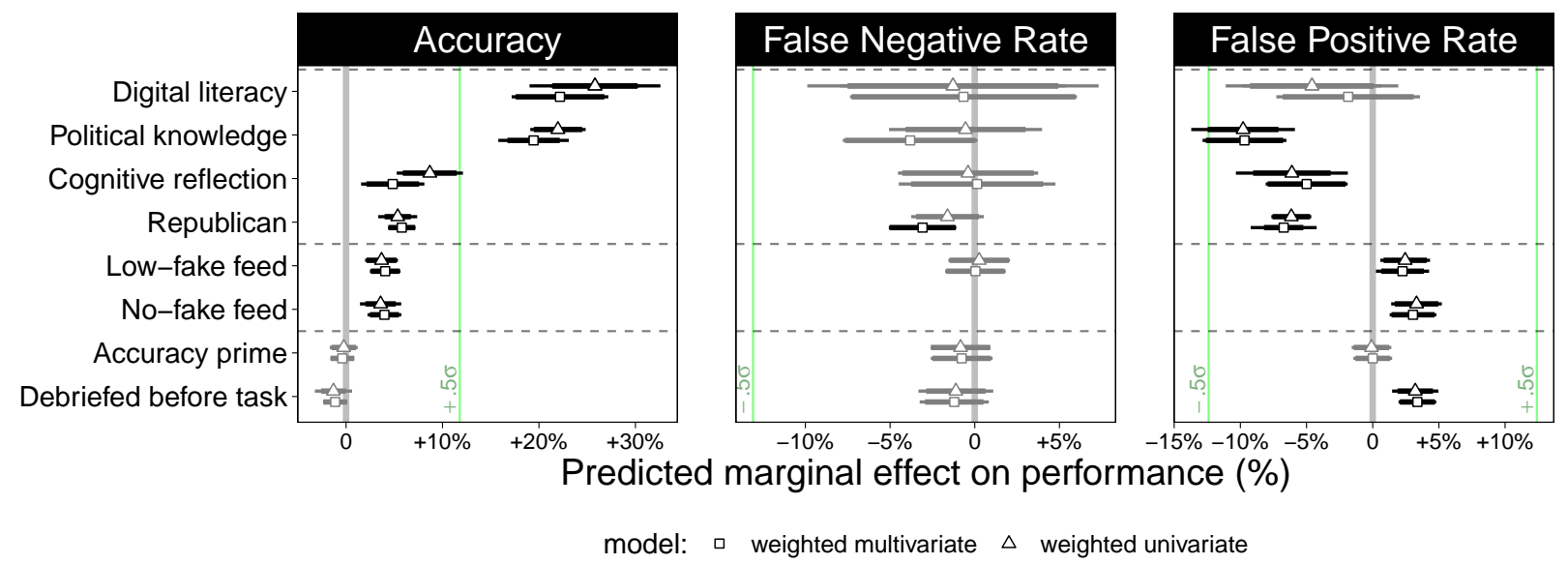

Notes: Predictors are grouped by dashed grey lines into respondent traits (all re-scaled to the $[0,1]$ range), detection environment (relative to high-fake), and intervention assignment. Predictors include all group indicators from Table 1 excluding age which has no significant effects on performance (see Appendix Tables F23, F24, F24). The multivariate model estimates the effects of all predictors jointly and additionally controls for age group, education, and internet usage. Both models are weighted via a post-stratification model (see Appendix Section E). Appendix Figure F24 shows that the cut-off for non-responses in the task does not change the substantive interpretation of detection experiment results.

\subsection{Skepticism of authentic videos, but not deepfakes, varies sig- nificantly by partisanship}

Remarkably, although partisanship overall predicts small effects on performance relative to other traits, an examination of individual clips (Figure 5) reveals some massive performance gaps between Democrats and Republicans, but only for real videos. 58\% of Republicans believed that real leaked footage of Obama caught insinuating a post-election deal with the Russian president was authentic compared to $22 \%$ of Democrats, a highly significant differential according to a simple Chi-squared test $\left(\chi^{2}=333.34, p<0.01\right)$. Performance is flipped for the clip of Donald Trump's public misnaming of Apple CEO Tim Cook which was correctly identified by $87 \%$ of Democrats, but only $51 \%$ of Republicans $\left(\chi^{2}=75.15, p<0.01\right)$. Most striking is that for an authentic clip from a presidential address of Trump urging Americans to take cautions around the COVID-19 pandemic, the finding holds in the opposite direction: although a positive portrayal ${ }^{6}$, at least for Democrats who by and large hold similarly cautionary attitudes towards COVID-19 (Clinton et al., 2020), only 60\% of Democratic viewers flagged it as authentic whereas fully $81 \%$ of Republicans believed it to be real $\left(\chi^{2}=169.96, p<0.01\right)$. Controlling for both clip and respondent characteristics, Appendix Figure G31 shows that Re-

\footnotetext{
${ }^{6}$ Positive portrayal, here, means depiction of valence traits or characteristics that, all else equal, voters should unanimously prefer more of rather than less of (Bartels, 2002).
} 
Figure 5: Detection Performance Comparisons Across Partisanship and Clip Authenticity

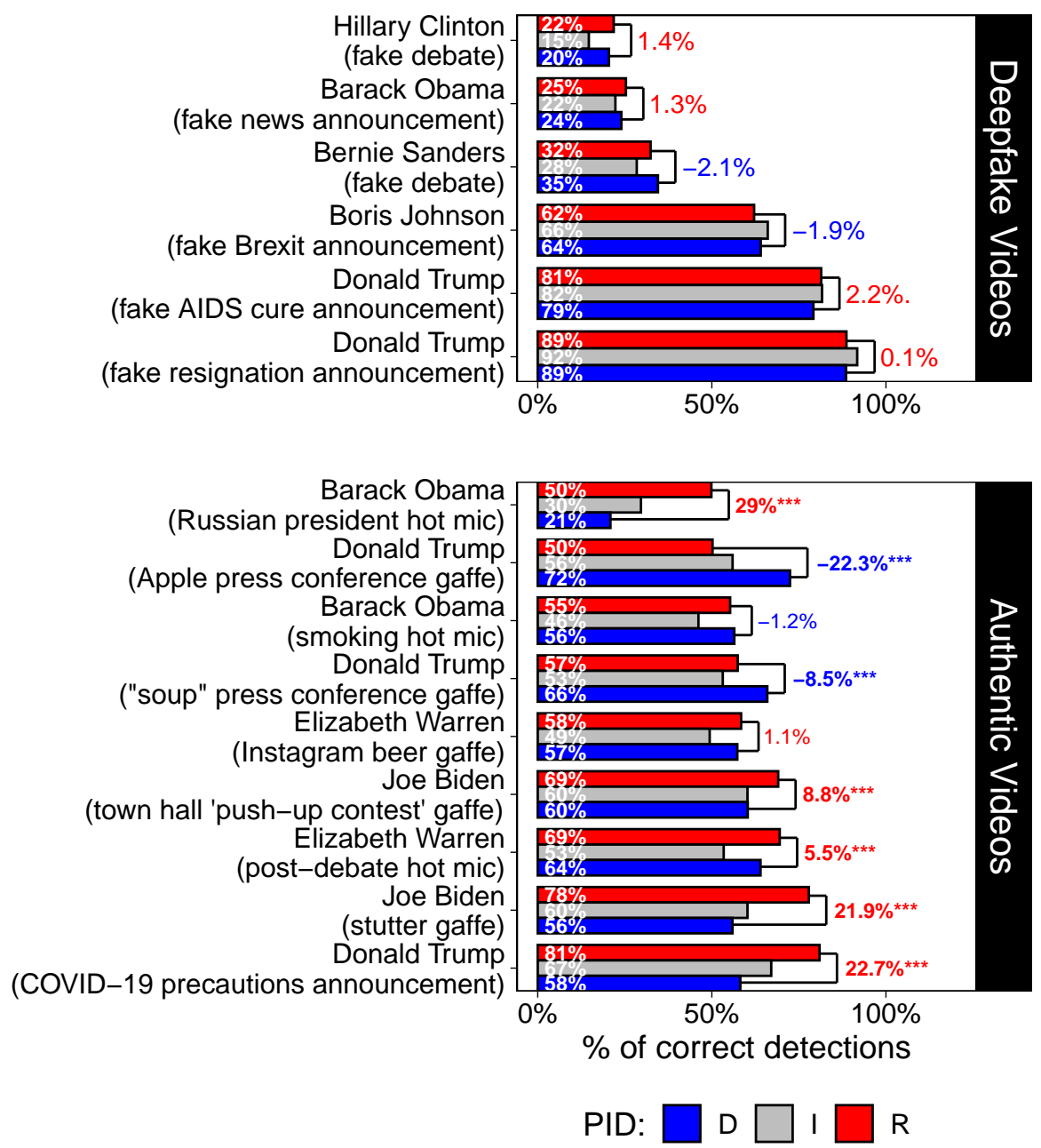

Notes: $p$-values for differences in correct detection proportions between Democrats and Republicans $\left({ }^{* * *}\right.$ indicates $\left.p^{\prime}<0.001\right)$ derived from two-proportions $z$-tests where $p^{\prime}$ is the transformed larger $p$-value after adjusting for multiple comparisons via (Benjamini and Hochberg, 1995).

publican identity only predicts a boost in performance when asked to corroborate real scandal video clippings of Obama. Thus, individual clips' performance suggests that partisans fare much worse in correctly identifying real clips, but not deepfakes, portraying their own party's elites in a scandal. In contrast, digital literacy, political knowledge, and cognitive reflection bolster correct detections roughly evenly for all clips (Appendix Figure G30).

Taken together with the previous finding, this provides a nuanced answer to RQ3. Baseline discernment accuracy is not particularly high for any subgroup, however performance varies significantly by subgroup. Literacy (both political and technological) reduces false skepticism, while partisanship increases skepticism about real scandal videos of in-party elites. 


\section{Discussion}

We have demonstrated that deepfakes, even when designed specifically to defame a prominent politician, are not uniquely credible or emotionally manipulative: they are no more effective than the same misinformation presented as text or audio or the same target attacked via a campaign ad or mocked in a satirical skit. Partisan group identity appears to harm discernment performance, but for authentic videos more than for deepfakes. Our experiments reveal that several cognitive characteristics are essential components of how citizens process both authentic and fake video media. In particular, the respondents with the highest levels of general knowledge about politics, literacy in digital technology, and propensity for cognitive reflection performed the best in the detection experiment. Our study contributes to a growing body of research on manipulated video media (Vaccari and Chadwick, 2020; Wittenberg et al., 2020; Dobber et al., 2020; Ternovski, Kalla and Aronow, 2021), which, taken together, cast doubt on the fear that deepfakes themselves will directly deceive the public of false events on a mass scale. In light of this, policy-makers should devote more time and resources to bolster the credibility of real news videos and curb the development and spread of deepfake videos that perpetrate psychological or social damages against their targets. A recent count of deepfakes on the Internet finds that most are non-consensual pornographic clips of women, suggesting that perhaps the greater, more novel harm of deepfakes is the harassment of its targets, not the deception of its viewers (Harris, 2018).

\subsection{External Validity}

We conclude with a discussion of four external validity considerations about our results. First, it is possible that deepfakes of other, less salient elites may produce larger effects relative to text or audio than the ones seen here. However, thusfar, deepfakes of this kind (at least accessible to the public) have been exceedingly rare, possibly for technical limitations: as we describe in Appendix B, deepfakes require a large training set of high-definition facial images, which may be unavailable for a city councilor or a low-profile Congressman. Hence, we believe our effects are representative of the kind likely to be seen in the present population of deepfakes, though research on 'downballot deepfakes' would be valuable.

In the detection task experiment, we selected a diverse set of publicly accessible deepfakes of elites that vary in source logos, elite targets, input technology and setting. However, we cannot control for all idiosyncratic features of each clip (e.g. title, tone) nor show that either our deepfakes or authentic clips are exactly representative of these features in the news environment. One thing we can consider is how our results might differ if elites in our detection task were shown in proportion to how often they were actually involved in scandals. For example, according to journalistic (Leonhardt and Thompson, 2017; Quealy, 2021) and scholarly (Bode et al., 2020) accounts of President Trump's behavior, it is possible that news consumers during this period would encounter many more authentic scandal videos of Trump than of other elites. A back-of-the-envelope correction of this under-representation 
by simply double-counting each subjects' response to each Trump clip complete nullifies the aggregate effect of Republican partisanship on accuracy shown in Figure 4. More realistically, Republicans and Democrats disproportionately encounter favorable media coverage of their party's elites to begin with; if all Democrats' and Republicans' false positive rates are re-graded by dropping non-congenial clips in their detection task, Democrats reduce false positives from $24.3 \%$ to $13.7 \%$, while Republicans improve from $18 \%$ to $17.8 \%$. Thus, both the supply of real scandals and selective exposure in real-world news-seeking (to the extent it occurs) could attenuate the false skepticism we have observed.

In this study, we elicited credibility perceptions of clippings ("is this clip real?"), which may be distinct from belief in the occurrence of the depicted event ("did X happen?"). In theory, someone could flag a video as a deepfake, yet believe that the event still occurred. However, manipulation checks on two clips in our detection task suggest that respondents who believe the video is fake generally believe the event did not occur and vice versa (Figure G32 and Figure G33 in Appendix G). Exploring the theoretical and empirical distinctions between these outcomes is a research agenda of its own.

Finally, we recognize that deepfake technology will continue to improve beyond the scope of this experiment. Although we have faithfully replicated the deepfake production process using the best available technology at the time of fielding, readers may live in a world where open-source deepfake technology is capable of generating photorealistic deepfakes completely indistinguishable from authentic videos. In this case, reactions to deepfakes may more closely resemble the responses to real videos we have seen here, where cognitive effort and literacy still improve discernment, while partisanship still continues to drive false beliefs depending on what is shown. Thus, while we encourage technological solutions to constrain the spread of manipulated video, there will never be a substitute for an informed, digitally literate, and reflective public for the practice of democracy.

\section{Materials and Methods}

Our design is motivated by a number of considerations. Firstly, the two experiments capture different quantities of interest by way of comparing different types of randomized media exposure. The incidental exposure experiment measures the perceived credibility of a single, carefully masked deepfake video relative to the equivalent scandal depicted via other formats, or similar reference stimuli about the candidate in question (RQ1, RQ2). In the incidental exposure experiment, we also compare affect toward the politicians in each clip as an auxiliary outcome. In contrast, the detection task captures the credibility of deepfakes relative to authentic videos (RQ3) measured by overall discernment accuracy and errors due to false positives.

Second, the experiments both inherently and by their ordering allow us to test credibility perceptions across differing levels of information provision. The first experiment simulates exposure to a deepfake "in the wild" with, at most, verbal description about deepfakes for those 
Table 2: Overview of Experiments Embedded in Survey

\begin{tabular}{|c|c|c|c|}
\hline & Exposure(s) & $\begin{array}{l}\text { Pre-Exposure } \\
\text { Interventions }\end{array}$ & Outcomes \\
\hline $\begin{array}{l}(1) \\
\text { Incidental } \\
\text { Exposure }\end{array}$ & $\begin{array}{l}\text { 1. Pre-exposure authentic } \\
\text { coverage of } 2020 \text { Democratic } \\
\text { Primary candidates } \\
\text { 2. Randomized exposure to text, } \\
\text { audio, video, skit clip of } \\
\text { Elizabeth Warren scandal, attack } \\
\text { ad, or control (no stimuli) } \\
\text { 3. Post-exposure authentic } \\
\text { coverage of } 2020 \text { Democratic } \\
\text { Primary candidates }\end{array}$ & $\begin{array}{l}\text { - Information } \\
\text { about deepfakes }\end{array}$ & $\begin{array}{l}\text { - Belief that } \\
\text { candidate } \\
\text { clippings are not } \\
\text { fake/doctored } \\
\text { (credibility) } \\
\text { - Favorability } \\
\text { of candidates } \\
\text { (affect) }\end{array}$ \\
\hline $\begin{array}{l}------- \\
(2) \\
\text { Detection } \\
\text { Task }\end{array}$ & $\begin{array}{l}\text { Randomized task environment: } \\
\text { clips of political elites } \\
\text { clips, two deepfakes of political } \\
\text { elites } \\
\text { - High-fake feed: two authentic } \\
\text { clips, six deepfakes of political } \\
\text { elites }\end{array}$ & $\begin{array}{l}\text { - Debrief of } \\
\text { deepfakes } \\
\text { exposed to in }(1) \\
\text { before task } \\
\text { - Accuracy } \\
\text { prime }\end{array}$ & $\begin{array}{l}\text { - Deepfake } \\
\text { detection } \\
\text { accuracy } \\
\text { positive rate } \\
\text { - Deepfake false } \\
\text { negative rate }\end{array}$ \\
\hline
\end{tabular}

randomized to receive information. All participants in the detection task, on the other hand, are explicitly told about deepfakes and some are even provided visual examples of deepfakes if randomly assigned to be debriefed about their incidental exposure before the task.

Third, and arguably most important for external validity, our two experiments allow us to test credibility perceptions across multiple deepfakes that differ in their targets, quality, and technology. In the first experiment, as we will describe in the next section, we hired a professional firm to produce several novel deepfakes of a single politician depicted in several realistic scandals via face swap. In the second experiment, we used a representative set of preexisting deepfakes of many different elites made by experts and amateurs alike never existed before made via lip sync and face swap. Although, in either experiment, we cannot causally attribute credibility due to particular aspects of each video, we draw our overall conclusions using a realistic, externally valid set of deepfake stimuli.

To adjust for observable demographic skews in our respondent pool, all analyses are replicated using post-stratification weights estimated from the U.S. Census in Appendix F. Details of this post-stratification and other characteristics of the sample are given in Appendix E. 


\subsection{Incidental exposure experiment}

In the first experiment, we implement a 2 x 6 factorial design pairing a randomized informational message about deepfakes with randomization into one of six conditions - a deepfake video (presented as a leaked mobile phone recording), or alternatively audio, text, or skit of a political scandal involving a 2020 Democratic primary candidate Elizabeth Warren, a campaign attack ad against Warren, or a control condition of no clip at all - after which we measure several outcomes. In the incidental exposure experiment, we selected Elizabeth Warren because she was both a salient politician during the primary election, and (at the time of fielding) had not been the target of any visible deepfake online. Thus credibility perceptions would not be contaminated from prior exposure as would be the case if we recycled an existing deepfake.

To create a natural environment for media consumption, we surround the experimentally manipulated media exposure with four media clips, two before and two after. These reports are all real coverage of different Democratic primary candidates, presented either in audio, textual, or video form. The order and content of these media are fixed, and primarily serve to mask the main manipulation, replicating the visual style of Facebook posts. The six conditions of our manipulation (video, audio, text, skit, ad, control) and their exact differences from each other are shown in Table 3, where video is the group assigned to the deepfake.

Participants in the video, audio, and skit conditions are randomly exposed to one of five different scandal events to reduce the possibility that our results are being driven by a single story. Each scandal is entirely fictitious, and the media associated with it was created in collaboration with a professional actor and a tech industry partner. Specifically, the audio condition consists of the audio recording of the actor making a scandalous statement. Participants in the skit condition are exposed to the original videos used in the creation of the deepfake video, prior to the modifications made by the neural network algorithm. That is, this condition displays the unaltered video of the paid actress hired to impersonate Elizabeth Warren which is clearly framed as a skit: the title of the corresponding deepfake in the video condition is shown, but "Leak" is replaced with "Spot-On Impersonation". Finally, the video condition employs a deepfake constructed from the footage used in the skit condition. Details on the production of these stimuli are provided in Appendix B and each of the five scripts are provided in Table B4. We do not register any hypotheses about heterogeneous effects across these stories within condition, but conduct exploratory analyses which show small differences across conditions (Appendix $G$ ).

Finally, in the ad condition, subjects are exposed to a real negative campaign ad titled, "Tell Senator Warren: No Faux Casino, Pocahontas!", which criticizes Senator Warren's supposedly illicit support for federally funding a local casino owned by an Indian tribe, despite her previous opposition to such legislation and her disputed claims of Cherokee heritage. Although the ad frames Warren as politically insincere, similar to script (e) and primes the viewer of her Cherokee heritage controversy, similar to script (c), it stylistically and informationally differs 
Table 3: Experimental Conditions in Incidental Exposure Experiment

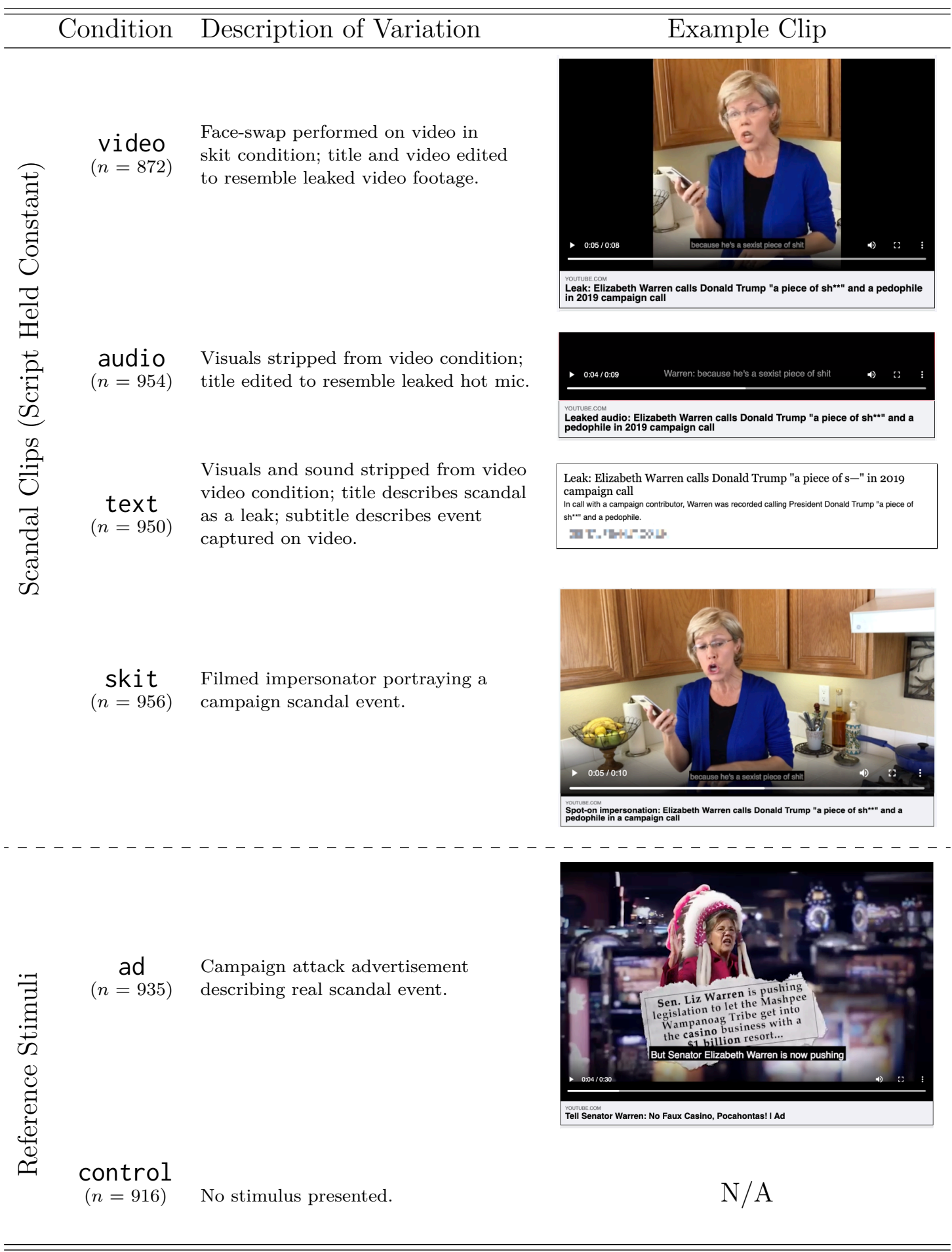

in many other ways, and thus is not an exact ad counterfactual of our deepfake. Nevertheless, the ad serves as a benchmark comparison for a deepfake's affective effect, since it is an actual campaign stimulus used in the primary election to activate negative emotions towards Warren.

Following the feed, respondents are asked to evaluate the credibility of each textual, audio, or video clip in the feed (the extent to which they believe the clip is "fake or doctored" 
on a 5 point scale) in between other distraction evaluations (funny, offensive, informative). Consequently, respondents are also asked to evaluate how warmly or coldly they feel towards each of the Democratic candidates on a continuous 100 point feeling thermometer.

Our main counterfactuals of the deepfake video condition are the text and audio conditions. Importantly, we do not make a comparison of credibility ("is this fake or doctored?") of the skit and ad stimuli with the three scandal clippings, due to concerns about differential item functioning: it is possible that respondents say the ad or skit is "fake or doctored" because they correctly perceive the skit as a staged depiction or the ad as an edited video rather than because they incorrectly perceive it as depicting Warren participating in a fabricated event. However, we can still usefully compare affective responses towards Warren between the scandal clippings and these reference stimuli.

\subsection{Detection task experiment}

After completing the battery of questions in which we measure our primary outcomes of interest and ask another attention check question, the subjects begin the second experimental task that measures their ability to discriminate between authentic and deepfake videos.

Before this task, half of the subjects (in addition to all of the subjects not taking part in this task) are debriefed about whether or not they were exposed to a deepfake in the first experiment. The other half are debriefed after this final task. This randomization allows us to test for the effect of the debrief, which unlike the verbal information randomly provided in the first stage provides visual examples of deepfakes. Additionally, half of all respondents are provided an accuracy prime - an intervention designed to increase the salience of information accuracy (Pennycook and Rand, 2019).

In the task itself, we employ videos created by (Agarwal et al., 2019) and a mix of other publicly available deepfake videos of both lip-sync and face-swap varieties. To the extent that respondents have previously viewed these videos, we should expect detection performance to be biased upwards, although no respondent explicitly indicated as such in open feedback. For the pool of authentic videos, we primarily selected, where possible, real-world video scandals of the elites used in the deepfake pool. Unlike in the incidental exposure experiment, in both the deepfake and non-deepfake pools, we have clips of Republican (Donald Trump) and Democrats (Barack Obama, Joe Biden, Elizabeth Warren), creating both Democratic and Republican out-partisans in the detection task. Subjects were randomly assigned to one of three environmental conditions: the percentage of deepfakes in their video feed was either $75 \%$ (high-fake), 25\% (low-fake) or 0\% (no-fake). Appendix C displays screenshots and descriptions of each of these videos. Misclassifications (or reductions in accuracy) in the detection task can be decomposed into false negatives, or misclassifications of deepfakes as authentic, and false positives, or misclassification of authentic clips as deepfakes. We measure both, in addition to overall accuracy, to gauge our respondents' discernment abilities and the source of their errors. 


\subsection{Ethical considerations}

Creating deepfakes raises important ethical concerns, which we aimed to address at every stage of our research design. First, given the risk of deepfakes disrupting elections, understanding their effects is of the utmost importance: this research has the potential to improve the resilience of democratic politics to this technological threat by better informing policy and consumer behavior. Second, we created deepfakes of a candidate who was not currently running for office to ensure that our experiment could not plausibly influence the outcome of an election. Third, we designed "active debriefs" that required subjects to affirm in writing whether they were exposed to false media. Finally, deepfakes are increasingly part of the standard media environment, so our study only exposes subjects to things they should be prepared to encounter online. We discuss these points in more detail in Appendix D.

\section{References}

Abadi, Martín, Paul Barham, Jianmin Chen, Zhifeng Chen, Andy Davis, Jeffrey Dean, Matthieu Devin, Sanjay Ghemawat, Geoffrey Irving, Michael Isard et al. 2016. Tensorflow: A System for Large-Scale Machine Learning. In 12th USENIX Symposium on Operating Systems Design and Implementation. pp. 265-283.

Abram, Cleo. 2020. "The most urgent threat of deepfakes isn't politics. It's porn."

URL: https: //www.vox.com/2020/6/8/21284005/urgent-threat-deepfakes-politics-porn-krist

Agarwal, Shruti, Hany Farid, Yuming Gu, Mingming He, Koki Nagano and Hao Li. 2019. Protecting World Leaders Against Deep Fakes. In Proceedings of the IEEE Conference on Computer Vision and Pattern Recognition Workshops. pp. 38-45.

Ajder, Henry, Giorgio Patrini, Francesco Cavalli and Laurence Cullen. 2019. "The State of Deepfakes: Landscape, Threats, and Impact." Policy Brief .

URL: http://regmedia.co.uk/2019/10/08/deepfake_report.pdf

Alexander, Deborah and Kristi Andersen. 1993. "Gender as a Factor in the Attribution of Leadership Traits." Political Research Quarterly 46(3):527-545.

Alvarez, R Michael. 1998. Information and Elections. University of Michigan Press.

Aral, Sinan and Dean Eckles. 2019. "Protecting Elections From Social Media Manipulation." Science 365(6456):858-861.

Aronow, Peter M., Josh Kalla, Lilla Orr and John Ternovsk. 2020. "Evidence of Rising Rates of Inattentiveness on Lucid in 2020." Working Paper.

URL: https://osf.io/preprints/socarxiv/8sbe4

Barbera, Pablo. 2018. Explaining the Spread of Misinformation on Social Media: Evidence From the 2016 US Presidential Election. In Symposium: Fake News and the Politics of Misinformation. APSA. 
Bartels, Larry M. 2002. "The Impact of Candidate Traits in American Presidential Elections." Leaders' Personalities and the Outcomes of Democratic Elections pp. 44-69.

Bateman, Jon. 2020. "Deepfakes and Synthetic Media in the Financial System: Assessing Threat Scenarios.".

Benjamini, Yoav and Yosef Hochberg. 1995. "Controlling the False Discovery Rate: A Practical and Powerful Approach to Multiple Testing." Journal of the Royal Statistical Society: Series $B$ (Methodological) 57(1):289-300.

Berelson, Bernard R, Paul F Lazarsfeld and William N McPhee. 1954. Voting: A Study of Opinion Formation in a Presidential Campaign. University of Chicago Press.

Blum, Jeremy. 2020. “Trump Rant About 'Anarchist' Protesters Wielding Deadly 'Cans Of Soup' Goes Viral.".

URL: $\quad$ https://www.huffpost.com/entry/trump-deadly-cans-of-soup_n_ $5 f 4 f b c c 6 c 5 b 69 e b 5 c 0379 f 01$

Bode, Leticia, Ceren Budak, Jonathan M Ladd, Frank Newport, Josh Pasek, Lisa O Singh, Stuart N Soroka and Michael W Traugott. 2020. Words That Matter: How the News and Social Media Shaped the 2016 Presidential Campaign. Brookings Institution Press.

Brenton, Harry, Marco Gillies, Daniel Ballin and David Chatting. 2005. The Uncanny Valley: Does It Exist? In Proceedings of the Conference of Human Computer Interaction.

Brown, Nina Iacono. 2019. "Congress Wants to Solve Deepfakes by 2020. That Should Worry Us.".

URL: https://slate.com/technology/2019/07/congress-deepfake-regulation-230-2020. html

Caprara, Gian Vittorio, Shalom Schwartz, Cristina Capanna, Michele Vecchione and Claudio Barbaranelli. 2006. "Personality and Politics: Values, Traits, and Political Choice." Political Psychology 27(1):1-28.

Carpini, Michael X Delli and Scott Keeter. 1996. What Americans Know About Politics and Why It Matters. Yale University Press.

Cassese, Erin C and Mirya R Holman. 2019. "Playing the Woman Card: Ambivalent Sexism in the 2016 US Presidential Race." Political Psychology 40(1):55-74.

Christianson, Sven-åke and Elizabeth F Loftus. 1987. "Memory for Traumatic Events." Applied Cognitive Psychology 1(4):225-239.

Clinton, J., J. Cohen, J. Lapinski and M. Trussler. 2020. "Partisan Pandemic: How Partisanship and Public Health Concerns Affect Individuals' Social Mobility During COVID-19." Science Advances . 
Davis, Raina. 2020. "Technology Factsheet: Deepfakes." Policy Brief .

URL: https://www. belfercenter.org/publication/technology-factsheet-deepfakes

Dobber, Tom, Nadia Metoui, Damian Trilling, Natali Helberger and Claes de Vreese. 2020. "Do (Microtargeted) Deepfakes Have Real Effects on Political Attitudes?" The International Journal of Press/Politics .

Downs, Anthony. 1957. An Economic Theory of Democracy. New York.

Druckman, James N and Mary C McGrath. 2019. "The Evidence for Motivated Reasoning in Climate Change Preference Formation." Nature Climate Change 9(2):111-119.

Enders, Adam M and Steven M Smallpage. 2019. "Informational Cues, Partisan-Motivated Reasoning, and the Manipulation of Conspiracy Beliefs." Political Communication 36(1):83102.

Frum, David. 2020. "The Very Real Threat of Trump's Deepfake.”.

URL: https://www.theatlantic.com/ideas/archive/2020/04/trumps-first-deepfake/610750/

Galston, William A. 2020. "Is seeing still believing? The deepfake challenge to truth in politics.".

URL: https://www.brookings.edu/research/is-seeing-still-believing-the-deepfake-challengeto-truth-in-politics/

Gazis, Olivia and Stefan Becket. 2019. "Senators Pressure Social Media Giants to Crack Down on "Deepfakes".".

URL: https: //www. cbsnews.com/news/deepfakes-mark-warner-marco-rubio-pressure-social-me

Glick, Peter and Susan T Fiske. 1996. "The Ambivalent Sexism Inventory: Differentiating Hostile and Benevolent Sexism." Journal of Personality and Social Psychology 70(3):491.

Goldberg, Matthew H, Sander van der Linden, Matthew T Ballew, Seth A Rosenthal, Abel Gustafson and Anthony Leiserowitz. 2019. "The Experience of Consensus: Video as an Effective Medium to Communicate Scientific Agreement on Climate Change." Science Communication 41(5):659-673.

Goodman, J. David. 2012. "Microphone Catches a Candid Obama.".

URL: https://www.nytimes.com/2012/03/27/us/politics/ obama-caught-on-microphone-telling-medvedev-of-flexibility.html

Government Accountability Office: Science, Technology Assessment and Analytics. 2020. "Science and Tech Spotlight: Deepfakes.".

URL: https://www.gao.gov/assets/710/704774.pdf

Grabe, Maria Elizabeth and Erik Page Bucy. 2009. Image Bite Politics: News and the Visual Framing of Elections. Oxford University Press. 
Guess, Andrew, Jonathan Nagler and Joshua Tucker. 2019. "Less Than You Think: Prevalence and Predictors of Fake News Dissemination on Facebook." Science Advances 5(1).

Guess, Andrew M., Michael Lerner, Benjamin Lyons, Jacob M. Montgomery, Brendan Nyhan, Jason Reifler and Neelanjan Sircar. 2020. "A Digital Media Literacy Intervention Increases Discernment Between Mainstream and False News in the United States and India." Proceedings of the National Academy of Sciences 117(27):15536-15545.

URL: https://www. pnas.org/content/117/27/15536

Harris, Douglas. 2018. "Deepfakes: False Pornography Is Here and the Law Cannot Protect You." Duke L. E Tech. Rev. 17:99.

Harwell, Drew. 2019. “Top AI Researchers Race to Detect 'Deepfake' Videos: 'We are outgunned'.".

URL: https://www. washingtonpost.com/technology/2019/06/12/ top-ai-researchers-race-detect-deepfake-videos-we-are-outgunned/

Herman, Edward S and Noam Chomsky. 2010. Manufacturing Consent: The Political Economy of the Mass Media. Random House.

Hollyer, James R, B Peter Rosendorff and James Raymond Vreeland. 2019. "Transparency, Protest and Democratic Stability." British Journal of Political Science 49(4):1251-1277.

Hwang, Tim and Clint Watts. 2020. "Opinion: Deepfakes are coming for American democracy. Here's how we can prepare.".

URL:

https://www. washingtonpost.com/opinions/2020/09/10/ deepfakes-are-coming-american-democracy-heres-how-we-can-prepare/

Jamieson, Kathleen Hall, Kathleen Hall et al. 1995. Beyond the Double Bind: Women and Leadership. Oxford University Press.

Jerit, Jennifer and Yangzi Zhao. 2020. "Political Misinformation." Annual Review of Political Science 23:77-94.

Kahan, Dan M. 2012. "Ideology, Motivated Reasoning, and Cognitive Reflection: An Experimental Study." Judgment and Decision Making 8:407-24.

Kassin, Saul M and David A Garfield. 1991. "Blood and Guts: General and Trial-Specific Effects of Videotaped Crime Scenes on Mock Jurors." Journal of Applied Social Psychology 21(18):1459-1472.

Ko, Allan, Merry Mou and Nathan Matias. 2016. "The Obligation to Experiment." Medium .

Krook, Mona Lena and Juliana Restrepo Sanín. 2020. "The Cost of Doing Politics? Analyzing Violence and Harassment Against Female Politicians." Perspectives on Politics 18(3):740755. 
Kuklinski, James H, Paul J Quirk, Jennifer Jerit, David Schwieder and Robert F Rich. 2000. "Misinformation and the Currency of Democratic Citizenship." Journal of Politics $62(3): 790-816$.

Leeper, Thomas J and Rune Slothuus. 2014. "Political Parties, Motivated Reasoning, and Public Opinion Formation." Political Psychology 35:129-156.

Leonhardt, David and Stuart Thompson. 2017. "Trump's Lies.".

URL: https: //www. nytimes.com/interactive/2017/06/23/opinion/trumps-lies.html

Lewis, Rebecca. 2018. "Alternative Influence: Broadcasting the Reactionary Right on YouTube." Data \& Society 18.

Lippmann, Walter. 1922. Public Opinion. New Cork.

Lum, Zi-Ann. 2019. "Obama Tells Canadian Crowd He's Worried About 'Deepfake' Videos.". URL: https://www.huffingtonpost.ca/entry/obama-deepfake-video_ca_ 5cf29aafe4b0e8085e3ad233

Lupia, Arthur. 2016. Uninformed: Why People Know So Little About Politics and What We Can Do About It. Oxford University Press.

Makhzani, Alireza, Jonathon Shlens, Navdeep Jaitly, Ian Goodfellow and Brendan Frey. 2015. "Adversarial Autoencoders." Working Paper.

Mori, Masahiro, Karl F MacDorman and Norri Kageki. 2012. "The Uncanny Valley." IEEE Robotics $\&$ Automation Magazine 19(2):98-100.

Munger, Kevin, Mario Luca, Jonathan Nagler and Joshua Tucker. 2020. "The (Null) Effects of Clickbait Headlines on Polarization, Trust, and Learning." Public Opinion Quarterly .

Osmundsen, Mathias, Alexander Bor, Peter Bjerregaard Vahlstrup, Anja Bechmann and Michael Bang Petersen. 2020. "Partisan Polarization Is the Primary Psychological Motivation Behind "Fake News" Sharing on Twitter.".

Parkin, Simon. 2019. "The Rise of the Deepfake and the Threat to Democracy.". URL: https://www. theguardian.com/technology/ng-interactive/2019/jun/22/ the-rise-of-the-deepfake-and-the-threat-to-democracy

Pennycook, Gordon and David G Rand. 2019. "Lazy, Not Biased: Susceptibility to Partisan Fake News Is Better Explained by Lack of Reasoning Than by Motivated Reasoning." Cognition 188:39-50.

Pennycook, Gordon, Jonathon McPhetres, Yunhao Zhang, Jackson G Lu and David G Rand. 2020. "Fighting COVID-19 misinformation on social media: Experimental evidence for a scalable accuracy-nudge intervention." Psychological Science 31(7):770-780. 
Pennycook, Gordon, Ziv Epstein, Mohsen Mosleh, Antonio A Arechar, Dean Eckles and David G Rand. 2019. "Understanding and Reducing the Spread of Misinformation Online." Working Paper .

Pierce, Patrick A. 1993. "Political Sophistication and the Use of Candidate Traits in Candidate Evaluation." Political Psychology pp. 21-35.

Popkin, Samuel L. 1991. The Reasoning Voter: Communication and Persuasion in Presidential Campaigns. University of Chicago Press.

Prochaska, Stephen, Michael Grass and Jevin West. 2020. "Deepfakes in the 2020 Election and Beyond: Lessons From the 2020 Workshop Series." Center for an Informed Republic . URL: https://cpb-us-e1.wpmucdn.com/sites.uw.edu/dist/6/4560/files/2020/10/ CIP_Deepfakes_Report_Extended.pdf

Quealy, Kevin. 2021. "Trump's Lies.".

URL: https://www.nytimes.com/interactive/2021/01/19/upshot/ trump-complete-insult-list.html

Rini, Regina. 2020. "Deepfakes and the Epistemic Backstop." Philosopher's Imprint 20(24).

Schaffner, Brian F, Matthew MacWilliams and Tatishe Nteta. 2018. "Understanding White Polarization in the 2016 Vote for President: The Sobering Role of Racism and Sexism." Political Science Quarterly 133(1):9-34.

Schick, Nina. 2020. "Deepfakes are jumping from porn to politics. It's time to fight back.". URL: https://www.wired.co.uk/article/deepfakes-porn-politics

Snyder Jr, James M and David Strömberg. 2010. "Press Coverage and Political Accountability." Journal of Political Economy 118(2):355-408.

Strömberg, David. 2004. "Mass Media Competition, Political Competition, and Public Policy." The Review of Economic Studies 71(1):265-284.

Suwajanakorn, Supasorn, Steven M Seitz and Ira Kemelmacher-Shlizerman. 2017. "Synthesizing Obama: Learning Lip Sync From Audio." ACM Transactions on Graphics (TOG) $36(4): 1-13$.

Tappin, Ben M, Gordon Pennycook and David G Rand. 2020. "Rethinking the Link Between Cognitive Sophistication and Politically Motivated Reasoning." Journal of Experimental Psychology: General .

Teele, Dawn, Joshua Kalla and Frances McCall Rosenbluth. 2017. "The Ties That Double Bind: Social Roles and Women's Underrepresentation in Politics." American Political Science Review .

Ternovski, John, Joshua Kalla and Peter Michael Aronow. 2021. "Deepfake Warnings for 
Political Videos Increase Disbelief but Do Not Improve Discernment: Evidence from Two Experiments.".

Toews, Rob. 2020. "Deepfakes Are Going To Wreak Havoc On Society. We Are Not Prepared.".

URL: $\quad$ https://www.forbes.com/sites/robtoews/2020/05/25/ deepfakes-are-going-to-wreak-havoc-on-society-we-are-not-prepared/?sh= $7 f d 212087494$

Trump's bizarre "Tim/Apple" tweet is a reminder the president refuses to own tiny mistakes. N.d.

URL: https://www.vox.com/2019/3/11/18259996/trump-tim-cook-apple-tweet-time-and-words

Tucker, Joshua A, Andrew Guess, Pablo Barberá, Cristian Vaccari, Alexandra Siegel, Sergey Sanovich, Denis Stukal and Brendan Nyhan. 2018. "Social media, political polarization, and political disinformation: A review of the scientific literature." Hewlett Foundation .

Vaccari, Cristian and Andrew Chadwick. 2020. "Deepfakes and Disinformation: Exploring the Impact of Synthetic Political Video on Deception, Uncertainty, and Trust in News." Social Media+ Society 6(1).

Wellek, Stefan. 2010. Testing Statistical Hypotheses of Equivalence and Noninferiority. CRC press.

Wittenberg, Chloe, Jonathan Zong, David Rand et al. 2020. "The (Minimal) Persuasive Advantage of Political Video Over Text." Working Paper .

Yadav, Aman, Michael M Phillips, Mary A Lundeberg, Matthew J Koehler, Katherine Hilden and Kathryn H Dirkin. 2011. "If a Picture Is Worth a Thousand Words Is Video Worth a Million? Differences in Affective and Cognitive Processing of Video and Text Cases." Journal of Computing in Higher Education 23(1):15-37.

Zimmer, Ben. 2019. "Elizabeth Warren and the Down-to-Earth Trap.".

URL:

https://www. theatlantic.com/entertainment/archive/2019/01/

why-elizabeth-warrens-beer-moment-fell-flat/579544/ 


\section{Political Deepfakes Are As Credible As Other Fake Media And (Sometimes) Real Media}

\section{Supplementary Information}

\section{Contents}

A Experiment Overview $\quad 2$

B Stimuli in Exposure Experiment $\quad 3$

B.1 Production details . . . . . . . . . . . . . . . . . . . 3

B.2 Face-swap algorithm . . . . . . . . . . . . . . . . . 4

C Stimuli in Detection Experiment $\quad 5$

C.1 Authentic videos . . . . . . . . . . . . . . . . . . . 6

C.2 Deepfake videos . . . . . . . . . . . . . . . . . . . 9

$\begin{array}{ll}\text { D Ethical Considerations } & 11\end{array}$

E Sample Description $\quad 12$

$\begin{array}{lll}\text { F } & \text { Pre-Registered Analyses } & 13\end{array}$

G Exploratory Analyses $\quad 31$ 


\section{A Experiment Overview}

Figure A6: Graphical Summary of Experimental Flow

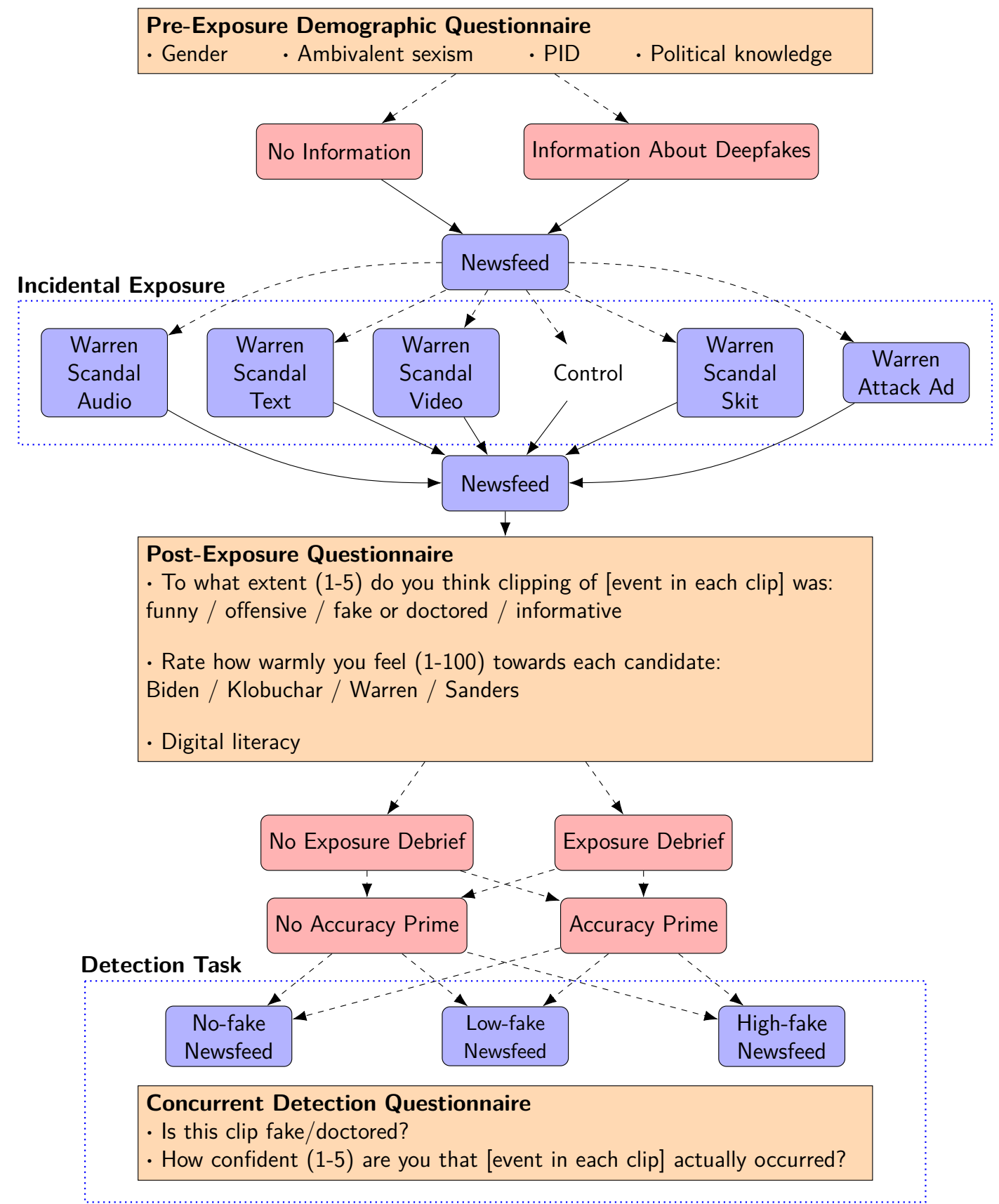

Notes: orange cells denote covariate and outcome measurements, blue cells denote exposures, and red cells denote treatments. In the audio, text, skit, and video cells, respondents are further randomized to one of the 5 clippings in Table B4. Subjects who do not receive an exposure debrief prior to the detection task receive it immediately after in overall debrief. 


\section{B Stimuli in Exposure Experiment}

\section{B.1 Production details}

We discuss the ethical reasoning behind our research design in more detail in Appendix D, but we first highlight here our selection of Elizabeth Warren for on both ethical and practical grounds. Senator Elizabeth Warren is a salient politician, making our experiment more ecologically valid than one with a low-profile or hypothetical politician (nearly all political deepfakes target high-profile politicians), but she is not slated for re-election until 2024. We selected a female candidate because women are more likely to be the targets of non-political deepfakes (Ajder et al., 2019; Abram, 2020) and harassment more broadly (Krook and Sanín, 2020) and we specifically test whether pre-existing prejudice against women among subjects changes the effect of the deepfake.

Prior to production, we consulted Buzzfeed CEO Jonah Peretti, who produced the first viral deepfake video in 2018 of Barack Obama telling the world that "President Trump is a complete and utter dipsh*t". In the correspondence below, he explained how the deepfake, created via a professional actor's expert impersonation and synthesized via face-swap, came to exist, emphasizing the need for high-quality impersonator and post-production:

"The idea was shaped by Jordan's ability to do a good Obama impersonation - so that part isn't fancy tech. Jordan is just better at impressions than other people making deep fakes and he did Obama as a character on Key \& Peele.

Then we worked with Jared who used a combination of deep fake software downloaded from Reddit and Adobe products we use to do video effects and post production work. It wasn't straightforward and required a combination of approaches and Jared's prodigious talents."

In collaboration with an industry partner and following the lessons from our correspondence with Buzzfeed, we produced a series of deepfake videos using target footage of 2020 presidential candidate and senator Elizabeth Warren and performances of a professional Elizabeth Warren impersonator. Warren's campaign disseminated a series of campaign video recordings of the senator in her home kitchen making personal thank-you calls to campaign donors and, in some cases, discussing policy matters and events during the campaign. We produced a series of videos performances of the impersonator in a similar kitchen performing several different sketches that each represented a potential "scandal" for Warren. To script these scandals, we carefully studied past controversial hot mic scandals of Democratic politicians as well as exact statements made by Warren in these campaign videos. We then scripted statements in Warren's natural tone and affliction that appeared plausible in the universe of political hot mic statements. As such, these statements are not meant to invoke extreme disbelief or incredulity, though testing the credulity threshold of deepfake scandals in a principled manner could the subject of future research. Table B4 describes the content of the final performances selected for our experiment. We used the audio from these sketches for the audio condition 
Table B4: Descriptions and Scripts of Scandal Performances

\begin{tabular}{|c|c|c|}
\hline Scandal Description & Title & Script \\
\hline In-Party Incivility & $\begin{array}{l}\text { LEAK: Elizabeth Warren calls } \\
\text { Joe Biden "a piece of sh*t" and } \\
\text { a pedophile in } 2019 \text { campaign call }\end{array}$ & $\begin{array}{l}\text { "Why shouldn't you vote } \\
\text { for Joe Biden in } 2020 ? \\
\text { Well, I'll tell you } \\
\text { why: because he's a } \\
\text { sexist piece of shit } \\
\text { who likes to grope } \\
\text { young girls, that's why." }\end{array}$ \\
\hline \multicolumn{3}{|c|}{--------------------------------------------------------------} \\
\hline Out-Party Incivility & $\begin{array}{l}\text { LEAK: Elizabeth Warren calls } \\
\text { Donald Trump "a piece of sh*t" and } \\
\text { a pedophile in } 2019 \text { campaign call }\end{array}$ & $\begin{array}{l}\text { "Why shouldn't you vote } \\
\text { for Donald Trump in } 2020 ? \\
\text { Well, I'll tell you } \\
\text { why: because he's a } \\
\text { sexist piece of shit } \\
\text { who likes to grope } \\
\text { young girls, that's why." }\end{array}$ \\
\hline \multicolumn{3}{|c|}{ - - - - - - - - - - - - - - - - - - - - - - - - - - - - - - - - - - - - - - - - - - - - - - - - - - - - - - - } \\
\hline $\begin{array}{l}\text { Past Controversy } \\
\text { (racialized comment) }\end{array}$ & $\begin{array}{l}\text { LEAK: Elizabeth Warren re-claims } \\
\text { Cherokee heritage in } 2019 \text { campaign call }\end{array}$ & $\begin{array}{l}\text { "Well, you know, as someone } \\
\text { who has Cherokee ancestry, } \\
\text { who's proud of their } \\
\text { Native heritage, I deeply } \\
\text { identify with other indigenous } \\
\text { people and people of color } \\
\text { in this country } \\
\text { and I will do everything } \\
\text { I can to fight for } \\
\text { you in Washington." }\end{array}$ \\
\hline \multicolumn{3}{|c|}{ - - - - - - - - - - - - - - - - - - - - - - - - - - - - - - - - - - - - - - - - - - - - - - - - - - - - - - - - - - - - - - - } \\
\hline $\begin{array}{l}\text { Novel Controversy } \\
\text { (homophobic comment) }\end{array}$ & $\begin{array}{l}\text { LEAK: Elizabeth Warren admits she } \\
\text { doesn't "endorse the LGBTQ lifestyle" } \\
\text { in } 2019 \text { campaign call }\end{array}$ & $\begin{array}{l}\text { "Well, as a Christian woman } \\
\text { of faith, I don't personally } \\
\text { support the LGBTQ lifestyle, } \\
\text { but I will try to do } \\
\text { what I can for } \\
\text { marriage equality in Washington." }\end{array}$ \\
\hline-------------- & ---------------------------- & ---------------- \\
\hline Political Insincerity & $\begin{array}{l}\text { LEAK: Elizabeth Warren flips stance } \\
\text { on student loan debt in } 2019 \text { campaign call }\end{array}$ & $\begin{array}{l}\text { "Well, I know I've said } \\
\text { that before, but I don't } \\
\text { really think that } \\
\text { eliminating student loan } \\
\text { debt for anyone is } \\
\text { fair or realistic." }\end{array}$ \\
\hline
\end{tabular}

and the video plus audio for the parody skit. We then performed the procedure to create a face-swap deepfake to produce the final deepfake video treatments, one for each selected scandal performance.

\section{B.2 Face-swap algorithm}

Deepfakes that swap the face of a target (e.g. President Barack Obama) with an actor (e.g. Hollywood actor Jordan Peele) - dubbed face-swaps in Figure 1 - are synthesized via a particular class of artificial neural networks called Adversarial Autoencoders (Makhzani et al., 2015).

The deepfaker's task is to train two autoencoders to accurately represent (encode) the two respective faces in a latent space and accurately reconstruct (decode) them as images. Let 
$\mathbf{X}_{\text {target }}$ denote a set of facial images of the target and $\mathbf{X}_{\text {actor }}$ denote a set of facial images of the actor. Denoting $\mathcal{G}_{\text {target }}$ as the function for the target autoencoder and $\mathcal{G}_{\text {actor }}$ as the function for the actor autoencoder, the networks are structured as $\mathcal{G}_{\text {target }}(x)=\delta_{\text {target }}\{\pi(x)\}$ and $\mathcal{G}_{\text {actor }}\left(x^{\prime}\right)=$ $\delta_{\text {actor }}\left\{\pi\left(x^{\prime}\right)\right\}$ where $\pi$ is an encoder subnetwork, $\delta_{\text {target }}$ and $\delta_{\text {actor }}$ are the decoder subnetworks for the target and actor respectively, and $x \in \mathbf{X}_{\text {target }}, x^{\prime} \in \mathbf{X}_{\text {actor. Both autoencoders share }}$ an encoder function $\pi$ which discover a common latent representation for the targets' and actors' faces; separate decoders are charged with realistically reconstructing the input faces. The objective function to be optimized is:

$$
\min _{\substack{\pi, \delta_{\text {target }}, \delta_{\text {actor }}}} \mathbb{E}_{x \sim \mathbf{X}_{\text {target }}}\left[\left\|\delta_{\text {target }}\{\pi(x)\}-x\right\|^{2}\right]+\mathbb{E}_{x^{\prime} \sim \mathbf{X}_{\text {actor }}}\left[\left\|\delta_{\text {actor }}\left\{\pi\left(x^{\prime}\right)\right\}-x^{\prime}\right\|^{2}\right]
$$

To produce a deepfake given a audiovisual performance of the actor with respective facial image frames $\mathbf{Y}_{\text {actor }}=\left[y_{1}, \ldots, y_{N}\right]$, we input the frames into the trained target autoencoder which outputs $\mathbf{Y}_{\text {actor }}=\left[\delta_{\text {target }}\left\{\pi\left(y_{1}\right)\right\}, \ldots, \delta_{\text {target }}\left\{\pi\left(y_{N}\right)\right\}\right]$ that can be recombined with the audio of the actor's performance.

To maximize the realism of outputs created from actor inputs fed to the target autoencoder, we train a third discriminator neural network $\mathcal{D}$ which aims to accurately classify the latent representations of images as belonging to either the target or actor. The final adversial objective is given as:

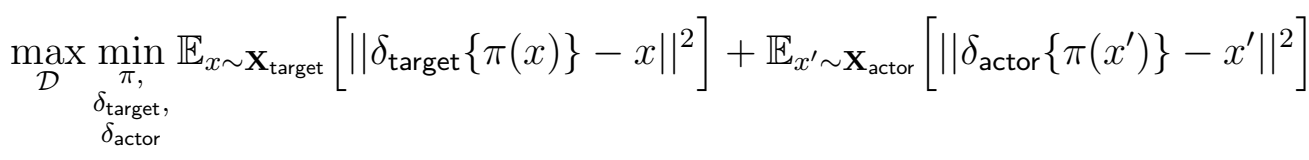

$$
\begin{aligned}
& +\mathbb{E}_{x^{\prime \prime} \sim \mathbf{X}}\left[\left\|\mathcal{D}\left\{\pi\left(x^{\prime \prime}\right)\right\}-\mathbf{1}\left\{x^{\prime \prime} \in \mathbf{X}_{\text {actor }}\right\}\right\|^{2}\right]
\end{aligned}
$$

Optimization of this objective function can be performed via alternating iterative updating of the two networks' weights using stochastic gradient descent. After sufficient rounds of training, the target autoencoder can accurately reproduce the target's face using images of only the actor's face and is thus able to effectively 'fool' the discriminator.

In practice, this workflow for deepfake synthesis is implemented using the Tensorflow library (Abadi et al., 2016). Deepfake producers utilize code from several popular public code repositories which implement variants of this base framework - including multiple discriminators and autoencoders, regularization schemes, and particular network architecture choices.

Finally, we reduce the resolution and bit-rate of our stimuli. This increases realism in two ways: (1) by masking any artifacts of the visual alterations of each face-swap and (2) by credibly presenting each video as a 'leaked' mobile phone recording.

\section{Stimuli in Detection Experiment}

This section provides sceenshots of the videos used in the detection experiment. All subject are assigned a mix of videos in which there are either no deepfakes (i.e., all displayed videos are of real media), a low proportion of deepfakes, or a high proportion of deepfakes. Each of 
these three conditions employs eight videos. While the order in which videos are presented varies within these conditions, the videos within each condition are fixed across subjects.

This section shows screenshots of each of these videos. Section C.1 shows screenshots and descriptions of all the authentic videos, while section Section C.2 shows screenshots and descriptions of the deepfakes employed in this experiment.

Subjects assigned to the no-fake condition saw real videos C7 through C14. Subjects in the low-fake condition saw fake videos $\mathrm{C} 16$ and $\mathrm{C} 17$, and real videos C9, C10, C11, C13, C14, and C15. Subjects in the high-fake condition saw fake videos C16, C17, C18, C19, C20, C21 and real videos $\mathrm{C} 8$ and $\mathrm{C} 13$.

Heterogeneity in detection performance at the clip level (both for the entire pool and across subgroups) can be found in Section G.

\section{C.1 Authentic videos}

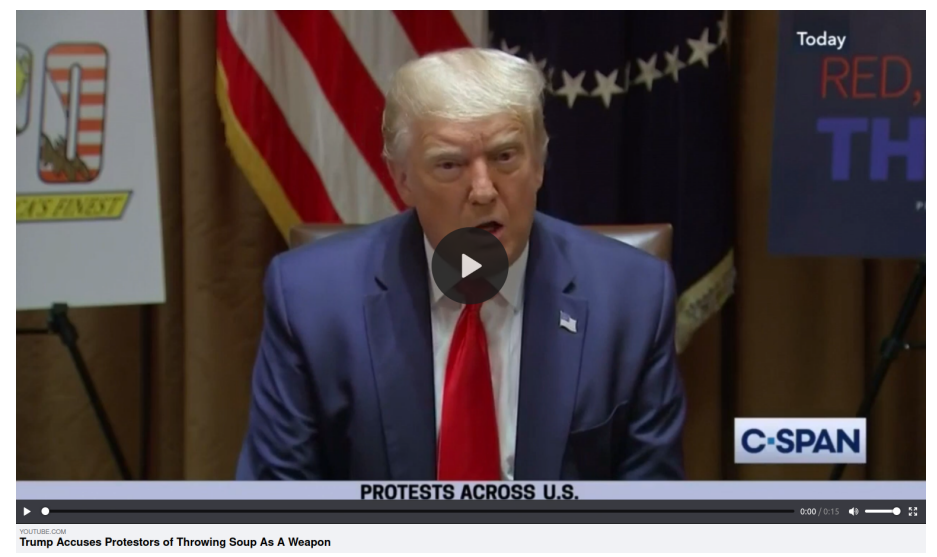

Figure C7: Donald Trump ("soup" press conference gaffe). Following national demonstrations in the summer of 2020, President Donald Trump decries protestors weaponizing cans of soup against police officers in a soon-to-be viral press conference clip (Blum, 2020).

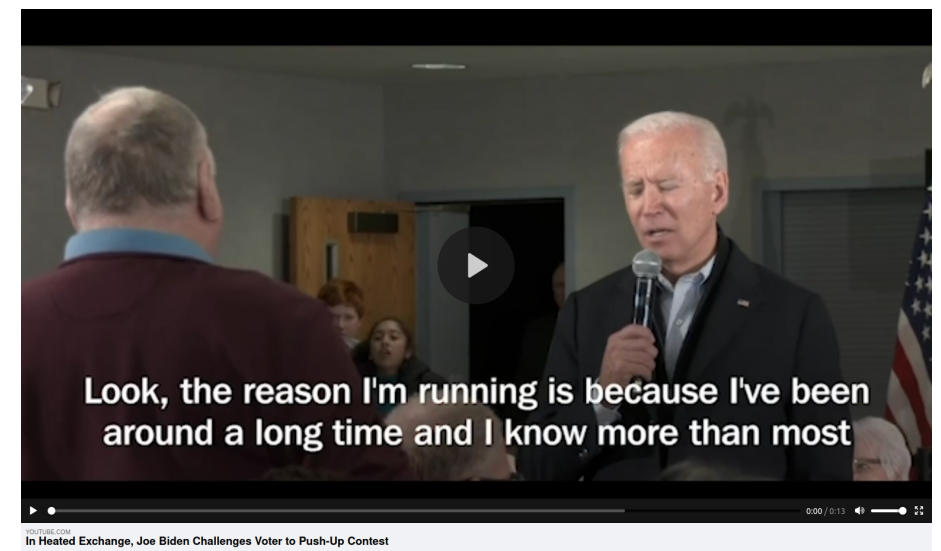

Figure C8: Joe Biden (town hall 'push-up contest' gaffe). After a heated exchange, Democratic presidential candidate Joe Biden challenges a combative voter at a town hall to a pushup contest. 


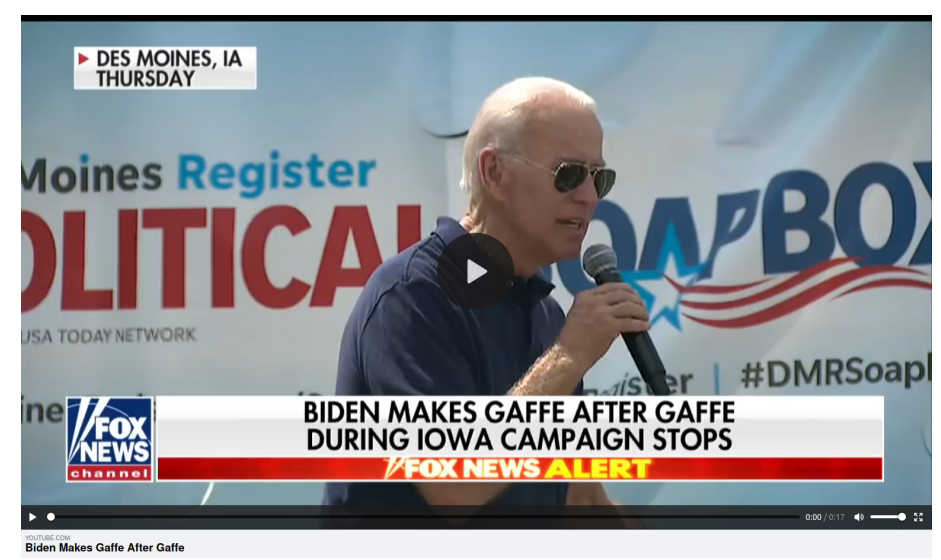

Figure C9: Joe Biden (stutter gaffe). A video compilation of Joe Biden stuttering in various campaign appearances.

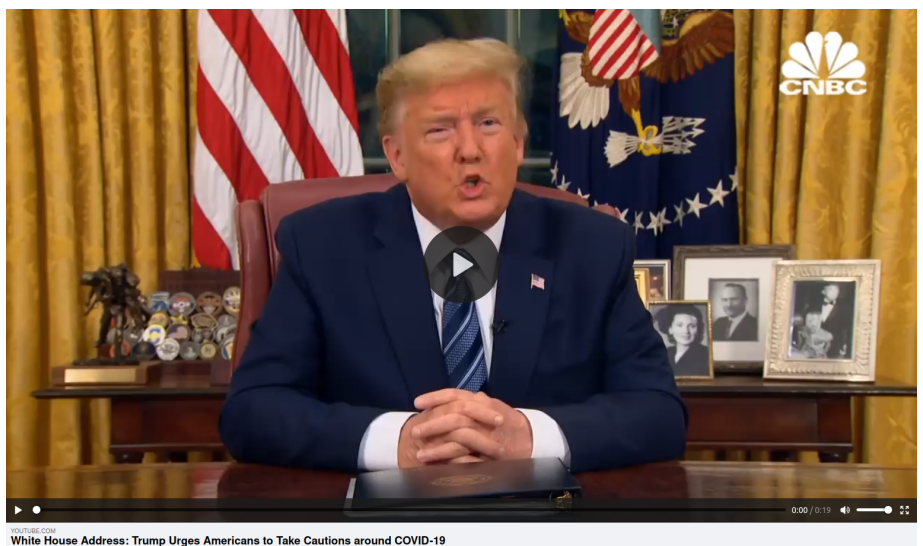

Figure C10: Donald Trump (COVID-19 precautions announcement). In a public address from the White House, President Trump urges Americans to take personal precautions to avoid COVID-19.

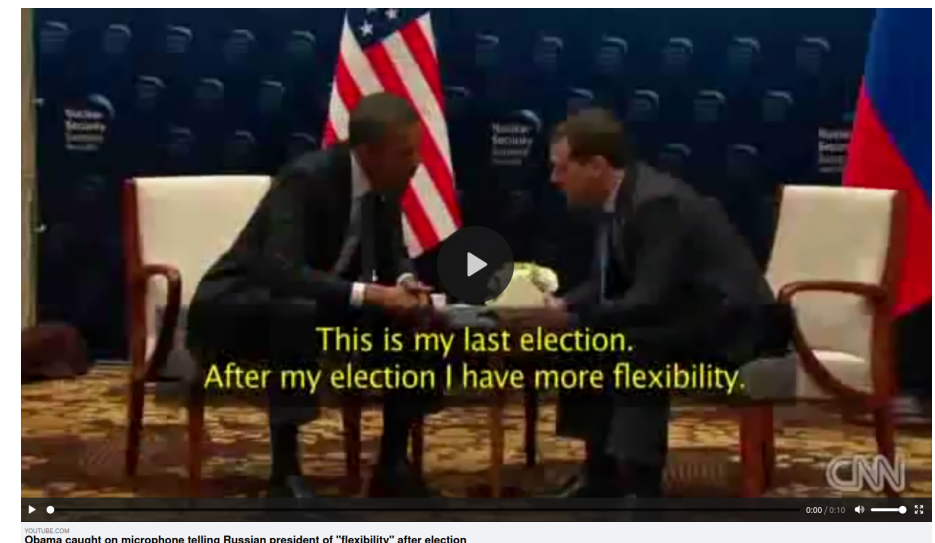

Figure C11: Barack Obama (Russian president hot mic). President Barack Obama is caught on a hot mic telling Russian President Dmitry Medvedev of "more flexibility" following his "last election" to negotiate on the issue of missile defense; an exchange that critics suggested revealed a lack of concern about re-election and lack of diplomatic transparency criticized (Goodman, 2012). 


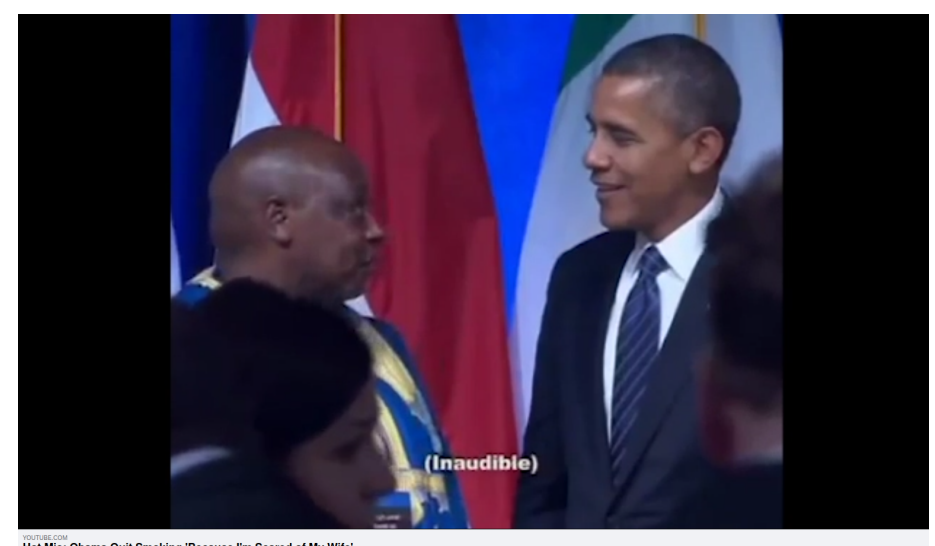

Figure C12: Barack Obama (smoking hot mic). President Barack Obama is caught on a hot mic to a U.N. National Assembly attendee saying that he quit smoking because "[he's] scared of [his] wife".

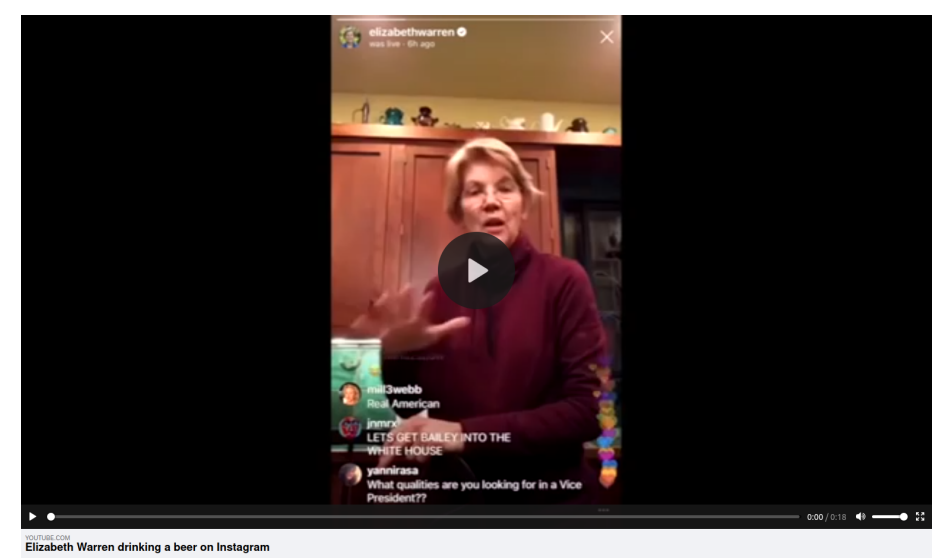

Figure C13: Elizabeth Warren (Instagram beer gaffe). Democratic primary candidate Elizabeth Warren furnishes a beer on an livestream video broadcasted on Instagram, a moment criticized as inauthentic and pandering by news media (Zimmer, 2019).

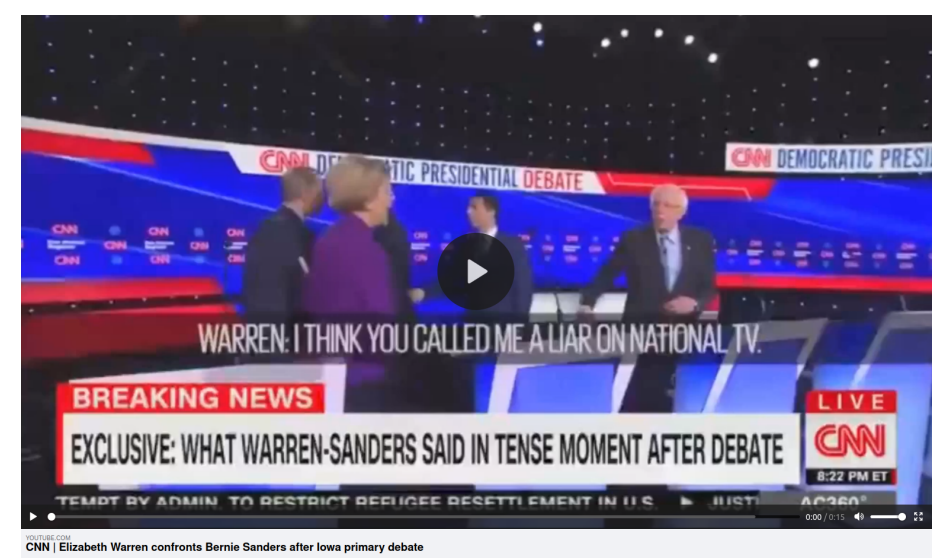

Figure C14: Elizabeth Warren (post-debate hot mic). Democratic primary candidate Elizabeth Warren confronts fellow candidate Bernie Sanders on live television for "calling [her] a liar on national TV". 


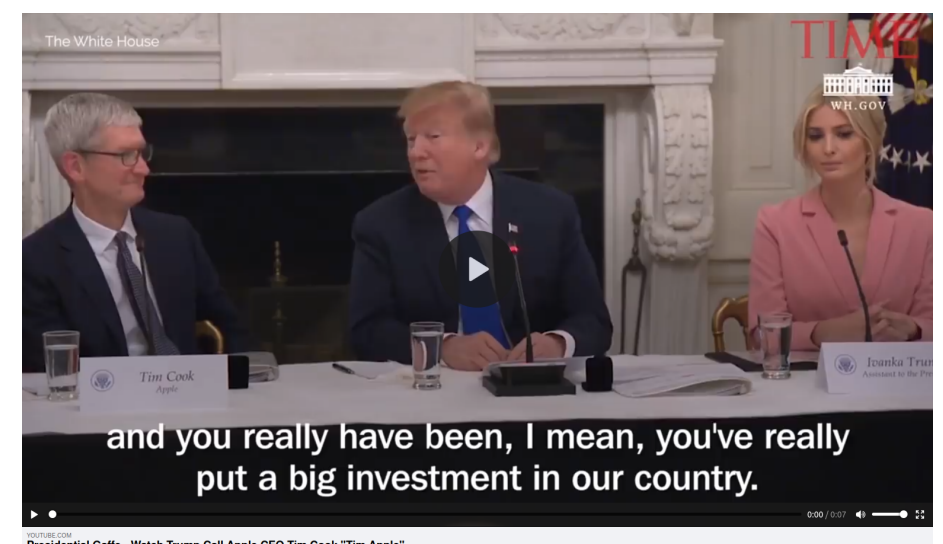

Figure C15: Donald Trump (Apple press conference gaffe). During an on-camera White House event, President Donald Trump mistakenly calls Apple CEO Tim Cook "Tim Apple" in a clip to go viral soon after (Trump's bizarre "Tim/Apple" tweet is a reminder the president refuses to own tiny mistakes, N.d.).

\section{C.2 Deepfake videos}

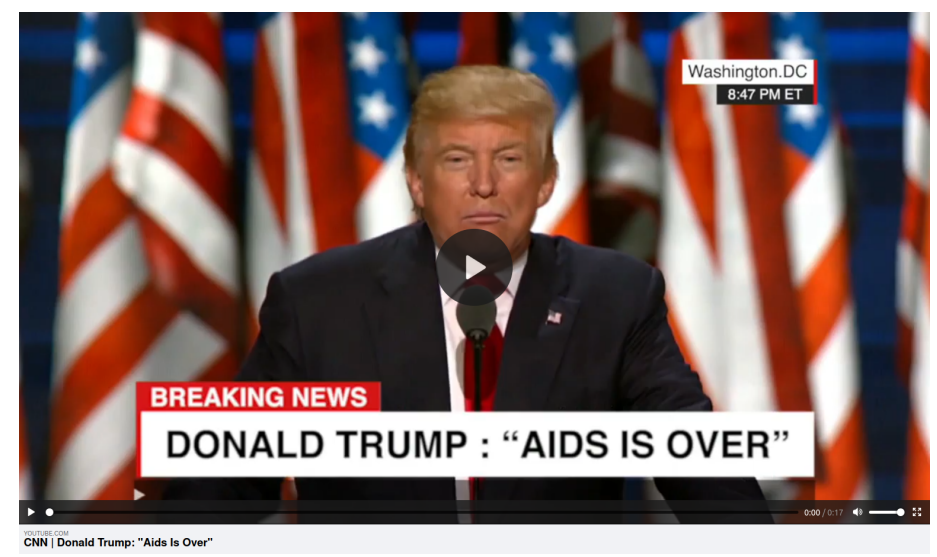

Figure C16: Donald Trump (fake AIDS cure announcement). In a campaign rally speech, President Donald Trump announces that under his administration, scientists have found a cure to AIDS.

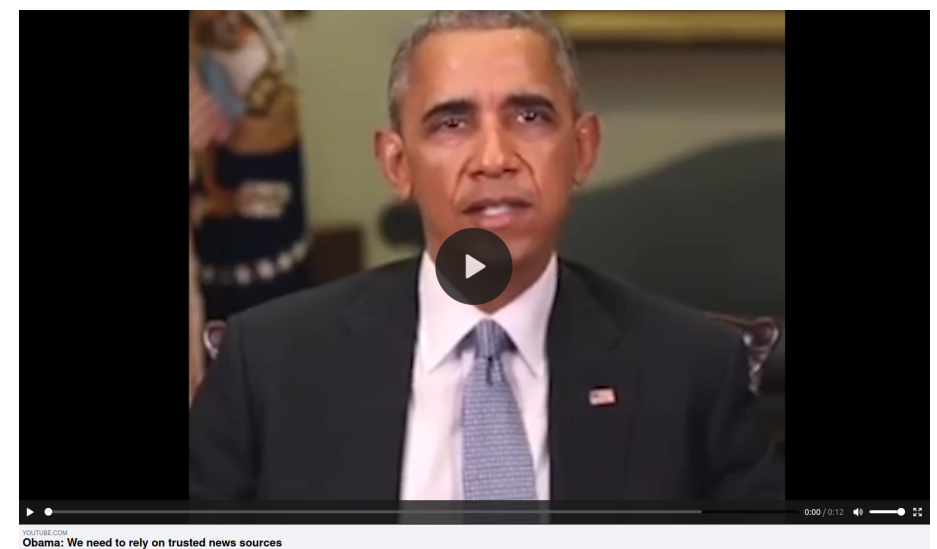

Figure C17: Barack Obama (fake news announcement). In a White House address, President Barack Obama stresses the importance of relying on trusted news sources. 


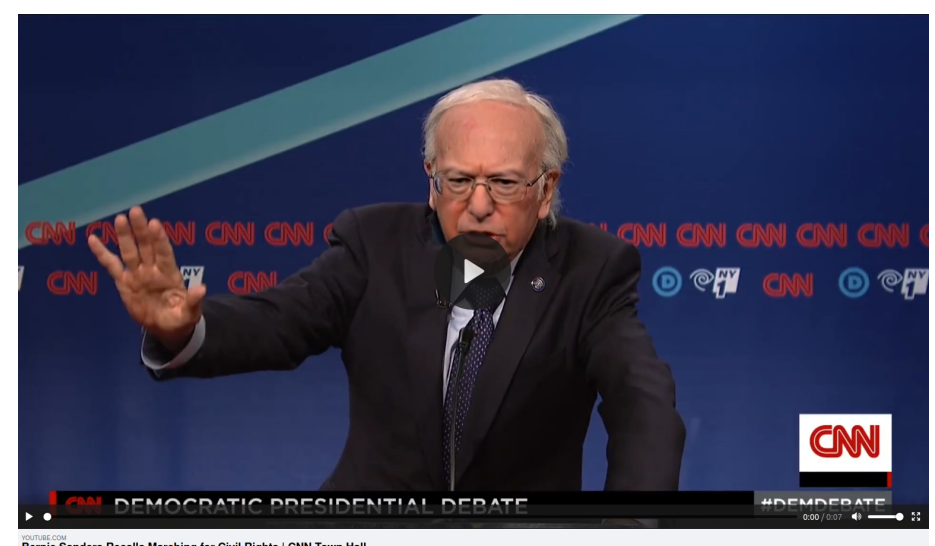

Figure C18: Bernie Sanders (fake debate). In a televised presidential town hall event, Democratic primary candidate Bernie Sanders recalls marching for civil rights in Selma, Alabama.

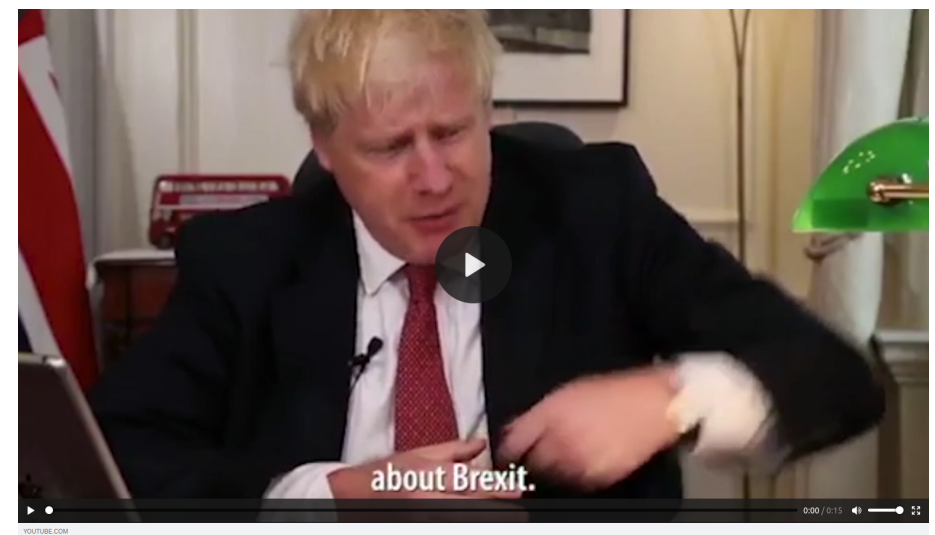

Figure C19: Boris Johnson (fake Brexit announcement). Sitting Prime Minister Boris Johnson announces that in order to "rise above the divide [on Brexit]", he will endorse opposition party leader Jeremy Corbyn in the upcoming U.K. general election.

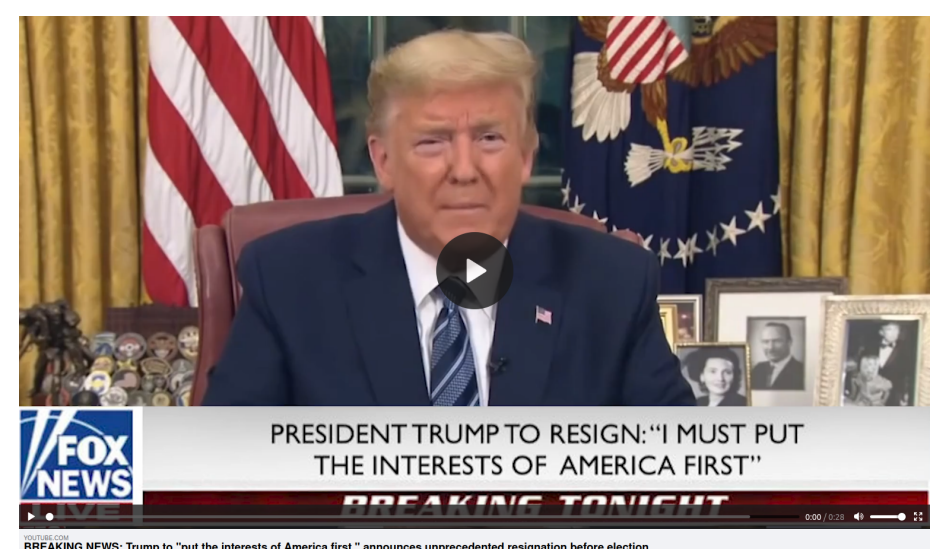

Figure C20: Donald Trump (fake resignation announcement). In a White House address, President Donald Trump notes the American public's disappointment in his leadership and announces his resignation before the 2020 election, citing a need to "put the interests of America first". 


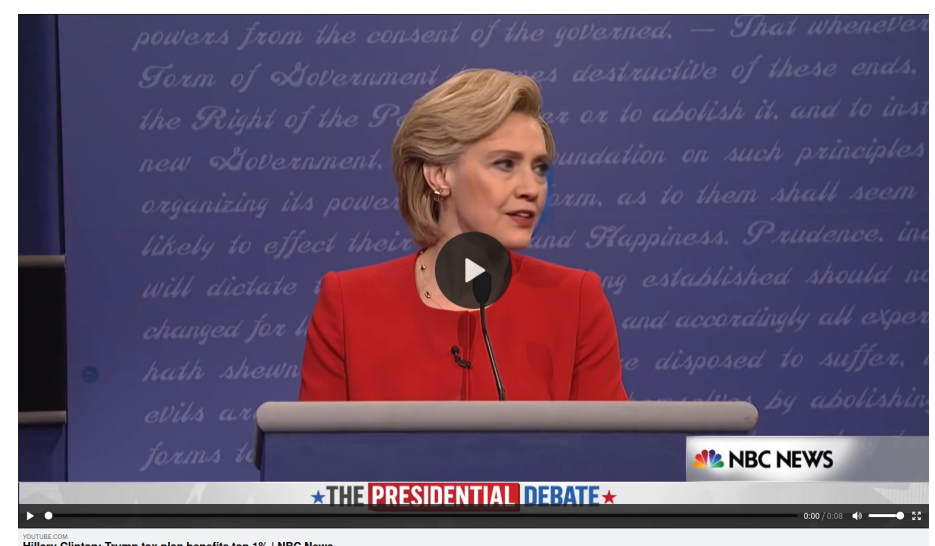

Figure C21: Hillary Clinton (fake debate). In a televised debate, 2016 Democratic presidential candidate Hillary Clinton labels opponent Donald Trump's tax plan as only benefiting the 1\%.

\section{Ethical Considerations}

We highlight the ethical considerations pursuant to a study that uses stimuli which are expected to be uniquely deceptive.

First, in addition to the subjects randomly assigned to a debrief in the middle of the survey, we extensively debrief all subjects at the completion of the survey. This debrief goes beyond the standard description of study procedures. We require respondents to type out the following phrase, depending on which experimental arm they were assigned to:

The [video/audio/text] about Elizabeth Warren is false.

Second, to minimize the risk of influencing the proximate election, we opted to make a deepfake of high-profile 2020 Democratic Presidential candidate who was not ultimately selected as the nominee. Elizabeth Warren is a salient politician, making our experiment more ecologically valid than one with a low-profile or hypothetical politician, but she is slated for re-election until 2024. We selected a female candidate because women are more likely to be the targets of non-political deepfakes, and we specifically test for whether pre-existing prejudice against women among subjects changes the effect of the deepfake. Two of the treatments do refer to Presidential nominees Trump and Biden, but since they are otherwise identical, any effects they produce would be offset.

Third, we carefully weigh the risks to subjects against the potential risks that may be averted with the knowledge gained through our experiment. The potential long-term consequences of exposure to a single piece of media are minimal. That is, participants are unlikely to change their political behavior as a response to treatment, given our extensive debrief. Given that we have no experimental evidence either way, it is at least as likely that our experiment will benefit subjects as cause harm. The experiment gives subjects experience detecting fake media, followed up by the debrief which contains feedback and information about how the deepfake process works. Given the importance and seeming inevitability of more deepfakes 
in the future, and the uncertainty around their effects, we argue that academics in fact have an "obligation to experiment" (Ko, Mou and Matias, 2016). We believe that improved understanding of how deepfakes function and evidence from our low-cost interventions will in fact serve to prevent real-world harms from deepfakes in the future.

Finally, a similar argument applies to the knowledge we generate from the perspective of policy-makers, journalists, and election administrators (Agarwal et al., 2019). More specifically, our study can inform future legislation or platform policies designed to minimize the threat posed by this technology. ${ }^{7}$

\section{E Sample Description}

Our survey experiment was fielded to a nationally representative sample on the Lucid survey research platform to a total of 17,501 subjects launched in two waves between September 29th 2020 and October 29th 2020. Of this 17,501, only 5,750 subjects successfully completed the survey experiment or passed a series of quality checks. One of these quality checks was a battery of randomly dispersed attention checks in response to a recently-publicized issue with in-attention among survey respondents during this period as documented in Aronow et al. (2020). Additionally, we imposed a series of "technology checks," namely that the subjects be able to watch and listen to a video. In addition, 629 respondents failed front-end pre-treatment attention checks: namely, they entered gender or age values that did not match up (or come to close to matching up) with respondent demographic characteristics provided by Lucid. We coded these respondents as "low-quality" respondents which we drop in our analyses as a robustness measure. As expected by Aronow et al. (2020), results largely hold across the two cohorts, but nearly all coefficient estimates are slightly diminished for the low-quality cohort.

Table E5 compares our sample's demographic traits to the demographic traits in the most recent Current Population Survey (CPS) - in particular, traits like education, age, and household income that are hypothesized to have correlations with deepfake deception and affective appeal (by their correlation with digital literacy, internet usage, and political knowledge) as well race, gender and ethnicity which are correlates of partisanship, another predictor of our measured behavioral responses. To adjust for remaining disrepancies, we generate poststratification weights via raking to match the CPS marginal population totals. We perform weighted regression in our analyses as a robustness measure to guard against measurement error from possible demographic skews.

\footnotetext{
${ }^{7}$ See SB 6513 introduced in the Washington state legislature at the time of writing, intended to restrict the use of deepfake audio or visual media in campaigns for elective office.
} 
Table E5: Sample Demographics and Representativeness After Post-Stratification

\begin{tabular}{|c|c|c|c|c|}
\hline & & CPS & Unweighted Sample & Weighted Sample \\
\hline \multirow[t]{4}{*}{ Education } & $<$ High school & $10.95 \%$ & $1.1 \%$ & $2.87 \%$ \\
\hline & High school & $47.14 \%$ & $29.88 \%$ & $45.52 \%$ \\
\hline & College & $30.3 \%$ & $47.17 \%$ & $35.98 \%$ \\
\hline & Postgraduate & $11.61 \%$ & $21.86 \%$ & $15.63 \%$ \\
\hline \multirow[t]{5}{*}{ Age } & $18-24$ & $10.42 \%$ & $6.33 \%$ & $8.9 \%$ \\
\hline & $25-34$ & $13.88 \%$ & $12.66 \%$ & $14.91 \%$ \\
\hline & $35-44$ & $12.58 \%$ & $16.97 \%$ & $16.91 \%$ \\
\hline & $45-64$ & $25.76 \%$ & $31.25 \%$ & $34.17 \%$ \\
\hline & $65+$ & $15.81 \%$ & $32.77 \%$ & $25.11 \%$ \\
\hline \multirow[t]{6}{*}{ Household Income } & $<\$ 25 \mathrm{k}$ & $19.11 \%$ & $30.16 \%$ & $22.63 \%$ \\
\hline & $\$ 100 \mathrm{k}-\$ 150 \mathrm{k}$ & $14.95 \%$ & $6.1 \%$ & $10.67 \%$ \\
\hline & $>\$ 150 \mathrm{k}$ & $15.47 \%$ & $4.77 \%$ & $10.44 \%$ \\
\hline & $\$ 25 \mathrm{k}-\$ 49 \mathrm{k}$ & $20.79 \%$ & $21.74 \%$ & $23.17 \%$ \\
\hline & $\$ 50 \mathrm{k}-\$ 74 \mathrm{k}$ & $17.2 \%$ & $15.63 \%$ & $18.6 \%$ \\
\hline & $\$ 75 \mathrm{k}-\$ 99 \mathrm{k}$ & $12.48 \%$ & $19.27 \%$ & $14.5 \%$ \\
\hline \multirow[t]{2}{*}{ Gender } & Male & $48.75 \%$ & $33.58 \%$ & $44.19 \%$ \\
\hline & Female & $51.25 \%$ & $66.14 \%$ & $55.81 \%$ \\
\hline \multirow[t]{4}{*}{ Race } & Asian & $5.42 \%$ & $3.95 \%$ & $4.4 \%$ \\
\hline & Black & $10.28 \%$ & $5.76 \%$ & $8.41 \%$ \\
\hline & Other & $4.18 \%$ & $3.81 \%$ & $3.79 \%$ \\
\hline & White & $80.12 \%$ & $85.79 \%$ & $83.4 \%$ \\
\hline \multirow[t]{2}{*}{ Hispanic } & Yes & $14.66 \%$ & $5.18 \%$ & $8.59 \%$ \\
\hline & No & $85.34 \%$ & $94.1 \%$ & $91.41 \%$ \\
\hline
\end{tabular}

Notes: Weights are constructed via Iterative Proportional Fitting to match sample marginal totals to CPS marginal totals on displayed demographic traits. Weights in the final column used for all analyses in paper.

\section{F Pre-Registered Analyses}

Our pre-analysis plan containing all pre-reigstered hypotheses can be found at https://osf. io/cdfh3/. For all models, unless otherwise noted or displayed, controls include age group, education, 3 point party ID, cognitive reflection, political knowledge, internet usage, and an indicator for mobile (vs. desktop) exposure. The reference stimuli for all analyses of the incidental exposure experiment is video. Reference category for environment in the detection task experiment is high-fake. Cognitive reflection, political knowledge, ambivalent sexism, and internet usage are all re-scaled to $[0,1]$. Unless otherwise noted, analyses exclude respondents who receive information prior to the incidental exposure experiment, however results (effect magnitudes, statistical significance) are substantively similar in all cases with their inclusion. As pre-registered, all $p$-values are "step-up" adjusted to $p \cdot r / K$ where $r$ denotes the rank of the unadjusted $p$-value amongst $K$ total estimated $p$-values (Benjamini-Hochberg procedure). Analyses do not additionally adjust for respondent wave, for brevity, though we find that including respondent wave as either an interaction term or a linear term does not change our results. 
Table F6: Models of Credibility Confidence of Scandal Clipping in Incidental Exposure Experiment

\begin{tabular}{|c|c|c|c|c|c|c|c|}
\hline & \multicolumn{7}{|c|}{ Confidence that clipping was credible [1-5] } \\
\hline & $(1)$ & $(2)$ & $(3)$ & $(4)$ & $(5)$ & $(6)$ & $(7)$ \\
\hline Audio & $\begin{array}{c}0.08 \\
(0.09)\end{array}$ & $\begin{array}{c}0.14 \\
(0.09)\end{array}$ & $\begin{array}{c}0.10 \\
(0.09)\end{array}$ & $\begin{array}{c}0.09 \\
(0.09)\end{array}$ & $\begin{array}{c}0.12 \\
(0.09)\end{array}$ & $\begin{array}{c}0.11 \\
(0.09)\end{array}$ & $\begin{array}{l}0.17^{*} \\
(0.09)\end{array}$ \\
\hline Text & $\begin{array}{l}-0.02 \\
(0.09)\end{array}$ & $\begin{array}{l}-0.11 \\
(0.09)\end{array}$ & $\begin{array}{c}0.03 \\
(0.09)\end{array}$ & $\begin{array}{l}-0.02 \\
(0.09)\end{array}$ & $\begin{array}{c}-0.15^{*} \\
(0.08)\end{array}$ & $\begin{array}{c}0.02 \\
(0.09)\end{array}$ & $\begin{array}{l}-0.06 \\
(0.09)\end{array}$ \\
\hline On Mobile & & & & $\begin{array}{c}0.04 \\
(0.09)\end{array}$ & $\begin{array}{c}0.13 \\
(0.09)\end{array}$ & $\begin{array}{l}0.18^{*} \\
(0.09)\end{array}$ & $\begin{array}{c}0.29^{* * *} \\
(0.09)\end{array}$ \\
\hline Age 65+ & & & & $\begin{array}{c}0.12 \\
(0.08)\end{array}$ & $\begin{array}{c}0.16 \\
(0.08)\end{array}$ & $\begin{array}{l}0.14^{*} \\
(0.08)\end{array}$ & $\begin{array}{l}0.20^{*} \\
(0.08)\end{array}$ \\
\hline High School & & & & $\begin{array}{l}-0.23 \\
(0.38)\end{array}$ & $\begin{array}{c}-0.46^{*} \\
(0.23)\end{array}$ & $\begin{array}{l}-0.42 \\
(0.39)\end{array}$ & $\begin{array}{c}-0.51^{* *} \\
(0.23)\end{array}$ \\
\hline College & & & & $\begin{array}{l}-0.19 \\
(0.37)\end{array}$ & $\begin{array}{l}-0.40 \\
(0.23)\end{array}$ & $\begin{array}{l}-0.35 \\
(0.38)\end{array}$ & $\begin{array}{l}-0.38 \\
(0.23)\end{array}$ \\
\hline Postgrad & & & & $\begin{array}{l}-0.35 \\
(0.38)\end{array}$ & $\begin{array}{c}-0.48^{*} \\
(0.24)\end{array}$ & $\begin{array}{l}-0.52 \\
(0.39)\end{array}$ & $\begin{array}{c}-0.53^{*} \\
(0.24)\end{array}$ \\
\hline Independent PID & & & & & $\begin{array}{c}0.19 \\
(0.11)\end{array}$ & $\begin{array}{c}0.15 \\
(0.11)\end{array}$ & $\begin{array}{c}0.20 \\
(0.11)\end{array}$ \\
\hline Republican PID & & & & & $\begin{array}{c}0.54^{* * *} \\
(0.08)\end{array}$ & $\begin{array}{c}0.53^{* * *} \\
(0.08)\end{array}$ & $\begin{array}{c}0.54^{* * *} \\
(0.08)\end{array}$ \\
\hline Cognitive Reflection & & & & $\begin{array}{l}-0.02 \\
(0.15)\end{array}$ & $\begin{array}{c}0.02 \\
(0.15)\end{array}$ & $\begin{array}{c}0.07 \\
(0.16)\end{array}$ & $\begin{array}{c}0.18 \\
(0.16)\end{array}$ \\
\hline Male & & & & $\begin{array}{l}-0.07 \\
(0.08)\end{array}$ & $\begin{array}{l}-0.03 \\
(0.07)\end{array}$ & $\begin{array}{l}-0.03 \\
(0.08)\end{array}$ & $\begin{array}{l}0.002 \\
(0.08)\end{array}$ \\
\hline Political Knowledge & & & & $\begin{array}{c}0.17 \\
(0.16)\end{array}$ & $\begin{array}{c}0.24 \\
(0.16)\end{array}$ & $\begin{array}{c}0.22 \\
(0.17)\end{array}$ & $\begin{array}{c}0.31 \\
(0.16)\end{array}$ \\
\hline Internet Usage & & & & $\begin{array}{c}0.56 \\
(0.33)\end{array}$ & $\begin{array}{l}0.89^{* *} \\
(0.33)\end{array}$ & $\begin{array}{c}0.54 \\
(0.34)\end{array}$ & $\begin{array}{c}0.62 \\
(0.35)\end{array}$ \\
\hline Ambivalent Sexism & & & & $\begin{array}{c}0.14^{* * *} \\
(0.04)\end{array}$ & $\begin{array}{c}0.04 \\
(0.04)\end{array}$ & $\begin{array}{c}0.04 \\
(0.05)\end{array}$ & $\begin{array}{c}0.05 \\
(0.05)\end{array}$ \\
\hline Constant & $\begin{array}{c}3.40^{* * *} \\
(0.06)\end{array}$ & $\begin{array}{c}3.44^{* * *} \\
(0.06)\end{array}$ & $\begin{array}{c}3.39^{* * *} \\
(0.07)\end{array}$ & $\begin{array}{c}2.58^{* * *} \\
(0.51)\end{array}$ & $\begin{array}{c}2.45^{* * *} \\
(0.42)\end{array}$ & $\begin{array}{c}2.68^{* * *} \\
(0.53)\end{array}$ & $\begin{array}{c}2.47^{* * *} \\
(0.44)\end{array}$ \\
\hline $\begin{array}{l}\text { Weighted? } \\
\text { Low-Quality Dropped? }\end{array}$ & & $\checkmark$ & $\checkmark$ & & $\checkmark$ & $\checkmark$ & $\begin{array}{l}\checkmark \\
\checkmark\end{array}$ \\
\hline $\mathrm{N}$ & 1,356 & 1,356 & 1,209 & 1,356 & 1,356 & 1,209 & 1,209 \\
\hline $\mathrm{R}^{2}$ & 0.001 & 0.01 & 0.001 & 0.02 & 0.06 & 0.05 & 0.07 \\
\hline Adjusted $\mathrm{R}^{2}$ & -0.0003 & 0.005 & -0.001 & 0.01 & 0.05 & 0.04 & 0.05 \\
\hline
\end{tabular}

Notes: $\cdot p \cdot r / K<.1 * p \cdot r / K<.05^{* *} p \cdot r / K<.01 * * * p \cdot r / K<.001$ 
Table F7: Models of Binarized Credibility Confidence of Scandal Clipping in Incidental Exposure Experiment

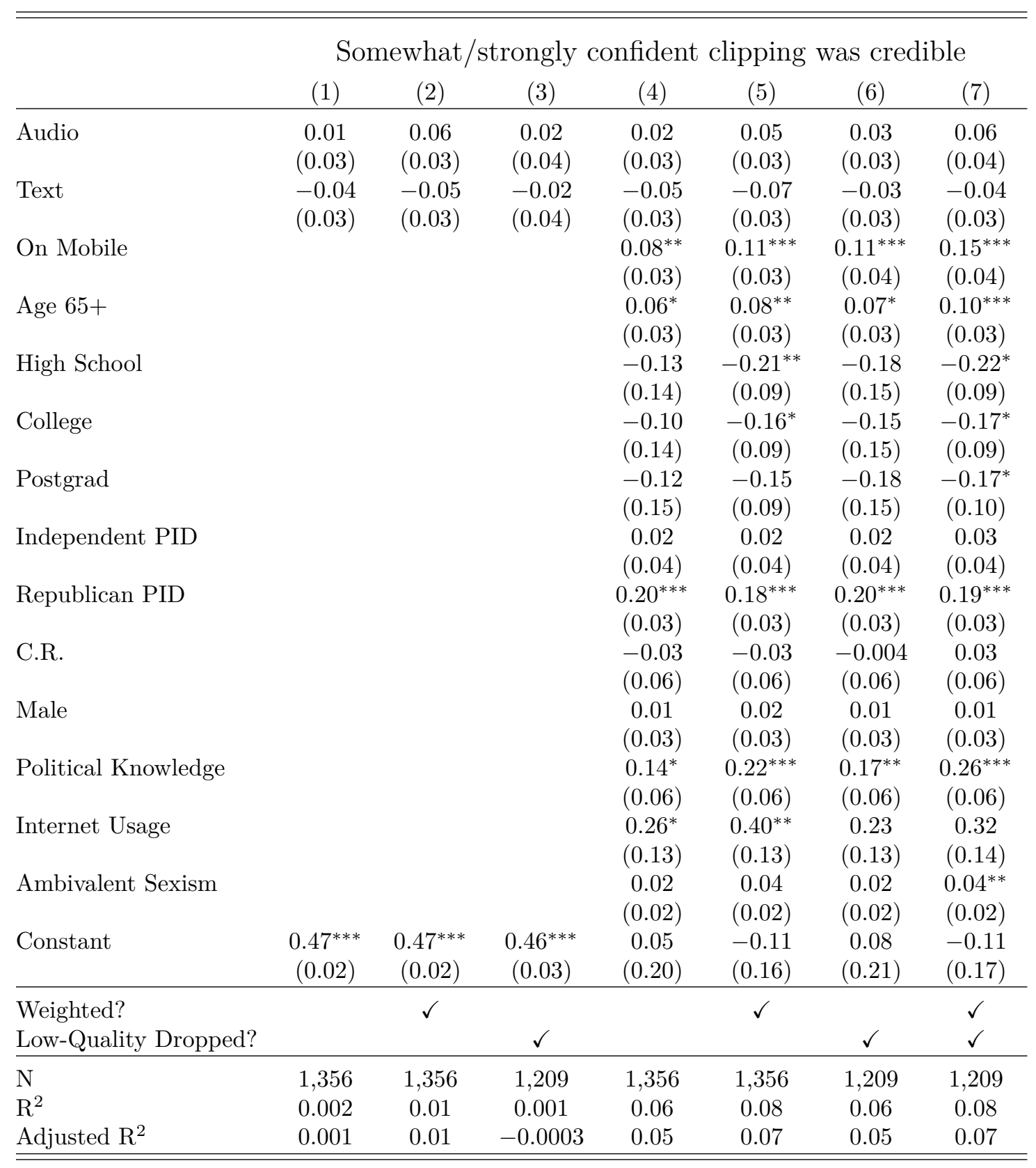

Notes: $\cdot p \cdot r / K<.1^{*} p \cdot r / K<.05^{* *} p \cdot r / K<.01 * * * p \cdot r / K<.001$ 
Table F8: Models of Information Provision and Credibility Confidence of Clipping in Incidental Exposure Experiment

\begin{tabular}{|c|c|c|c|c|c|c|c|}
\hline & \multicolumn{7}{|c|}{ Confidence that clipping was credible [1-5] } \\
\hline & $(1)$ & $(2)$ & (3) & $(4)$ & $(5)$ & (6) & (7) \\
\hline Information & $\begin{array}{c}-0.35^{* * *} \\
(0.09)\end{array}$ & $\begin{array}{c}-0.29^{* * *} \\
(0.09)\end{array}$ & $\begin{array}{c}-0.35^{* *} \\
(0.10)\end{array}$ & $\begin{array}{c}-0.38^{* * *} \\
(0.09)\end{array}$ & $\begin{array}{c}-0.34^{* * *} \\
(0.09)\end{array}$ & $\begin{array}{c}-0.38^{* * *} \\
(0.09)\end{array}$ & $\begin{array}{c}-0.31^{* * *} \\
(0.09)\end{array}$ \\
\hline Audio & $\begin{array}{c}0.08 \\
(0.09)\end{array}$ & $\begin{array}{c}0.14 \\
(0.09)\end{array}$ & $\begin{array}{c}0.10 \\
(0.09)\end{array}$ & $\begin{array}{c}0.11 \\
(0.09)\end{array}$ & $\begin{array}{c}0.14 \\
(0.09)\end{array}$ & $\begin{array}{c}0.12 \\
(0.09)\end{array}$ & $\begin{array}{c}0.20^{* *} \\
(0.09)\end{array}$ \\
\hline Text & $\begin{array}{l}-0.02 \\
(0.09)\end{array}$ & $\begin{array}{l}-0.11 \\
(0.09)\end{array}$ & $\begin{array}{c}0.03 \\
(0.09)\end{array}$ & $\begin{array}{l}-0.01 \\
(0.09)\end{array}$ & $\begin{array}{l}-0.14 \\
(0.09)\end{array}$ & $\begin{array}{c}0.03 \\
(0.09)\end{array}$ & $\begin{array}{l}-0.06 \\
(0.09)\end{array}$ \\
\hline Info x Audio & $\begin{array}{c}0.09 \\
(0.12)\end{array}$ & $\begin{array}{l}-0.08 \\
(0.12)\end{array}$ & $\begin{array}{c}0.09 \\
(0.13)\end{array}$ & $\begin{array}{c}0.10 \\
(0.12)\end{array}$ & $\begin{array}{l}-0.03 \\
(0.12)\end{array}$ & $\begin{array}{c}0.12 \\
(0.13)\end{array}$ & $\begin{array}{l}-0.04 \\
(0.13)\end{array}$ \\
\hline Info $\mathrm{x}$ Text & $\begin{array}{c}0.20 \\
(0.12)\end{array}$ & $\begin{array}{c}0.22 \\
(0.12)\end{array}$ & $\begin{array}{c}0.18 \\
(0.13)\end{array}$ & $\begin{array}{c}0.24 \\
(0.12)\end{array}$ & $\begin{array}{l}0.30^{* *} \\
(0.12)\end{array}$ & $\begin{array}{c}0.25 \\
(0.13)\end{array}$ & $\begin{array}{l}0.23^{*} \\
(0.13)\end{array}$ \\
\hline Constant & $\begin{array}{c}3.40^{* * *} \\
(0.06) \\
\end{array}$ & $\begin{array}{c}3.44^{* * *} \\
(0.06)\end{array}$ & $\begin{array}{c}3.39^{* * *} \\
(0.07) \\
\end{array}$ & $\begin{array}{c}2.87^{* * *} \\
(0.36) \\
\end{array}$ & $\begin{array}{c}3.13^{* * *} \\
(0.29) \\
\end{array}$ & $\begin{array}{c}2.92^{* * *} \\
(0.38) \\
\end{array}$ & $\begin{array}{c}3.10^{* * *} \\
(0.32) \\
\end{array}$ \\
\hline Weighted? & & $\checkmark$ & & & $\checkmark$ & & $\checkmark$ \\
\hline Low-Quality Dropped? & & & $\checkmark$ & & & $\checkmark$ & $\checkmark$ \\
\hline Controls? & & & & $\checkmark$ & $\checkmark$ & $\checkmark$ & $\checkmark$ \\
\hline $\mathrm{N}$ & 2,724 & 2,724 & 2,419 & 2,724 & 2,724 & 2,419 & 2,419 \\
\hline $\mathrm{R}^{2}$ & 0.01 & 0.01 & 0.01 & 0.06 & 0.06 & 0.06 & 0.06 \\
\hline Adjusted $\mathrm{R}^{2}$ & 0.01 & 0.01 & 0.01 & 0.05 & 0.05 & 0.05 & 0.05 \\
\hline
\end{tabular}

Table F9: Models of Information Provision and Binarized Credibility Confidence of Clipping in Incidental Exposure Experiment

\begin{tabular}{lccccccc}
\hline \hline & \multicolumn{3}{c}{ Somewhat/strongly confident clipping was credible } \\
& $(1)$ & $(2)$ & $(3)$ & $(4)$ & $(5)$ & $(6)$ & $(7)$ \\
\hline Information & $-0.11^{* *}$ & $-0.09^{* *}$ & $-0.10^{* *}$ & -0.12 & -0.11 & -0.12 & -0.09 \\
& $(0.03)$ & $(0.03)$ & $(0.04)$ & $(0.03)$ & $(0.03)$ & $(0.04)$ & $(0.04)$ \\
Audio & 0.01 & $0.06^{*}$ & 0.02 & 0.02 & 0.06 & 0.03 & 0.07 \\
& $(0.03)$ & $(0.03)$ & $(0.04)$ & $(0.03)$ & $(0.03)$ & $(0.03)$ & $(0.04)$ \\
Text & -0.04 & -0.05 & -0.02 & -0.05 & -0.06 & -0.03 & -0.03 \\
& $(0.03)$ & $(0.03)$ & $(0.03)$ & $(0.03)$ & $(0.03)$ & $(0.03)$ & $(0.03)$ \\
Info x Audio & 0.02 & -0.04 & 0.01 & 0.03 & -0.02 & 0.02 & -0.04 \\
& $(0.05)$ & $(0.05)$ & $(0.05)$ & $(0.05)$ & $(0.05)$ & $(0.05)$ & $(0.05)$ \\
Info x Text & 0.09 & 0.08 & 0.07 & 0.11 & 0.12 & 0.10 & 0.09 \\
& $(0.05)$ & $(0.05)$ & $(0.05)$ & $(0.05)$ & $(0.05)$ & $(0.05)$ & $(0.05)$ \\
Constant & $0.47^{* * *}$ & $0.47^{* * *}$ & $0.46^{* * *}$ & 0.11 & 0.15 & 0.11 & 0.14 \\
& $(0.02)$ & $(0.02)$ & $(0.03)$ & $(0.14)$ & $(0.11)$ & $(0.15)$ & $(0.12)$ \\
\hline Weighted? & & $\checkmark$ & & & $\checkmark$ & & $\checkmark$ \\
Low-Quality Dropped? & & & $\checkmark$ & & & $\checkmark$ & $\checkmark$ \\
Controls? & & & & $\checkmark$ & $\checkmark$ & $\checkmark$ & $\checkmark$ \\
\hline $\mathrm{N}$ & 2,724 & 2,724 & 2,419 & 2,724 & 2,724 & 2,419 & 2,419 \\
$\mathrm{R}^{2}$ & 0.01 & 0.01 & 0.01 & 0.05 & 0.05 & 0.05 & 0.05 \\
Adjusted R $\mathrm{R}^{2}$ & 0.01 & 0.01 & 0.005 & 0.04 & 0.04 & 0.04 & 0.05 \\
\hline \hline
\end{tabular}

Notes: $\cdot p \cdot r / K<.1 * p \cdot r / K<.05^{* *} p \cdot r / K<.01 * * * p \cdot r / K<.001$ 


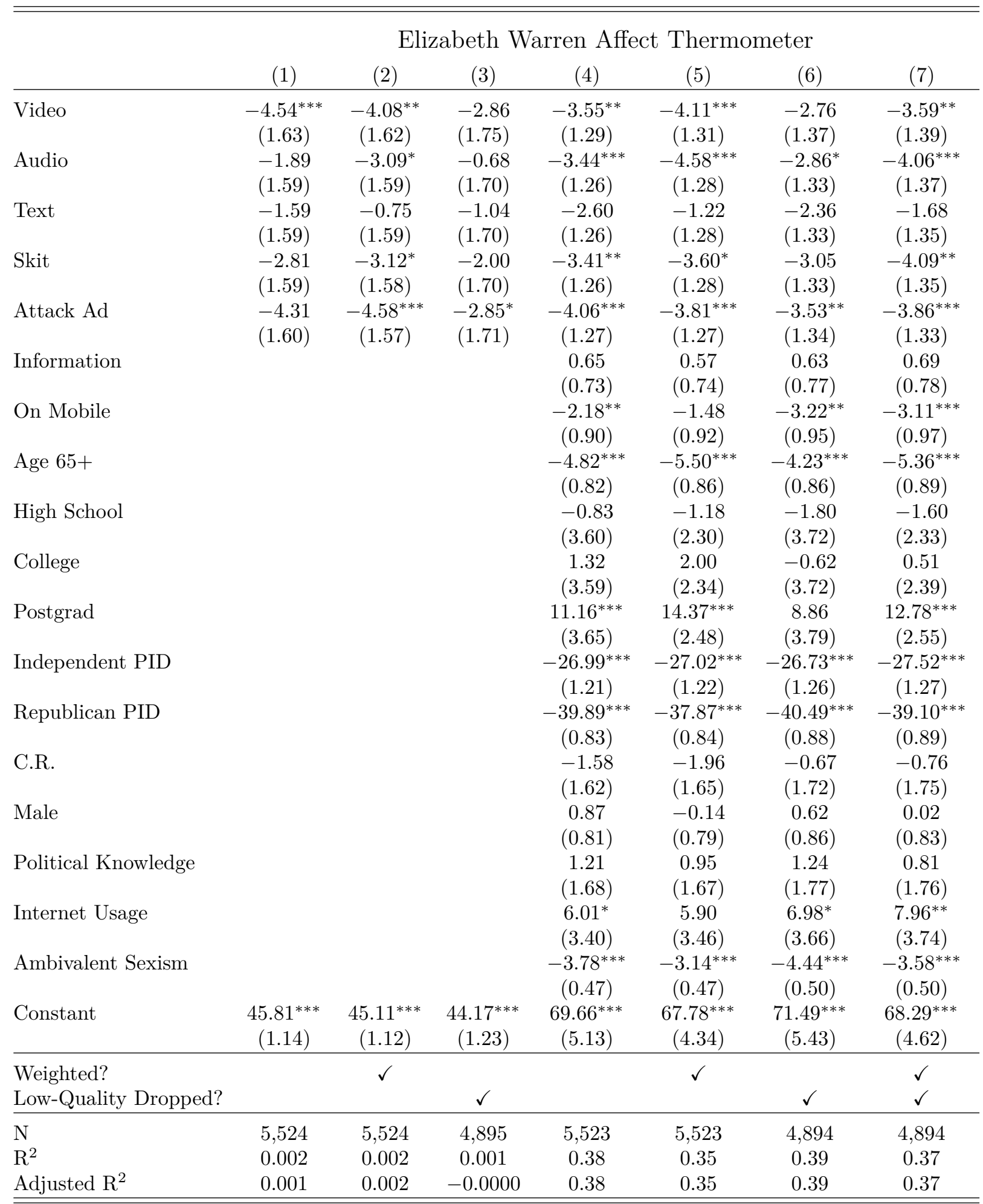

Notes: $\cdot p \cdot r / K<.1 * p \cdot r / K<.05 * * p \cdot r / K<.01 * * * p \cdot r / K<.001$

Reference category for clip type is control. 
Figure F22: Effects of Clip Type on Placebo Targets' Favorability in Incidental Exposure Experiment
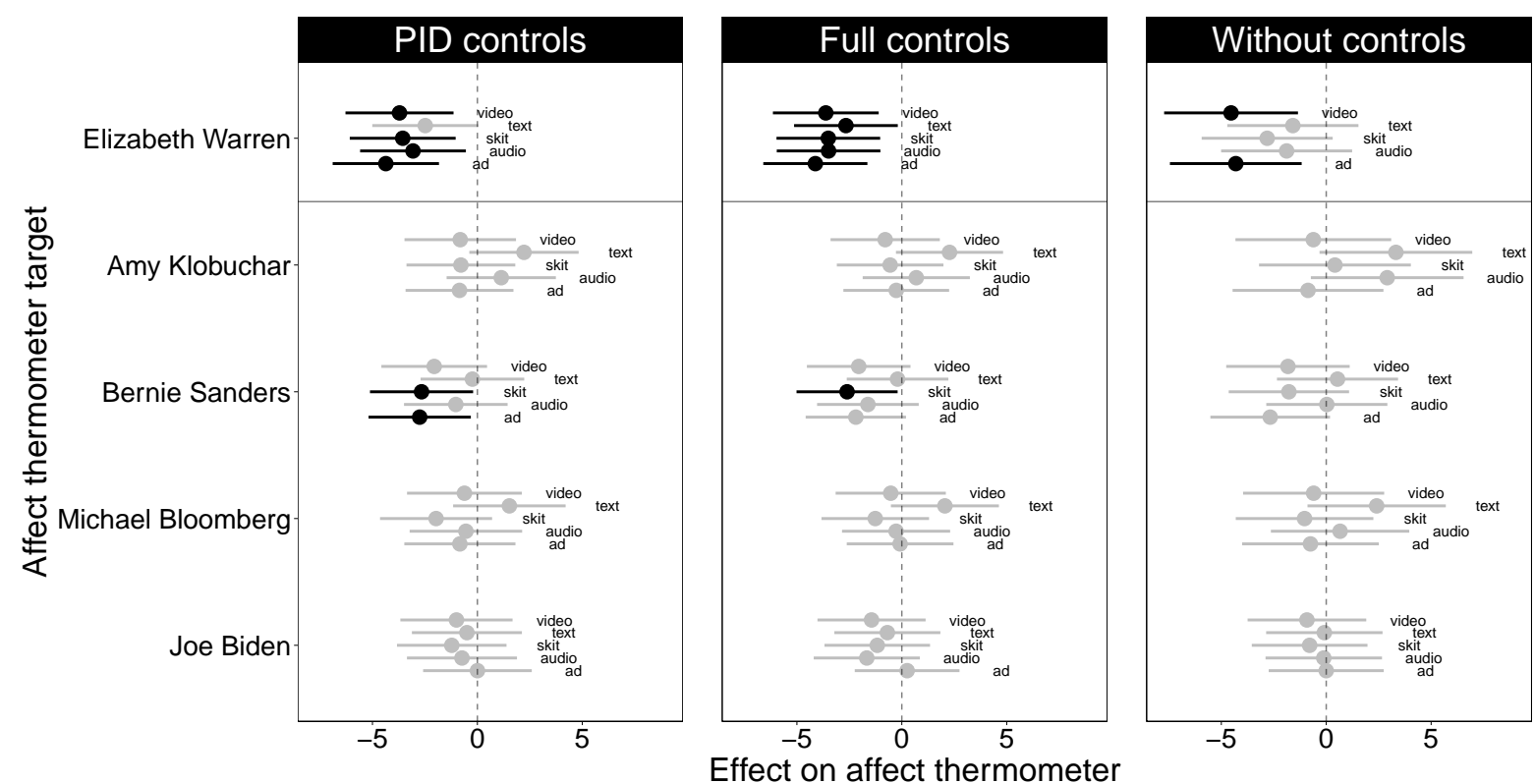

Notes: Shown are other candidates who ran in the 2020 Democratic primary for whom we selected clips to mask our deepfake in the incidental exposure experiment.

Table F11: Models of Information Provision and Media Trust in Incidental Exposure Experiment

\begin{tabular}{|c|c|c|c|c|c|c|c|}
\hline & \multicolumn{7}{|c|}{ Dependent variable: } \\
\hline & \multicolumn{7}{|c|}{ Trust in Media (Combined Index) } \\
\hline & $(1)$ & $(2)$ & $(3)$ & $(4)$ & $(5)$ & $(6)$ & $(7)$ \\
\hline Information & $\begin{array}{l}-0.02 \\
(0.02)\end{array}$ & $\begin{array}{c}-0.03 \\
(0.02)\end{array}$ & $\begin{array}{l}-0.02 \\
(0.02)\end{array}$ & $\begin{array}{l}-0.02 \\
(0.02)\end{array}$ & $\begin{array}{l}-0.02 \\
(0.02)\end{array}$ & $\begin{array}{l}-0.02 \\
(0.02)\end{array}$ & $\begin{array}{l}-0.02 \\
(0.02)\end{array}$ \\
\hline Constant & $\begin{array}{c}2.27^{* * *} \\
(0.02)\end{array}$ & $\begin{array}{c}2.29^{* * *} \\
(0.02)\end{array}$ & $\begin{array}{c}2.27^{* * *} \\
(0.02)\end{array}$ & $\begin{array}{c}2.20^{* * *} \\
(0.14)\end{array}$ & $\begin{array}{c}2.18^{* * *} \\
(0.12)\end{array}$ & $\begin{array}{c}2.20^{* * *} \\
(0.14)\end{array}$ & $\begin{array}{c}2.18^{* * *} \\
(0.12) \\
\end{array}$ \\
\hline Weighted? & & $\checkmark$ & & & $\checkmark$ & & $\checkmark$ \\
\hline Low-Quality Dropped? & & & $\checkmark$ & & & $\checkmark$ & $\checkmark$ \\
\hline Controls? & & & & $\checkmark$ & $\checkmark$ & $\checkmark$ & $\checkmark$ \\
\hline Observations & 3,231 & 3,231 & 3,231 & 3,231 & 3,231 & 3,231 & 3,231 \\
\hline $\mathrm{R}^{2}$ & 0.0002 & 0.001 & 0.0002 & 0.19 & 0.23 & 0.19 & 0.23 \\
\hline Adjusted $\mathrm{R}^{2}$ & -0.0001 & 0.0003 & -0.0001 & 0.19 & 0.23 & 0.19 & 0.23 \\
\hline
\end{tabular}


Table F12: Models of Information Provision and Media Trust Across Sources in Incidental Exposure Experiment

\begin{tabular}{lcccccccc}
\hline \hline & \multicolumn{7}{c}{ Trust in... } \\
\cline { 2 - 9 } & \multicolumn{1}{c}{ Offline Media } & \multicolumn{2}{c}{ Online Media } & \multicolumn{2}{c}{ Social Media } & \multicolumn{2}{c}{ Combined Index } \\
& $(1)$ & $(2)$ & $(3)$ & $(4)$ & $(5)$ & $(6)$ & $(7)$ & $(8)$ \\
\hline Information & 0.004 & 0.003 & -0.03 & -0.03 & -0.04 & -0.04 & -0.02 & -0.02 \\
& $(0.03)$ & $(0.03)$ & $(0.03)$ & $(0.03)$ & $(0.03)$ & $(0.03)$ & $(0.02)$ & $(0.02)$ \\
Constant & $2.62^{* * *}$ & 2.77 & $2.30^{* * *}$ & 1.96 & $1.87^{* * *}$ & 1.89 & $2.27^{* * *}$ & $2.20^{* * *}$ \\
& $(0.02)$ & $(0.18)$ & $(0.02)$ & $(0.17)$ & $(0.02)$ & $(0.18)$ & $(0.02)$ & $(0.14)$ \\
\hline Controls? & & $\checkmark$ & & $\checkmark$ & & $\checkmark$ & & $\checkmark$ \\
\hline Observations & 3,231 & 3,231 & 3,231 & 3,231 & 3,231 & 3,231 & 3,231 & 3,231 \\
$\mathrm{R}^{2}$ & 0.0000 & 0.17 & 0.0003 & 0.13 & 0.0005 & 0.17 & 0.0002 & 0.19 \\
Adjusted $\mathrm{R}^{2}$ & -0.0003 & 0.17 & 0.0000 & 0.13 & 0.0002 & 0.16 & -0.0001 & 0.19 \\
\hline \hline \multirow{2}{*}{ Note: } & $p \cdot r / K<.1 * p \cdot r / K<.05 * * p \cdot r / K<.01 * * * p \cdot r / K<.001$ \\
& Respondents in skit and ad conditions are excluded.
\end{tabular}

Table F13: Models of Deepfake Exposure, Credibility, and Media Trust in Incidental Exposure Experiment

\begin{tabular}{|c|c|c|c|c|c|c|c|}
\hline & \multicolumn{7}{|c|}{ Trust in Media (Combined Index) } \\
\hline & $(1)$ & $(2)$ & $(3)$ & $(4)$ & $(5)$ & $(6)$ & $(7)$ \\
\hline Credible & $\begin{array}{c}-0.11^{* * *} \\
(0.02)\end{array}$ & $\begin{array}{c}-0.07^{* * *} \\
(0.02)\end{array}$ & $\begin{array}{l}-0.12 \\
(0.04)\end{array}$ & $\begin{array}{c}-0.08^{* * *} \\
(0.02)\end{array}$ & $\begin{array}{c}-0.08^{* * *} \\
(0.02)\end{array}$ & $\begin{array}{c}-0.08^{* * *} \\
(0.02)\end{array}$ & $\begin{array}{c}-0.14^{* * *} \\
(0.04)\end{array}$ \\
\hline Video & $\begin{array}{c}-0.30^{* *} \\
(0.11)\end{array}$ & $\begin{array}{c}-0.28^{* *} \\
(0.10)\end{array}$ & $\begin{array}{l}-0.09 \\
(0.05)\end{array}$ & $\begin{array}{c}-0.45^{* * *} \\
(0.10)\end{array}$ & $\begin{array}{c}-0.25^{* *} \\
(0.11)\end{array}$ & $\begin{array}{c}-0.41^{* * *} \\
(0.11)\end{array}$ & $\begin{array}{c}-0.20^{* * *} \\
(0.05)\end{array}$ \\
\hline Credible x Video & $\begin{array}{c}0.07^{* *} \\
(0.03)\end{array}$ & $\begin{array}{c}0.07 \\
(0.03)\end{array}$ & $\begin{array}{c}0.10 \\
(0.07)\end{array}$ & $\begin{array}{c}0.10^{* * *} \\
(0.03)\end{array}$ & $\begin{array}{c}0.06^{*} \\
(0.03)\end{array}$ & $\begin{array}{c}0.09^{* * *} \\
(0.03)\end{array}$ & $\begin{array}{l}0.19^{*} \\
(0.07)\end{array}$ \\
\hline Constant & $\begin{array}{c}2.66^{* * *} \\
(0.06) \\
\end{array}$ & $\begin{array}{c}2.58^{* * *} \\
(0.24) \\
\end{array}$ & $\begin{array}{c}2.40^{* * *} \\
(0.24)\end{array}$ & $\begin{array}{c}2.46^{* * *} \\
(0.20) \\
\end{array}$ & $\begin{array}{c}2.59^{* * *} \\
(0.25)\end{array}$ & $\begin{array}{c}2.57^{* * *} \\
(0.21)\end{array}$ & $\begin{array}{c}2.28^{* * *} \\
(0.20)\end{array}$ \\
\hline Weighted? & & & & $\checkmark$ & & $\checkmark$ & $\checkmark$ \\
\hline Low-Quality Dropped? & & & & & $\checkmark$ & $\checkmark$ & $\checkmark$ \\
\hline Controls? & & $\checkmark$ & $\checkmark$ & $\checkmark$ & $\checkmark$ & $\checkmark$ & $\checkmark$ \\
\hline Credibility Binarized? & & & $\checkmark$ & & & & $\checkmark$ \\
\hline $\mathrm{N}$ & 1,354 & 1,354 & 1,354 & 1,354 & 1,207 & 1,207 & 1,354 \\
\hline $\mathrm{R}^{2}$ & 0.03 & 0.23 & 0.23 & 0.27 & 0.23 & 0.27 & 0.27 \\
\hline Adjusted $\mathrm{R}^{2}$ & 0.03 & 0.22 & 0.22 & 0.27 & 0.22 & 0.26 & 0.26 \\
\hline
\end{tabular}

Notes: $\cdot p \cdot r / K<.1 * p \cdot r / K<.05 * * p \cdot r / K<.01 * * * p \cdot r / K<.001$

Respondents in skit and ad conditions are excluded. 
Table F14: Models of Deepfake Exposure, Credibility, and Media Trust Across Sources in Incidental Exposure Experiment

\begin{tabular}{lcccccccc}
\hline \hline & \multicolumn{7}{c}{ Trust in... } \\
\cline { 2 - 9 } & \multicolumn{2}{c}{ Offline Media } & Online Media & \multicolumn{2}{c}{ Social Media } & \multicolumn{2}{c}{ Combined Index } \\
& $(1)$ & $(2)$ & $(3)$ & $(4)$ & $(5)$ & $(6)$ & $(7)$ & $(8)$ \\
\hline Credibility & $-0.08^{* * *}$ & $-0.14^{* * *}$ & $-0.06^{* * *}$ & $-0.11^{* *}$ & $-0.08^{* * *}$ & $-0.12^{*}$ & $-0.07^{* * *}$ & -0.12 \\
& $(0.02)$ & $(0.05)$ & $(0.02)$ & $(0.05)$ & $(0.02)$ & $(0.05)$ & $(0.02)$ & $(0.04)$ \\
Video & -0.21 & -0.05 & $-0.25^{*}$ & -0.10 & $-0.37^{* *}$ & $-0.13^{*}$ & $-0.28^{* *}$ & -0.09 \\
& $(0.13)$ & $(0.06)$ & $(0.12)$ & $(0.06)$ & $(0.13)$ & $(0.06)$ & $(0.10)$ & $(0.05)$ \\
Credibility x Video & 0.05 & 0.06 & 0.06 & 0.14 & 0.08 & 0.09 & $0.07^{* *}$ & 0.10 \\
& $(0.03)$ & $(0.09)$ & $(0.03)$ & $(0.09)$ & $(0.04)$ & $(0.09)$ & $(0.03)$ & $(0.07)$ \\
Constant & $2.86^{* * *}$ & $2.68^{* * *}$ & $2.30^{* * *}$ & $2.16^{* * *}$ & $2.57^{* * *}$ & $2.38^{* * *}$ & $2.58^{* * *}$ & 2.40 \\
& $(0.30)$ & $(0.30)$ & $(0.29)$ & $(0.29)$ & $(0.31)$ & $(0.31)$ & $(0.24)$ & $(0.24)$ \\
\hline Controls? & $\checkmark$ & $\checkmark$ & $\checkmark$ & $\checkmark$ & $\checkmark$ & $\checkmark$ & $\checkmark$ & $\checkmark$ \\
Credibility Binarized? & & $\checkmark$ & & $\checkmark$ & & $\checkmark$ & $\checkmark$ & $\checkmark$ \\
\hline Observations & 1,354 & 1,354 & 1,354 & 1,354 & 1,354 & 1,354 & 1,354 & 1,354 \\
$\mathrm{R}^{2}$ & 0.21 & 0.20 & 0.16 & 0.16 & 0.20 & 0.19 & 0.23 & 0.23 \\
Adjusted R ${ }^{2}$ & 0.20 & 0.19 & 0.15 & 0.15 & 0.19 & 0.18 & 0.22 & 0.22 \\
\hline \hline
\end{tabular}

Note: $\quad \cdot p \cdot r / K<.1^{*} p \cdot r / K<.05^{* *} p \cdot r / K<.01{ }^{* * *} p \cdot r / K<.001$

Respondents in skit and ad conditions are excluded.

Table F15: Models of Cognitive Reflection and Credibility Confidence of Clipping in Incidental Exposure Experiment

\begin{tabular}{|c|c|c|c|c|c|c|c|}
\hline & \multicolumn{7}{|c|}{ Confidence that clipping was credible [1-5] } \\
\hline & (1) & $(2)$ & $(3)$ & (4) & $(5)$ & $(6)$ & $(7)$ \\
\hline \multirow[t]{2}{*}{ Audio } & 0.08 & 0.05 & 0.11 & 0.10 & 0.10 & 0.15 & 0.19 \\
\hline & $(0.11)$ & $(0.11)$ & $(0.11)$ & $(0.10)$ & $(0.10)$ & $(0.11)$ & $(0.11)$ \\
\hline \multirow[t]{2}{*}{ Text } & 0.11 & -0.04 & 0.14 & 0.11 & -0.04 & 0.14 & -0.02 \\
\hline & $(0.10)$ & $(0.10)$ & $(0.11)$ & $(0.10)$ & $(0.10)$ & $(0.11)$ & $(0.11)$ \\
\hline \multirow[t]{2}{*}{ C.R. } & -0.09 & -0.12 & -0.03 & -0.10 & -0.09 & -0.03 & -0.02 \\
\hline & $(0.20)$ & $(0.19)$ & $(0.21)$ & $(0.19)$ & $(0.19)$ & $(0.21)$ & $(0.20)$ \\
\hline \multirow[t]{2}{*}{ C.R. x Audio } & 0.12 & 0.13 & 0.07 & 0.16 & 0.08 & 0.08 & -0.06 \\
\hline & $(0.27)$ & $(0.28)$ & $(0.29)$ & $(0.26)$ & $(0.27)$ & $(0.29)$ & $(0.29)$ \\
\hline \multirow[t]{2}{*}{ C.R. x Text } & -0.11 & 0.11 & -0.07 & 0.01 & 0.17 & 0.03 & 0.25 \\
\hline & $(0.27)$ & $(0.27)$ & $(0.29)$ & $(0.26)$ & $(0.26)$ & $(0.28)$ & $(0.28)$ \\
\hline \multirow[t]{2}{*}{ Constant } & $3.26^{* * *}$ & $3.33^{* * *}$ & $3.23^{* * *}$ & $2.83^{* * *}$ & $3.17^{* * *}$ & $2.91^{* * *}$ & $3.17^{* * *}$ \\
\hline & $(0.08)$ & $(0.07)$ & $(0.08)$ & $(0.35)$ & $(0.29)$ & $(0.38)$ & $(0.31)$ \\
\hline Weighted? & & $\checkmark$ & & & $\checkmark$ & & $\checkmark$ \\
\hline Low-Quality Dropped? & & & $\checkmark$ & & & $\checkmark$ & $\checkmark$ \\
\hline Controls? & & & & $\checkmark$ & $\checkmark$ & $\checkmark$ & $\checkmark$ \\
\hline $\mathrm{N}$ & 2,724 & 2,724 & 2,419 & 2,724 & 2,724 & 2,419 & 2,419 \\
\hline $\mathrm{R}^{2}$ & 0.002 & 0.001 & 0.002 & 0.06 & 0.05 & 0.06 & 0.06 \\
\hline Adjusted $\mathrm{R}^{2}$ & 0.0001 & -0.001 & 0.0001 & 0.05 & 0.05 & 0.05 & 0.05 \\
\hline
\end{tabular}


Table F16: Models of Cognitive Reflection and Binarized Credibility Confidence of Clipping in Incidental Exposure Experiment

\begin{tabular}{|c|c|c|c|c|c|c|c|}
\hline & \multicolumn{7}{|c|}{ Somewhat/strongly confident clipping was credible } \\
\hline Audio & $\begin{array}{l}-0.01 \\
(0.04)\end{array}$ & $\begin{array}{l}-0.01 \\
(0.04)\end{array}$ & $\begin{array}{l}-0.01 \\
(0.04)\end{array}$ & $\begin{array}{c}-0.005 \\
(0.04)\end{array}$ & $\begin{array}{c}0.01 \\
(0.04)\end{array}$ & $\begin{array}{c}0.003 \\
(0.04)\end{array}$ & $\begin{array}{c}0.03 \\
(0.04)\end{array}$ \\
\hline Text & $\begin{array}{c}-0.001 \\
(0.04)\end{array}$ & $\begin{array}{l}-0.03 \\
(0.04)\end{array}$ & $\begin{array}{c}0.01 \\
(0.04)\end{array}$ & $\begin{array}{c}-0.002 \\
(0.04)\end{array}$ & $\begin{array}{l}-0.03 \\
(0.04)\end{array}$ & $\begin{array}{c}0.01 \\
(0.04)\end{array}$ & $\begin{array}{c}-0.02 \\
(0.04)\end{array}$ \\
\hline C.R. & $\begin{array}{l}-0.09 \\
(0.07)\end{array}$ & $\begin{array}{l}-0.12 \\
(0.07)\end{array}$ & $\begin{array}{l}-0.08 \\
(0.08)\end{array}$ & $\begin{array}{l}-0.11 \\
(0.07)\end{array}$ & $\begin{array}{l}-0.13 \\
(0.07)\end{array}$ & $\begin{array}{l}-0.10 \\
(0.08)\end{array}$ & $\begin{array}{l}-0.09 \\
(0.08)\end{array}$ \\
\hline C.R. x Audio & $\begin{array}{c}0.11 \\
(0.10)\end{array}$ & $\begin{array}{c}0.13 \\
(0.10)\end{array}$ & $\begin{array}{c}0.11 \\
(0.11)\end{array}$ & $\begin{array}{c}0.12 \\
(0.10)\end{array}$ & $\begin{array}{c}0.11 \\
(0.10)\end{array}$ & $\begin{array}{c}0.11 \\
(0.11)\end{array}$ & $\begin{array}{c}0.07 \\
(0.11)\end{array}$ \\
\hline C.R. $\mathrm{x}$ Text & $\begin{array}{c}0.004 \\
(0.10)\end{array}$ & $\begin{array}{c}0.08 \\
(0.10)\end{array}$ & $\begin{array}{c}0.01 \\
(0.11)\end{array}$ & $\begin{array}{c}0.04 \\
(0.10)\end{array}$ & $\begin{array}{c}0.10 \\
(0.10)\end{array}$ & $\begin{array}{c}0.04 \\
(0.11)\end{array}$ & $\begin{array}{c}0.10 \\
(0.11)\end{array}$ \\
\hline Constant & $\begin{array}{c}0.45^{* * *} \\
(0.03)\end{array}$ & $\begin{array}{c}0.47^{* * *} \\
(0.03)\end{array}$ & $\begin{array}{c}0.44^{* * *} \\
(0.03)\end{array}$ & $\begin{array}{c}0.11 \\
(0.13)\end{array}$ & $\begin{array}{c}0.17 \\
(0.11)\end{array}$ & $\begin{array}{c}0.12 \\
(0.14)\end{array}$ & $\begin{array}{c}0.17 \\
(0.12) \\
\end{array}$ \\
\hline $\begin{array}{l}\text { Weighted? } \\
\text { Low-Quality Dropped? } \\
\text { Controls? }\end{array}$ & & $\checkmark$ & $\checkmark$ & $\checkmark$ & $\checkmark$ & $\begin{array}{l}\checkmark \\
\checkmark\end{array}$ & $\begin{array}{l}\checkmark \\
\checkmark \\
\checkmark\end{array}$ \\
\hline $\mathrm{N}$ & 2,724 & 2,724 & 2,419 & 2,724 & 2,724 & 2,419 & 2,419 \\
\hline $\mathrm{R}^{2}$ & 0.002 & 0.002 & 0.001 & 0.05 & 0.05 & 0.05 & 0.05 \\
\hline Adjusted $\mathrm{R}^{2}$ & -0.0001 & 0.001 & -0.001 & 0.04 & 0.04 & 0.04 & 0.04 \\
\hline
\end{tabular}

Figure F23: Ambivalent Sexism and Affect Towards Placebo Targets

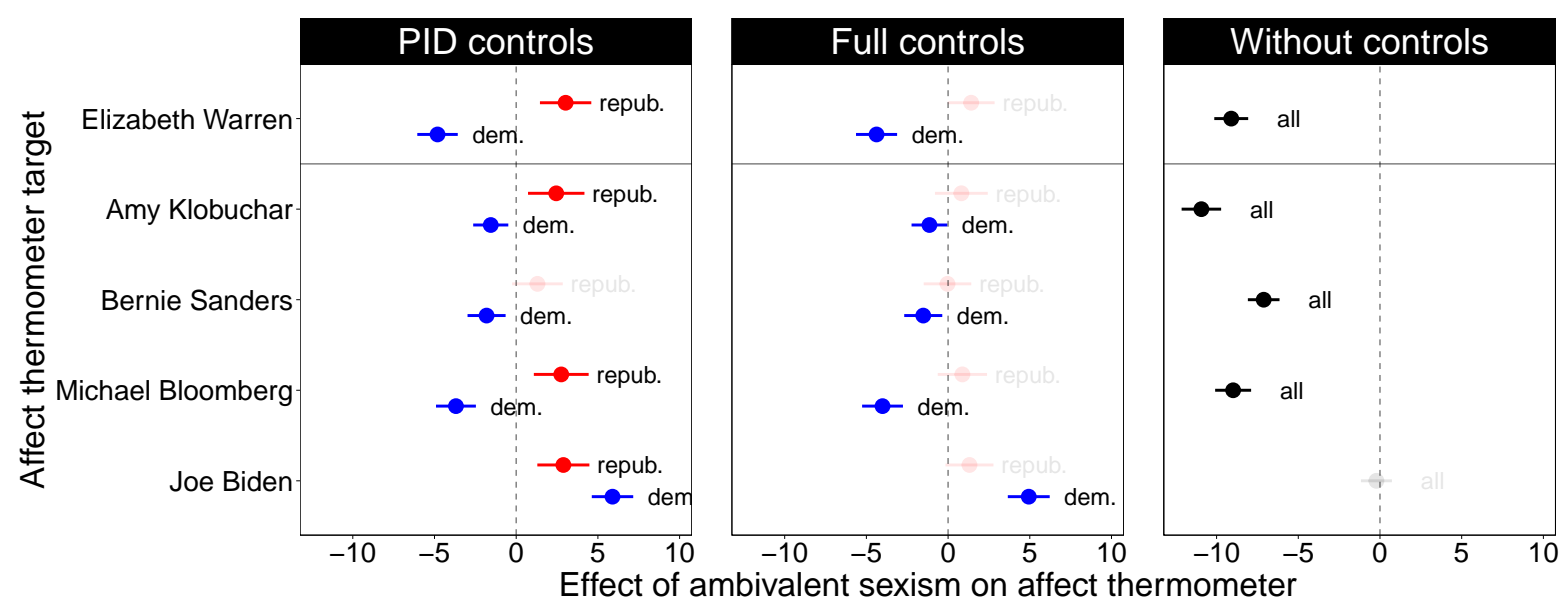

Notes: Shown are other politicians who ran in the 2020 Democratic primary. Conservatively, we would expect that ambivalent sexism would predict the strongest negative affective response towards other female candidates. 
Table F17: Models of Partisan Group Identity and Credibility Confidence of Clipping in Incidental Exposure Experiment

\begin{tabular}{|c|c|c|c|c|c|c|c|}
\hline & & Confic & ence tha & clippin & was cr & dible $[1$ & \\
\hline & $(1)$ & $(2)$ & $(3)$ & $(4)$ & $(5)$ & $(6)$ & $(7)$ \\
\hline Repub PID & 0.49 & $0.29^{*}$ & $0.44^{* * *}$ & $0.48^{* * *}$ & $0.31^{*}$ & $0.43^{* *}$ & 0.25 \\
\hline & $(0.15)$ & $(0.15)$ & $(0.16)$ & $(0.15)$ & $(0.15)$ & $(0.16)$ & $(0.16)$ \\
\hline Audio & 0.13 & 0.08 & 0.15 & 0.15 & 0.13 & 0.18 & 0.22 \\
\hline & $(0.14)$ & $(0.14)$ & $(0.14)$ & $(0.14)$ & $(0.14)$ & $(0.14)$ & $(0.14)$ \\
\hline Text & 0.09 & -0.17 & 0.06 & 0.10 & -0.14 & 0.09 & -0.18 \\
\hline & $(0.13)$ & $(0.13)$ & $(0.14)$ & $(0.13)$ & $(0.13)$ & $(0.14)$ & $(0.14)$ \\
\hline C.R. & -0.005 & -0.20 & 0.02 & 0.01 & -0.12 & 0.03 & -0.10 \\
\hline & $(0.25)$ & $(0.25)$ & $(0.27)$ & $(0.25)$ & $(0.25)$ & $(0.27)$ & $(0.27)$ \\
\hline Repub x Audio & -0.10 & -0.05 & -0.05 & -0.12 & -0.09 & -0.08 & -0.07 \\
\hline & $(0.21)$ & $(0.21)$ & $(0.23)$ & $(0.21)$ & $(0.21)$ & $(0.22)$ & $(0.22)$ \\
\hline Repub x Text & 0.05 & 0.31 & 0.19 & -0.005 & 0.23 & 0.12 & 0.38 \\
\hline & $(0.21)$ & $(0.21)$ & $(0.22)$ & $(0.21)$ & $(0.21)$ & $(0.22)$ & $(0.22)$ \\
\hline C.R. x Repub & -0.22 & 0.14 & -0.10 & -0.24 & 0.08 & -0.13 & 0.18 \\
\hline & $(0.39)$ & $(0.39)$ & $(0.43)$ & $(0.39)$ & $(0.38)$ & $(0.43)$ & $(0.41)$ \\
\hline Audio x C.R. & -0.05 & -0.06 & -0.11 & -0.03 & -0.10 & -0.09 & -0.24 \\
\hline & $(0.35)$ & $(0.36)$ & $(0.37)$ & $(0.35)$ & $(0.36)$ & $(0.37)$ & $(0.38)$ \\
\hline Text x C.R. & -0.17 & 0.19 & 0.02 & -0.14 & 0.13 & 0.05 & 0.39 \\
\hline & $(0.34)$ & $(0.35)$ & $(0.36)$ & $(0.33)$ & $(0.35)$ & $(0.36)$ & $(0.37)$ \\
\hline Repub x Audio x C.R. & 0.48 & 0.47 & 0.44 & 0.48 & 0.49 & 0.46 & 0.49 \\
\hline & $(0.54)$ & $(0.55)$ & $(0.59)$ & $(0.54)$ & $(0.54)$ & $(0.59)$ & $(0.58)$ \\
\hline Repub x Text x C.R. & 0.37 & -0.06 & -0.10 & 0.45 & 0.10 & -0.002 & -0.30 \\
\hline & $(0.54)$ & $(0.54)$ & $(0.58)$ & $(0.54)$ & $(0.53)$ & $(0.58)$ & $(0.57)$ \\
\hline Constant & $3.04^{* * *}$ & $3.21^{* * *}$ & $3.04^{* * *}$ & $2.91^{* * *}$ & $3.38^{* * *}$ & $2.99^{* * *}$ & $3.39^{* * *}$ \\
\hline & $(0.10)$ & $(0.10)$ & $(0.10)$ & $(0.36)$ & $(0.30)$ & $(0.38)$ & $(0.32)$ \\
\hline Weighted? & & $\checkmark$ & & & $\checkmark$ & & $\checkmark$ \\
\hline Low-Quality Dropped? & & & $\checkmark$ & & & $\checkmark$ & $\checkmark$ \\
\hline Controls? & & & & $\checkmark$ & $\checkmark$ & $\checkmark$ & $\checkmark$ \\
\hline $\mathrm{N}$ & 2,724 & 2,724 & 2,419 & 2,724 & 2,724 & 2,419 & 2,419 \\
\hline $\mathrm{R}^{2}$ & 0.04 & 0.03 & 0.04 & 0.06 & 0.05 & 0.06 & 0.06 \\
\hline Adjusted $\mathrm{R}^{2}$ & 0.03 & 0.03 & 0.03 & 0.05 & 0.05 & 0.05 & 0.05 \\
\hline
\end{tabular}

Notes: $\cdot p \cdot r / K<.1^{*} p \cdot r / K<.05^{* *} p \cdot r / K<.01^{* * *} p \cdot r / K<.001$

PID is pooled to Republican/Not Republican for brevity. PID interacted with C.R. to test possible mechanism of motivated reasoning (pre-registered), although as a reviewer pointed out this is not a sufficient test of a motivated reasoning mechanism by itself. 
Table F18: Models of Partisan Group Identity and Binarized Credibility Confidence of Clipping in Incidental Exposure Experiment

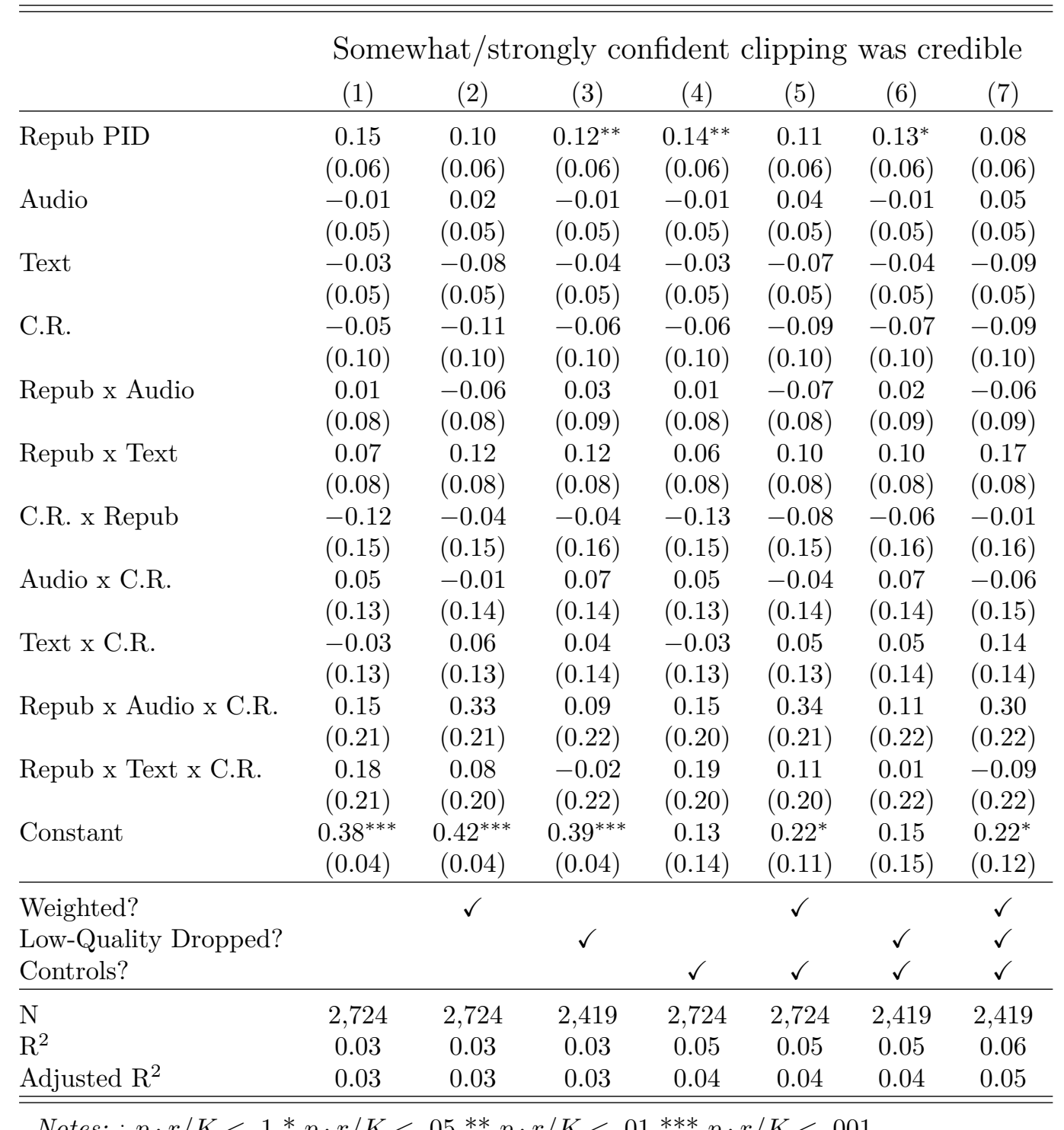

Notes: $\cdot p \cdot r / K<.1^{*} p \cdot r / K<.05^{* *} p \cdot r / K<.01 * * * p \cdot r / K<.001$ 
Table F19: Models of Partisan Group Identity and Scandal Target Affect in Incidental Exposure Experiment

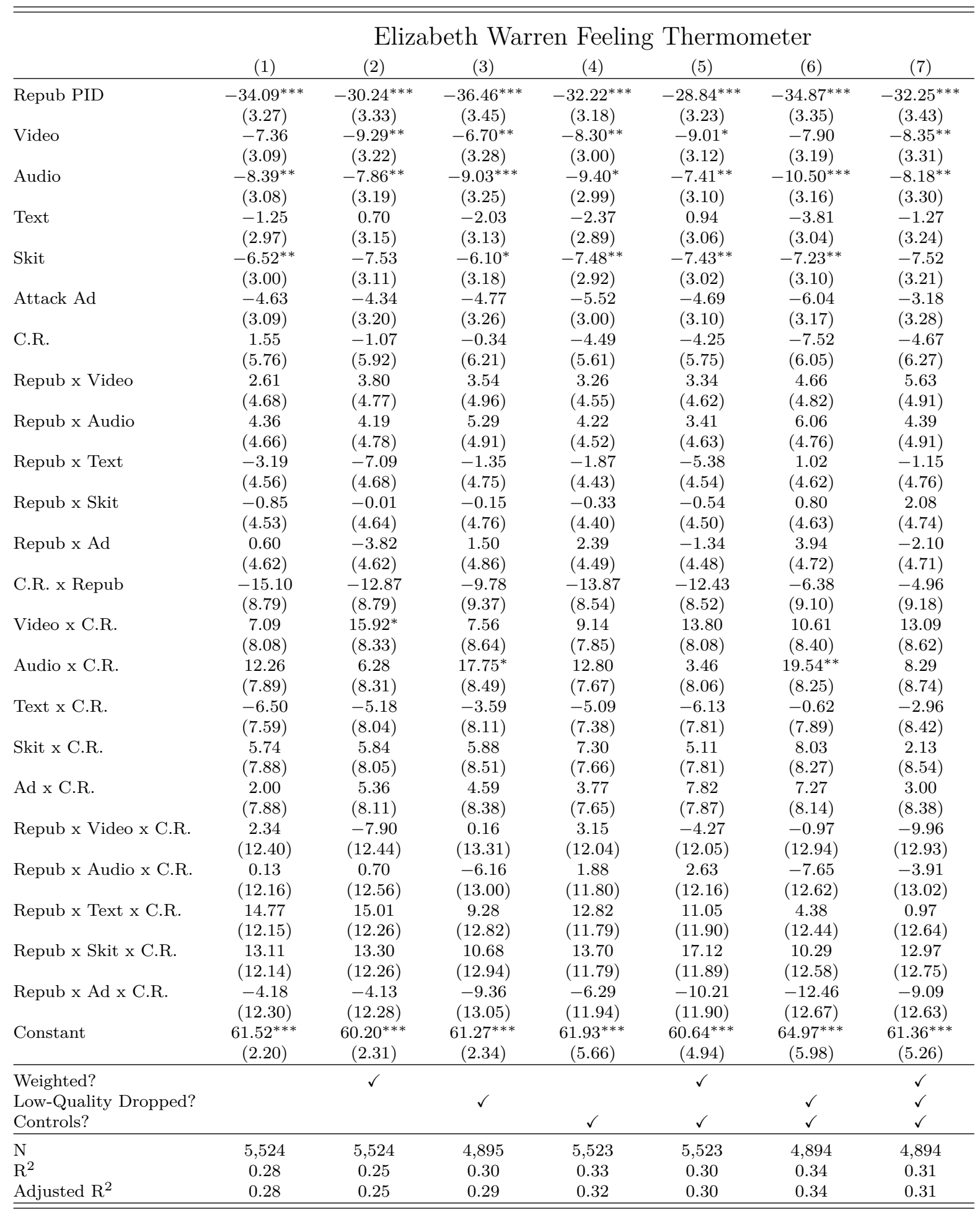

Notes: $\cdot p \cdot r / K<.1 * p \cdot r / K<.05 * * p \cdot r / K<.01^{* * *} p \cdot r / K<.001$ 
Table F20: Models of Ambivalent Sexism and Credibility Confidence in Scandal Clipping in Incidental Exposure Experiment

\begin{tabular}{|c|c|c|c|c|c|c|c|}
\hline & \multicolumn{7}{|c|}{ Confidence that clipping was credible [1-5] } \\
\hline & $(1)$ & $(2)$ & $(3)$ & $(4)$ & $(5)$ & $(6)$ & $(7)$ \\
\hline \multirow[t]{2}{*}{ Ambivalent Sexism } & $0.24^{* * *}$ & $0.15^{* * *}$ & $0.24^{* * *}$ & $0.15^{* * *}$ & 0.08 & $0.15^{* *}$ & 0.10 \\
\hline & $(0.05)$ & $(0.05)$ & $(0.06)$ & $(0.05)$ & $(0.05)$ & $(0.06)$ & $(0.06)$ \\
\hline \multirow[t]{2}{*}{ Audio } & 0.50 & 0.23 & 0.47 & $0.54^{* *}$ & 0.28 & $0.51^{* *}$ & 0.32 \\
\hline & $(0.21)$ & $(0.22)$ & $(0.23)$ & $(0.21)$ & $(0.22)$ & $(0.23)$ & $(0.23)$ \\
\hline \multirow[t]{2}{*}{ Text } & 0.14 & -0.11 & 0.15 & 0.23 & -0.05 & 0.25 & -0.07 \\
\hline & $(0.22)$ & $(0.22)$ & $(0.23)$ & $(0.21)$ & $(0.22)$ & $(0.23)$ & $(0.23)$ \\
\hline \multirow[t]{2}{*}{ A.S. x Audio } & $-0.13^{*}$ & -0.05 & -0.12 & -0.14 & -0.06 & -0.12 & -0.05 \\
\hline & $(0.07)$ & $(0.07)$ & $(0.08)$ & $(0.07)$ & $(0.07)$ & $(0.08)$ & $(0.08)$ \\
\hline \multirow[t]{2}{*}{ A.S. x Text } & -0.02 & 0.04 & -0.01 & -0.04 & 0.02 & -0.03 & 0.04 \\
\hline & $(0.07)$ & $(0.07)$ & $(0.08)$ & $(0.07)$ & $(0.07)$ & $(0.08)$ & $(0.08)$ \\
\hline \multirow[t]{2}{*}{ Constant } & $2.55^{* * *}$ & $2.86^{* * *}$ & $2.54^{* * *}$ & $2.66^{* * *}$ & $3.10^{* * *}$ & $2.76^{* * *}$ & $3.12^{* * *}$ \\
\hline & $(0.15)$ & $(0.16)$ & $(0.17)$ & $(0.37)$ & $(0.31)$ & $(0.39)$ & $(0.33)$ \\
\hline Weighted? & & $\checkmark$ & & & $\checkmark$ & & $\checkmark$ \\
\hline Low-Quality Dropped? & & & $\checkmark$ & & & $\checkmark$ & $\checkmark$ \\
\hline Controls? & & & & $\checkmark$ & $\checkmark$ & $\checkmark$ & $\checkmark$ \\
\hline $\mathrm{N}$ & 2,724 & 2,724 & 2,419 & 2,724 & 2,724 & 2,419 & 2,419 \\
\hline $\mathrm{R}^{2}$ & 0.02 & 0.01 & 0.02 & 0.06 & 0.05 & 0.06 & 0.06 \\
\hline Adjusted $\mathrm{R}^{2}$ & 0.02 & 0.01 & 0.02 & 0.05 & 0.05 & 0.05 & 0.05 \\
\hline
\end{tabular}

Table F21: Models of Ambivalent Sexism and Binarized Credibility Confidence in Scandal Clipping in Incidental Exposure Experiment

Somewhat/strongly confident clipping was credible

\begin{tabular}{lccccccc} 
& $(1)$ & $(2)$ & $(3)$ & $(4)$ & $(5)$ & $(6)$ & $(7)$ \\
\hline Ambivalent Sexism & $0.06^{* * *}$ & $0.04^{* *}$ & $0.06^{* * *}$ & 0.03 & 0.02 & 0.03 & 0.03 \\
& $(0.02)$ & $(0.02)$ & $(0.02)$ & $(0.02)$ & $(0.02)$ & $(0.02)$ & $(0.02)$ \\
Audio & 0.08 & 0.08 & 0.12 & 0.08 & 0.08 & 0.11 & 0.14 \\
& $(0.08)$ & $(0.08)$ & $(0.09)$ & $(0.08)$ & $(0.08)$ & $(0.09)$ & $(0.09)$ \\
Text & -0.03 & -0.07 & -0.02 & -0.01 & -0.07 & 0.0002 & -0.06 \\
& $(0.08)$ & $(0.08)$ & $(0.09)$ & $(0.08)$ & $(0.08)$ & $(0.09)$ & $(0.09)$ \\
A.S. x Audio & -0.02 & -0.02 & -0.03 & -0.02 & -0.01 & -0.03 & -0.03 \\
& $(0.03)$ & $(0.03)$ & $(0.03)$ & $(0.03)$ & $(0.03)$ & $(0.03)$ & $(0.03)$ \\
A.S. x Text & 0.01 & 0.02 & 0.01 & 0.01 & 0.02 & 0.01 & 0.02 \\
& $(0.03)$ & $(0.03)$ & $(0.03)$ & $(0.03)$ & $(0.03)$ & $(0.03)$ & $(0.03)$ \\
Constant & $0.25^{* * *}$ & $0.30^{* * *}$ & $0.24^{* * *}$ & 0.09 & 0.18 & 0.10 & 0.16 \\
& $(0.06)$ & $(0.06)$ & $(0.06)$ & $(0.14)$ & $(0.12)$ & $(0.15)$ & $(0.13)$ \\
\hline Weighted? & & $\checkmark$ & & & $\checkmark$ & & $\checkmark$ \\
Low-Quality Dropped? & & & $\checkmark$ & & & $\checkmark$ & $\checkmark$ \\
Controls? & & & & $\checkmark$ & $\checkmark$ & $\checkmark$ & $\checkmark$ \\
\hline $\mathrm{N}$ & 2,724 & 2,724 & 2,419 & 2,724 & 2,724 & 2,419 & 2,419 \\
$\mathrm{R}^{2}$ & 0.01 & 0.01 & 0.01 & 0.05 & 0.05 & 0.05 & 0.05 \\
Adjusted $\mathrm{R}^{2}$ & 0.01 & 0.01 & 0.01 & 0.04 & 0.04 & 0.04 & 0.04 \\
\hline \hline
\end{tabular}

Notes: $\cdot p \cdot r / K<.1 * p \cdot r / K<.05^{* *} p \cdot r / K<.01 * * * p \cdot r / K<.001$ 
Table F22: Models of Ambivalent Sexism and Scandal Target Affect in Incidental Exposure Experiment

\begin{tabular}{|c|c|c|c|c|c|c|c|}
\hline & \multicolumn{7}{|c|}{ Elizabeth Warren Feeling Thermometer } \\
\hline & $(1)$ & $(2)$ & (3) & $(4)$ & $(5)$ & $(6)$ & $(7)$ \\
\hline Ambivalent Sexism & $\begin{array}{c}-12.49^{* * *} \\
(1.30)\end{array}$ & $\begin{array}{c}-10.44^{* * *} \\
(1.29)\end{array}$ & $\begin{array}{c}-13.12^{* * *} \\
(1.43)\end{array}$ & $\begin{array}{c}-5.36^{* * *} \\
(1.09)\end{array}$ & $\begin{array}{c}-5.27^{* * *} \\
(1.10)\end{array}$ & $\begin{array}{c}-5.62^{* * *} \\
(1.19)\end{array}$ & $\begin{array}{c}-5.79^{* * *} \\
(1.20)\end{array}$ \\
\hline Video & $\begin{array}{l}-5.95 \\
(5.44)\end{array}$ & $\begin{array}{l}-7.72 \\
(5.59)\end{array}$ & $\begin{array}{l}-2.15 \\
(5.91)\end{array}$ & $\begin{array}{l}-4.53 \\
(4.49)\end{array}$ & $\begin{array}{l}-8.02 \\
(4.67)\end{array}$ & $\begin{array}{l}-2.55 \\
(4.87)\end{array}$ & $\begin{array}{l}-8.06 \\
(5.04)\end{array}$ \\
\hline Audio & $\begin{array}{c}-9.93^{*} \\
(5.30)\end{array}$ & $\begin{array}{l}-8.77 \\
(5.42)\end{array}$ & $\begin{array}{l}-9.18 \\
(5.74)\end{array}$ & $\begin{array}{c}-11.34^{* * *} \\
(4.39)\end{array}$ & $\begin{array}{c}-10.08^{*} \\
(4.54)\end{array}$ & $\begin{array}{c}-11.08^{* *} \\
(4.74)\end{array}$ & $\begin{array}{c}-11.23^{* *} \\
(4.91)\end{array}$ \\
\hline Text & $\begin{array}{l}-2.90 \\
(5.34)\end{array}$ & $\begin{array}{c}0.65 \\
(5.44)\end{array}$ & $\begin{array}{c}0.18 \\
(5.75)\end{array}$ & $\begin{array}{l}-7.71 \\
(4.41)\end{array}$ & $\begin{array}{l}-3.74 \\
(4.55)\end{array}$ & $\begin{array}{l}-5.41 \\
(4.74)\end{array}$ & $\begin{array}{l}-4.17 \\
(4.86)\end{array}$ \\
\hline Skit & $\begin{array}{l}-3.46 \\
(5.32)\end{array}$ & $\begin{array}{c}-10.15 \\
(5.40)\end{array}$ & $\begin{array}{l}-2.24 \\
(5.76)\end{array}$ & $\begin{array}{l}-6.04 \\
(4.40)\end{array}$ & $\begin{array}{c}-14.21^{* * *} \\
(4.52)\end{array}$ & $\begin{array}{l}-5.19 \\
(4.75)\end{array}$ & $\begin{array}{c}-16.91^{* * *} \\
(4.85)\end{array}$ \\
\hline A.S. x Video & $\begin{array}{c}0.66 \\
(1.84)\end{array}$ & $\begin{array}{c}1.30 \\
(1.87)\end{array}$ & $\begin{array}{l}-0.20 \\
(2.02)\end{array}$ & $\begin{array}{c}0.35 \\
(1.52)\end{array}$ & $\begin{array}{c}1.35 \\
(1.57)\end{array}$ & $\begin{array}{l}-0.07 \\
(1.66)\end{array}$ & $\begin{array}{c}1.58 \\
(1.70)\end{array}$ \\
\hline A.S. x Audio & $\begin{array}{c}2.88 \\
(1.81)\end{array}$ & $\begin{array}{c}2.10 \\
(1.81)\end{array}$ & $\begin{array}{c}2.95 \\
(1.97)\end{array}$ & $\begin{array}{l}2.81^{*} \\
(1.49)\end{array}$ & $\begin{array}{c}1.93 \\
(1.51)\end{array}$ & $\begin{array}{l}2.93^{*} \\
(1.62)\end{array}$ & $\begin{array}{c}2.51 \\
(1.64)\end{array}$ \\
\hline A.S. $x$ Text & $\begin{array}{c}0.39 \\
(1.83)\end{array}$ & $\begin{array}{l}-0.49 \\
(1.82)\end{array}$ & $\begin{array}{l}-0.59 \\
(1.97)\end{array}$ & $\begin{array}{c}1.82 \\
(1.51)\end{array}$ & $\begin{array}{c}0.89 \\
(1.53)\end{array}$ & $\begin{array}{c}1.08 \\
(1.63)\end{array}$ & $\begin{array}{c}0.90 \\
(1.63)\end{array}$ \\
\hline A.S. x Skit & $\begin{array}{c}0.25 \\
(1.82)\end{array}$ & $\begin{array}{c}2.42 \\
(1.81)\end{array}$ & $\begin{array}{c}0.07 \\
(1.97)\end{array}$ & $\begin{array}{c}0.93 \\
(1.50)\end{array}$ & $\begin{array}{c}3.73^{* *} \\
(1.52)\end{array}$ & $\begin{array}{c}0.77 \\
(1.62)\end{array}$ & $\begin{array}{c}4.53^{* * *} \\
(1.63)\end{array}$ \\
\hline Constant & $\begin{array}{c}80.89^{* * *} \\
(3.80) \\
\end{array}$ & $\begin{array}{c}74.99^{* * *} \\
(3.85) \\
\end{array}$ & $\begin{array}{c}81.06^{* * *} \\
(4.18) \\
\end{array}$ & $\begin{array}{c}74.98^{* * *} \\
(6.20) \\
\end{array}$ & $\begin{array}{c}75.34^{* * *} \\
(5.45) \\
\end{array}$ & $\begin{array}{c}74.59^{* * *} \\
(6.62) \\
\end{array}$ & $\begin{array}{c}74.02^{* * *} \\
(5.85) \\
\end{array}$ \\
\hline Weighted? & & $\checkmark$ & & & $\checkmark$ & & $\checkmark$ \\
\hline Low-Quality Dropped? & & & $\checkmark$ & & & $\checkmark$ & $\checkmark$ \\
\hline Controls? & & & & $\checkmark$ & $\checkmark$ & $\checkmark$ & $\checkmark$ \\
\hline $\mathrm{N}$ & 4,599 & 4,599 & 4,069 & 4,599 & 4,599 & 4,069 & 4,069 \\
\hline $\mathrm{R}^{2}$ & 0.08 & 0.06 & 0.10 & 0.38 & 0.35 & 0.39 & 0.36 \\
\hline Adjusted $\mathrm{R}^{2}$ & 0.08 & 0.06 & 0.09 & 0.37 & 0.34 & 0.39 & 0.36 \\
\hline
\end{tabular}

Notes: $\cdot p \cdot r / K<.1^{*} p \cdot r / K<.05^{* *} p \cdot r / K<.01^{* * *} p \cdot r / K<.001$ 
Table F23: Predictors of Detection Task Accuracy

\begin{tabular}{|c|c|c|c|c|c|c|}
\hline & $\begin{array}{c}\text { Deepfal } \\
(1)\end{array}$ & $\begin{array}{l}\text { Detect } \\
(2)\end{array}$ & $\begin{array}{c}\text { on Acct } \\
(3)\end{array}$ & $\begin{array}{c}\text { racy }(\% \\
(4)\end{array}$ & $\begin{array}{c}\text { Correct } \\
(5)\end{array}$ & $\begin{array}{c}\text { Classified) } \\
(6)\end{array}$ \\
\hline Digital Literacy & & $\begin{array}{c}0.25^{* * *} \\
(0.02)\end{array}$ & $\begin{array}{c}0.22^{* * *} \\
(0.02)\end{array}$ & $\begin{array}{c}0.22^{* * *} \\
(0.02)\end{array}$ & $\begin{array}{c}0.20^{* * *} \\
(0.02)\end{array}$ & $\begin{array}{c}0.21^{* * *} \\
(0.02)\end{array}$ \\
\hline Accuracy Prime & $\begin{array}{c}-0.002 \\
(0.01)\end{array}$ & & $\begin{array}{l}-0.01 \\
(0.01)\end{array}$ & $\begin{array}{c}-0.004 \\
(0.01)\end{array}$ & $\begin{array}{c}-0.005 \\
(0.01)\end{array}$ & $\begin{array}{c}-0.002 \\
(0.01)\end{array}$ \\
\hline Exp 1 Debrief & & & $\begin{array}{c}0.01 \\
(0.01)\end{array}$ & $\begin{array}{l}0.01^{*} \\
(0.01)\end{array}$ & $\begin{array}{l}0.01^{*} \\
(0.01)\end{array}$ & $\begin{array}{c}0.01 \\
(0.01)\end{array}$ \\
\hline Exp 1 Information & & & $\begin{array}{l}-0.01 \\
(0.01)\end{array}$ & $\begin{array}{c}-0.001 \\
(0.01)\end{array}$ & $\begin{array}{l}-0.01 \\
(0.01)\end{array}$ & $\begin{array}{c}-0.004 \\
(0.01)\end{array}$ \\
\hline Political Knowledge & & & $\begin{array}{c}0.18^{* * *} \\
(0.01)\end{array}$ & $\begin{array}{c}0.19^{* * *} \\
(0.01)\end{array}$ & $\begin{array}{c}0.18^{* * *} \\
(0.01)\end{array}$ & $\begin{array}{c}0.20^{* * *} \\
(0.01)\end{array}$ \\
\hline Internet Usage & & & $\begin{array}{l}-0.01 \\
(0.03)\end{array}$ & $\begin{array}{l}-0.05 \\
(0.03)\end{array}$ & $\begin{array}{c}0.001 \\
(0.03)\end{array}$ & $\begin{array}{l}-0.02 \\
(0.03)\end{array}$ \\
\hline Low-fake Env. & & & $\begin{array}{c}0.03^{* * *} \\
(0.01)\end{array}$ & $\begin{array}{c}0.04^{* * *} \\
(0.01)\end{array}$ & $\begin{array}{c}0.03^{* * *} \\
(0.01)\end{array}$ & $\begin{array}{c}0.05^{* * *} \\
(0.01)\end{array}$ \\
\hline No-fake Env. & & & $\begin{array}{c}0.04^{* * *} \\
(0.01)\end{array}$ & $\begin{array}{c}0.04^{* * *} \\
(0.01)\end{array}$ & $\begin{array}{c}0.04^{* * *} \\
(0.01)\end{array}$ & $\begin{array}{c}0.05^{* * *} \\
(0.01)\end{array}$ \\
\hline Age $65+$ & & & $\begin{array}{c}0.01 \\
(0.01)\end{array}$ & $\begin{array}{c}0.01 \\
(0.01)\end{array}$ & $\begin{array}{c}0.01 \\
(0.01)\end{array}$ & $\begin{array}{l}0.003 \\
(0.01)\end{array}$ \\
\hline High School & & & $\begin{array}{c}0.01 \\
(0.03)\end{array}$ & $\begin{array}{c}0.01 \\
(0.02)\end{array}$ & $\begin{array}{c}0.03 \\
(0.03)\end{array}$ & $\begin{array}{c}0.02 \\
(0.02)\end{array}$ \\
\hline College & & & $\begin{array}{c}0.02 \\
(0.03)\end{array}$ & $\begin{array}{c}0.02 \\
(0.02)\end{array}$ & $\begin{array}{c}0.04 \\
(0.03)\end{array}$ & $\begin{array}{c}0.03 \\
(0.02)\end{array}$ \\
\hline Postgrad & & & $\begin{array}{l}-0.01 \\
(0.03)\end{array}$ & $\begin{array}{l}-0.02 \\
(0.02)\end{array}$ & $\begin{array}{c}0.01 \\
(0.03)\end{array}$ & $\begin{array}{l}-0.01 \\
(0.02)\end{array}$ \\
\hline C.R. & & & $\begin{array}{c}0.06^{* * *} \\
(0.02)\end{array}$ & $\begin{array}{c}0.07^{* * *} \\
(0.02)\end{array}$ & $\begin{array}{c}0.07^{* * *} \\
(0.02)\end{array}$ & $\begin{array}{c}0.08^{* * *} \\
(0.02)\end{array}$ \\
\hline C.R. x Republican & & & $\begin{array}{c}-0.06^{*} \\
(0.03)\end{array}$ & $\begin{array}{l}-0.06 \\
(0.03)\end{array}$ & $\begin{array}{l}-0.06 \\
(0.03)\end{array}$ & $\begin{array}{c}-0.06^{*} \\
(0.03)\end{array}$ \\
\hline Ambivalent Sexism & & & $\begin{array}{c}0.001 \\
(0.004)\end{array}$ & $\begin{array}{l}-0.002 \\
(0.004)\end{array}$ & $\begin{array}{c}0.001 \\
(0.004)\end{array}$ & $\begin{array}{c}-0.0001 \\
(0.004)\end{array}$ \\
\hline Republican & & & $\begin{array}{c}0.09^{* * *} \\
(0.01)\end{array}$ & $\begin{array}{c}0.07^{* * *} \\
(0.01)\end{array}$ & $\begin{array}{c}0.09^{* * *} \\
(0.01)\end{array}$ & $\begin{array}{c}0.08 * * * \\
(0.01)\end{array}$ \\
\hline Constant & $\begin{array}{c}0.57 \\
(0.005) \\
\end{array}$ & $\begin{array}{c}0.36^{* * *} \\
(0.02) \\
\end{array}$ & $\begin{array}{c}0.16^{* * *} \\
(0.04) \\
\end{array}$ & $\begin{array}{l}0.19^{* * *} \\
(0.04)\end{array}$ & $\begin{array}{l}0.14^{* *} \\
(0.05)\end{array}$ & $\begin{array}{c}0.16^{* * *} \\
(0.04)\end{array}$ \\
\hline $\begin{array}{l}\text { Weighted? } \\
\text { Low-Quality Dropped? }\end{array}$ & & & & $\checkmark$ & $\checkmark$ & $\begin{array}{l}\checkmark \\
\checkmark\end{array}$ \\
\hline $\begin{array}{l}\mathrm{N} \\
\mathrm{R}^{2} \\
\text { Adjusted } \mathrm{R}^{2}\end{array}$ & $\begin{array}{c}5,497 \\
0.0000 \\
-0.0002\end{array}$ & $\begin{array}{c}5,497 \\
0.02 \\
0.02\end{array}$ & $\begin{array}{c}5,496 \\
0.09 \\
0.09\end{array}$ & $\begin{array}{c}5,496 \\
0.09 \\
0.09\end{array}$ & $\begin{array}{c}4,870 \\
0.09 \\
0.09\end{array}$ & $\begin{array}{c}4,870 \\
0.10 \\
0.10\end{array}$ \\
\hline
\end{tabular}


Table F24: Predictors of Detection Task False Positive Rate (FPR)

\begin{tabular}{|c|c|c|c|c|c|c|}
\hline & \multicolumn{6}{|c|}{ Detection FPR (\% Real Videos Classified as Deepfakes) } \\
\hline Digital Literacy & & $\begin{array}{c}-0.11^{* * *} \\
(0.03)\end{array}$ & $\begin{array}{c}-0.08^{* *} \\
(0.03)\end{array}$ & $\begin{array}{c}-0.11^{\text {*** }} \\
(0.03)\end{array}$ & $\begin{array}{l}-0.06 \\
(0.03)\end{array}$ & $\begin{array}{c}-0.08^{* *} \\
(0.03)\end{array}$ \\
\hline Accuracy Prime & $\begin{array}{l}-0.01 \\
(0.01)\end{array}$ & & $\begin{array}{l}0.004 \\
(0.01)\end{array}$ & $\begin{array}{l}-0.01 \\
(0.01)\end{array}$ & $\begin{array}{c}0.003 \\
(0.01)\end{array}$ & $\begin{array}{l}-0.01 \\
(0.01)\end{array}$ \\
\hline Exp 1 Debrief & & & $\begin{array}{c}-0.03^{* * *} \\
(0.01)\end{array}$ & $\begin{array}{c}-0.03^{* * *} \\
(0.01)\end{array}$ & $\begin{array}{c}-0.03^{* * *} \\
(0.01)\end{array}$ & $\begin{array}{c}-0.03^{* * *} \\
(0.01)\end{array}$ \\
\hline Exp 1 Information & & & $\begin{array}{c}0.01 \\
(0.01)\end{array}$ & $\begin{array}{c}0.001 \\
(0.01)\end{array}$ & $\begin{array}{c}0.01 \\
(0.01)\end{array}$ & $\begin{array}{l}0.005 \\
(0.01)\end{array}$ \\
\hline Political Knowledge & & & $\begin{array}{c}-0.13^{* * *} \\
(0.02)\end{array}$ & $\begin{array}{c}-0.14^{* * *} \\
(0.02)\end{array}$ & $\begin{array}{c}-0.13^{* * *} \\
(0.02)\end{array}$ & $\begin{array}{c}-0.14^{* * *} \\
(0.02)\end{array}$ \\
\hline Internet Usage & & & $\begin{array}{l}-0.01 \\
(0.03)\end{array}$ & $\begin{array}{c}0.01 \\
(0.03)\end{array}$ & $\begin{array}{l}-0.01 \\
(0.04)\end{array}$ & $\begin{array}{c}0.01 \\
(0.04)\end{array}$ \\
\hline Low-fake Env. & & & $\begin{array}{c}0.03^{* *} \\
(0.01)\end{array}$ & $\begin{array}{c}0.02^{* *} \\
(0.01)\end{array}$ & $\begin{array}{c}0.02^{* * *} \\
(0.01)\end{array}$ & $\begin{array}{c}0.01 \\
(0.01)\end{array}$ \\
\hline No-fake Env. & & & $\begin{array}{c}0.23^{* * *} \\
(0.01)\end{array}$ & $\begin{array}{c}0.22^{* * *} \\
(0.01)\end{array}$ & $\begin{array}{c}0.22^{* * *} \\
(0.01)\end{array}$ & $\begin{array}{c}0.21^{* * *} \\
(0.01)\end{array}$ \\
\hline Age $65+$ & & & $\begin{array}{c}0.003 \\
(0.01)\end{array}$ & $\begin{array}{c}-0.003 \\
(0.01)\end{array}$ & $\begin{array}{c}0.01 \\
(0.01)\end{array}$ & $\begin{array}{c}-0.0002 \\
(0.01)\end{array}$ \\
\hline High School & & & $\begin{array}{l}0.002 \\
(0.03)\end{array}$ & $\begin{array}{c}-0.004 \\
(0.02)\end{array}$ & $\begin{array}{l}-0.02 \\
(0.04)\end{array}$ & $\begin{array}{l}-0.02 \\
(0.02)\end{array}$ \\
\hline College & & & $\begin{array}{c}0.01 \\
(0.03)\end{array}$ & $\begin{array}{c}0.01 \\
(0.02)\end{array}$ & $\begin{array}{l}-0.02 \\
(0.04)\end{array}$ & $\begin{array}{l}-0.01 \\
(0.02)\end{array}$ \\
\hline Postgrad & & & $\begin{array}{c}0.04 \\
(0.04)\end{array}$ & $\begin{array}{c}0.02 \\
(0.02)\end{array}$ & $\begin{array}{l}0.002 \\
(0.04)\end{array}$ & $\begin{array}{c}0.0000 \\
(0.02)\end{array}$ \\
\hline C.R. & & & $\begin{array}{c}-0.06^{* *} \\
(0.02)\end{array}$ & $\begin{array}{c}-0.08^{* * *} \\
(0.02)\end{array}$ & $\begin{array}{c}-0.07^{* * *} \\
(0.02)\end{array}$ & $\begin{array}{c}-0.08^{* * *} \\
(0.02)\end{array}$ \\
\hline C.R. x Republican & & & $\begin{array}{c}0.03 \\
(0.03)\end{array}$ & $\begin{array}{c}0.03 \\
(0.03)\end{array}$ & $\begin{array}{c}0.04 \\
(0.03)\end{array}$ & $\begin{array}{c}0.03 \\
(0.03)\end{array}$ \\
\hline Ambivalent Sexism & & & $\begin{array}{l}0.0005 \\
(0.005)\end{array}$ & $\begin{array}{c}0.002 \\
(0.005)\end{array}$ & $\begin{array}{l}-0.002 \\
(0.005)\end{array}$ & $\begin{array}{c}0.001 \\
(0.005)\end{array}$ \\
\hline Republican & & & $\begin{array}{c}-0.07^{* * *} \\
(0.01)\end{array}$ & $\begin{array}{c}-0.07^{* * *} \\
(0.01)\end{array}$ & $\begin{array}{c}-0.08^{* * *} \\
(0.01)\end{array}$ & $\begin{array}{c}-0.07^{* * *} \\
(0.01)\end{array}$ \\
\hline Constant & $\begin{array}{c}0.28^{* * *} \\
(0.01)\end{array}$ & $\begin{array}{c}0.37^{* * *} \\
(0.02)\end{array}$ & $\begin{array}{c}0.41^{\text {*** }} \\
(0.05)\end{array}$ & $\begin{array}{c}0.44^{* * *} \\
(0.04)\end{array}$ & $\begin{array}{c}0.42^{* * *} \\
(0.05)\end{array}$ & $\begin{array}{c}0.45^{* * *} \\
(0.05) \\
\end{array}$ \\
\hline $\begin{array}{l}\text { Weighted? } \\
\text { Low-Quality Dropped? }\end{array}$ & & & & $\checkmark$ & $\checkmark$ & $\begin{array}{l}\checkmark \\
\checkmark\end{array}$ \\
\hline $\begin{array}{l}\mathrm{N} \\
\mathrm{R}^{2} \\
\text { Adjusted } \mathrm{R}^{2}\end{array}$ & $\begin{array}{c}5,495 \\
0.0002 \\
-0.0000\end{array}$ & $\begin{array}{l}5,495 \\
0.003 \\
0.003\end{array}$ & $\begin{array}{c}5,494 \\
0.16 \\
0.15\end{array}$ & $\begin{array}{c}5,494 \\
0.16 \\
0.16\end{array}$ & $\begin{array}{l}4,869 \\
0.16 \\
0.15\end{array}$ & $\begin{array}{c}4,869 \\
0.16 \\
0.16\end{array}$ \\
\hline
\end{tabular}

Notes: $\cdot p \cdot r / K<.1^{*} p \cdot r / K<.05^{* *} p \cdot r / K<.01 * * * p \cdot r / K<.001$ 
Table F25: Predictors of Detection Task False Negative Rate (FNR)

\begin{tabular}{|c|c|c|c|c|c|c|}
\hline & \multicolumn{6}{|c|}{ Detection FNR (\% Deepfakes Classified as Real Videos) } \\
\hline Digital Literacy & & $\begin{array}{l}-0.03 \\
(0.03)\end{array}$ & $\begin{array}{l}-0.04 \\
(0.03)\end{array}$ & $\begin{array}{l}-0.01 \\
(0.03)\end{array}$ & $\begin{array}{l}-0.05 \\
(0.03)\end{array}$ & $\begin{array}{l}-0.02 \\
(0.04)\end{array}$ \\
\hline Accuracy Prime & $\begin{array}{l}-0.01 \\
(0.01)\end{array}$ & & $\begin{array}{c}-0.005 \\
(0.01)\end{array}$ & $\begin{array}{l}-0.01 \\
(0.01)\end{array}$ & $\begin{array}{c}0.003 \\
(0.01)\end{array}$ & $\begin{array}{c}-0.003 \\
(0.01)\end{array}$ \\
\hline Exp 1 Debrief & & & $\begin{array}{c}0.01 \\
(0.01)\end{array}$ & $\begin{array}{c}0.01 \\
(0.01)\end{array}$ & $\begin{array}{c}0.01 \\
(0.01)\end{array}$ & $\begin{array}{c}0.01 \\
(0.01)\end{array}$ \\
\hline Exp 1 Information & & & $\begin{array}{c}-0.003 \\
(0.01)\end{array}$ & $\begin{array}{l}0.003 \\
(0.01)\end{array}$ & $\begin{array}{l}-0.01 \\
(0.01)\end{array}$ & $\begin{array}{c}-0.003 \\
(0.01)\end{array}$ \\
\hline Political Knowledge & & & $\begin{array}{l}0.003 \\
(0.02)\end{array}$ & $\begin{array}{l}-0.03 \\
(0.02)\end{array}$ & $\begin{array}{c}-0.002 \\
(0.02)\end{array}$ & $\begin{array}{l}-0.03 \\
(0.02)\end{array}$ \\
\hline Internet Usage & & & $\begin{array}{l}0.11^{* *} \\
(0.04)\end{array}$ & $\begin{array}{c}0.06 \\
(0.04)\end{array}$ & $\begin{array}{c}0.13^{* * *} \\
(0.04)\end{array}$ & $\begin{array}{c}0.09 \\
(0.04)\end{array}$ \\
\hline Low-fake Env. & & & $\begin{array}{c}0.01 \\
(0.01)\end{array}$ & $\begin{array}{l}0.002 \\
(0.01)\end{array}$ & $\begin{array}{c}0.01 \\
(0.01)\end{array}$ & $\begin{array}{c}-0.003 \\
(0.01)\end{array}$ \\
\hline No-fake Env. & & & $\begin{array}{c}0.01 \\
(0.01)\end{array}$ & $\begin{array}{c}0.02 \\
(0.01)\end{array}$ & $\begin{array}{c}0.02 \\
(0.01)\end{array}$ & $\begin{array}{l}0.02^{*} \\
(0.01)\end{array}$ \\
\hline Age $65+$ & & & $\begin{array}{c}0.01 \\
(0.04)\end{array}$ & $\begin{array}{c}0.02 \\
(0.03)\end{array}$ & $\begin{array}{c}0.01 \\
(0.04)\end{array}$ & $\begin{array}{c}0.01 \\
(0.03)\end{array}$ \\
\hline High School & & & $\begin{array}{c}0.03 \\
(0.04)\end{array}$ & $\begin{array}{c}0.04 \\
(0.03)\end{array}$ & $\begin{array}{c}0.03 \\
(0.04)\end{array}$ & $\begin{array}{c}0.03 \\
(0.03)\end{array}$ \\
\hline College & & & $\begin{array}{l}0.09^{*} \\
(0.04)\end{array}$ & $\begin{array}{c}0.13^{* * *} \\
(0.03)\end{array}$ & $\begin{array}{c}0.08 \\
(0.05)\end{array}$ & $\begin{array}{c}0.11^{* * *} \\
(0.03)\end{array}$ \\
\hline Postgrad & & & $\begin{array}{l}-0.05 \\
(0.02)\end{array}$ & $\begin{array}{l}-0.04 \\
(0.03)\end{array}$ & $\begin{array}{c}-0.06^{* *} \\
(0.03)\end{array}$ & $\begin{array}{l}-0.04 \\
(0.03)\end{array}$ \\
\hline Republican & & & $\begin{array}{c}0.09^{*} \\
(0.04)\end{array}$ & $\begin{array}{c}0.07 \\
(0.04)\end{array}$ & $\begin{array}{l}0.11^{* *} \\
(0.04)\end{array}$ & $\begin{array}{c}0.10^{* *} \\
(0.04)\end{array}$ \\
\hline C.R. & & & $\begin{array}{c}0.02^{* * *} \\
(0.01)\end{array}$ & $\begin{array}{c}0.02^{* * *} \\
(0.01)\end{array}$ & $\begin{array}{c}0.01 \\
(0.01)\end{array}$ & $\begin{array}{c}0.01 \\
(0.01)\end{array}$ \\
\hline Ambivalent Sexism & & & $\begin{array}{c}-0.04^{* * *} \\
(0.01)\end{array}$ & $\begin{array}{l}-0.03 \\
(0.02)\end{array}$ & $\begin{array}{c}-0.05^{* * *} \\
(0.02)\end{array}$ & $\begin{array}{c}-0.04^{* *} \\
(0.02)\end{array}$ \\
\hline C.R. x Republican & $\begin{array}{c}0.34^{* * *} \\
(0.01)\end{array}$ & $\begin{array}{c}0.36^{* * *} \\
(0.03)\end{array}$ & $\begin{array}{c}0.17^{* *} \\
(0.06)\end{array}$ & $\begin{array}{c}0.21^{* * *} \\
(0.06)\end{array}$ & $\begin{array}{c}0.20^{* * *} \\
(0.07)\end{array}$ & $\begin{array}{c}0.24^{* * *} \\
(0.06)\end{array}$ \\
\hline $\begin{array}{l}\text { Weighted? } \\
\text { Low-Quality Dropped? }\end{array}$ & & & & $\checkmark$ & $\checkmark$ & $\begin{array}{l}\checkmark \\
\checkmark\end{array}$ \\
\hline $\begin{array}{l}\mathrm{N} \\
\mathrm{R}^{2} \\
\text { Adjusted } \mathrm{R}^{2}\end{array}$ & $\begin{array}{c}3,690 \\
0.0002 \\
-0.0000\end{array}$ & $\begin{array}{c}3,690 \\
0.0003 \\
0.0000\end{array}$ & $\begin{array}{c}3,690 \\
0.02 \\
0.02\end{array}$ & $\begin{array}{c}3,690 \\
0.03 \\
0.02\end{array}$ & $\begin{array}{c}3,266 \\
0.02 \\
0.01\end{array}$ & $\begin{array}{c}3,266 \\
0.02 \\
0.02\end{array}$ \\
\hline
\end{tabular}

Notes: $\cdot p \cdot r / K<.1^{*} p \cdot r / K<.05^{* *} p \cdot r / K<.01^{* * *} p \cdot r / K<.001$ 
Figure F24: Sensitivity of Predictors of Detection Experiment Performance to NonResponse Thresholding

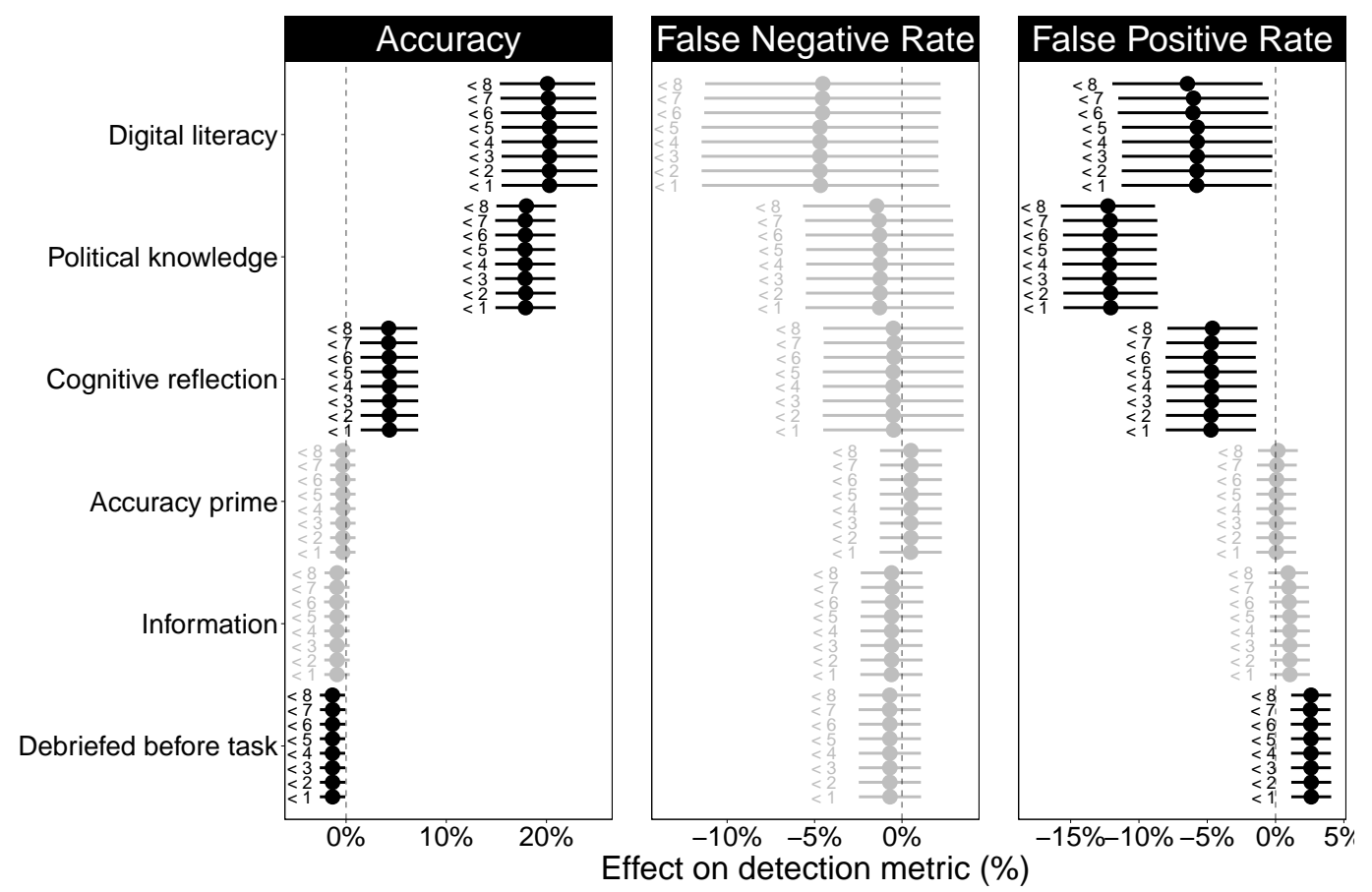

Notes: Each estimate is the effect of the corresponding predictor estimated from a model with full controls (see tables for detection task results) excluding respondents with $<x$ number of videos completed in the detection task. 
G Exploratory Analyses 
Figure G25: Baseline Comparisons of Credibility and Affective Response of Video in Incidental Exposure Experiment
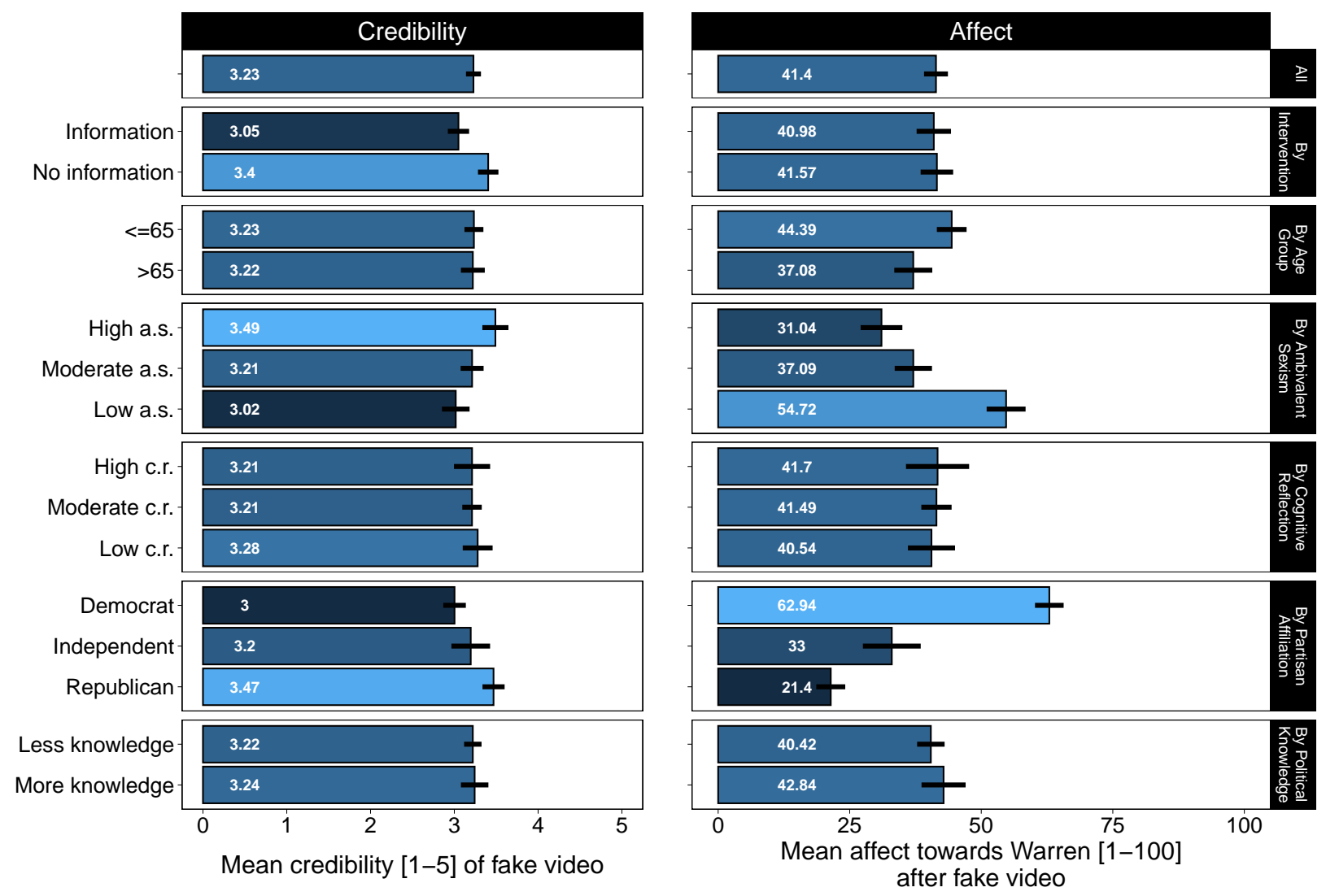
Figure G26: Heterogeneity in Incidental Exposure Credibility by Scandal Script

(a) Categorical Response

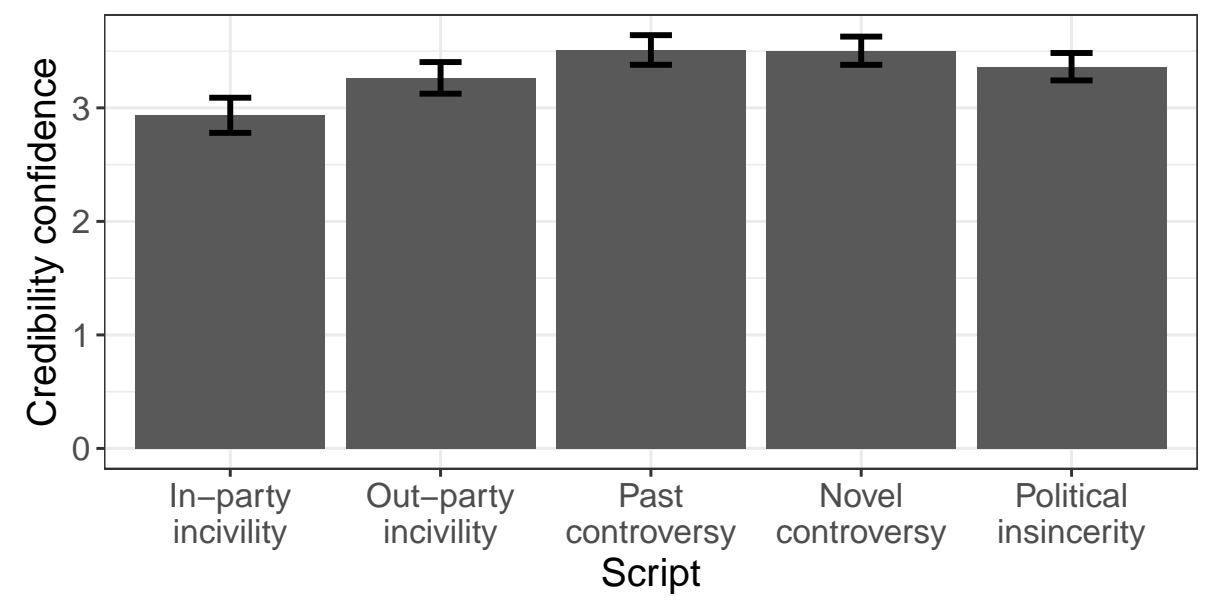

(b) Binarized Response

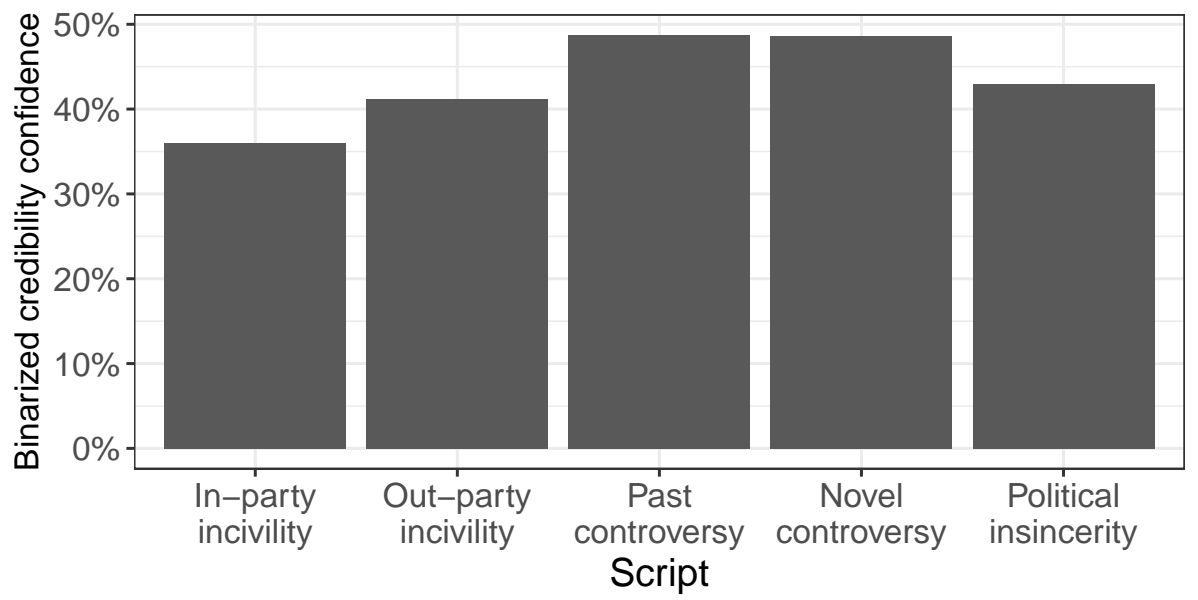

Notes: Results from the subset of respondents exposed to a scandal stimuli, not assigned an information treatment, and who provided a response to our deception question $(n=1848)$. 
Figure G27: Heterogeneity in Credibility Perception by Scandal Script and Medium

(a) Categorical Response

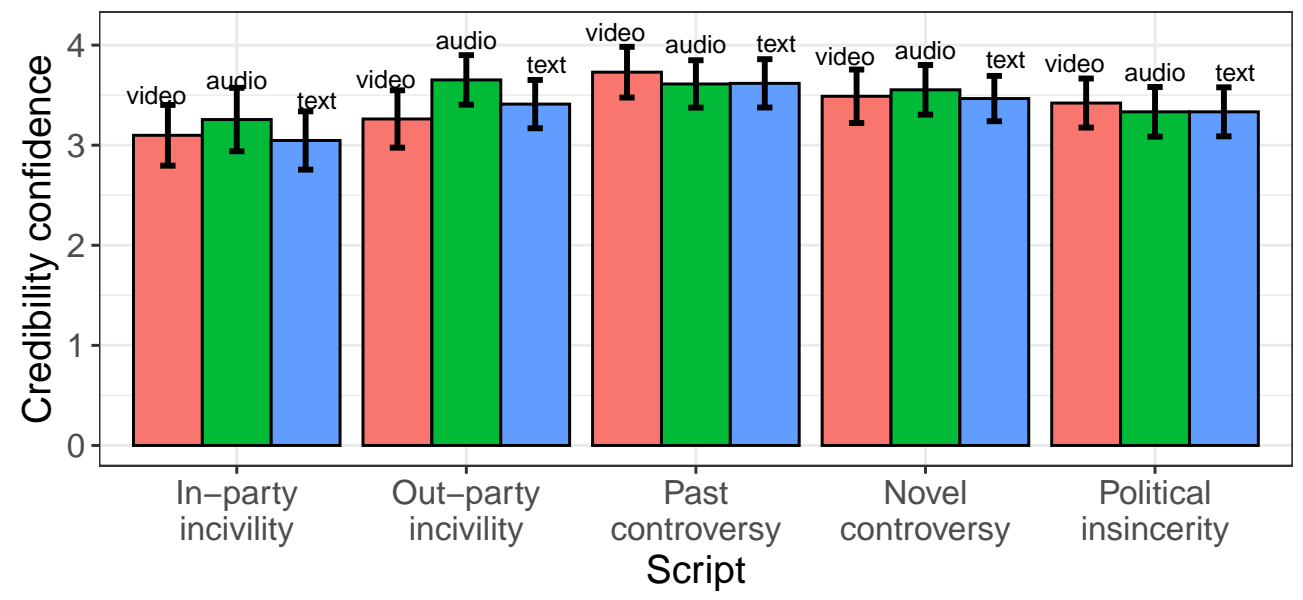

(b) Binarized Response

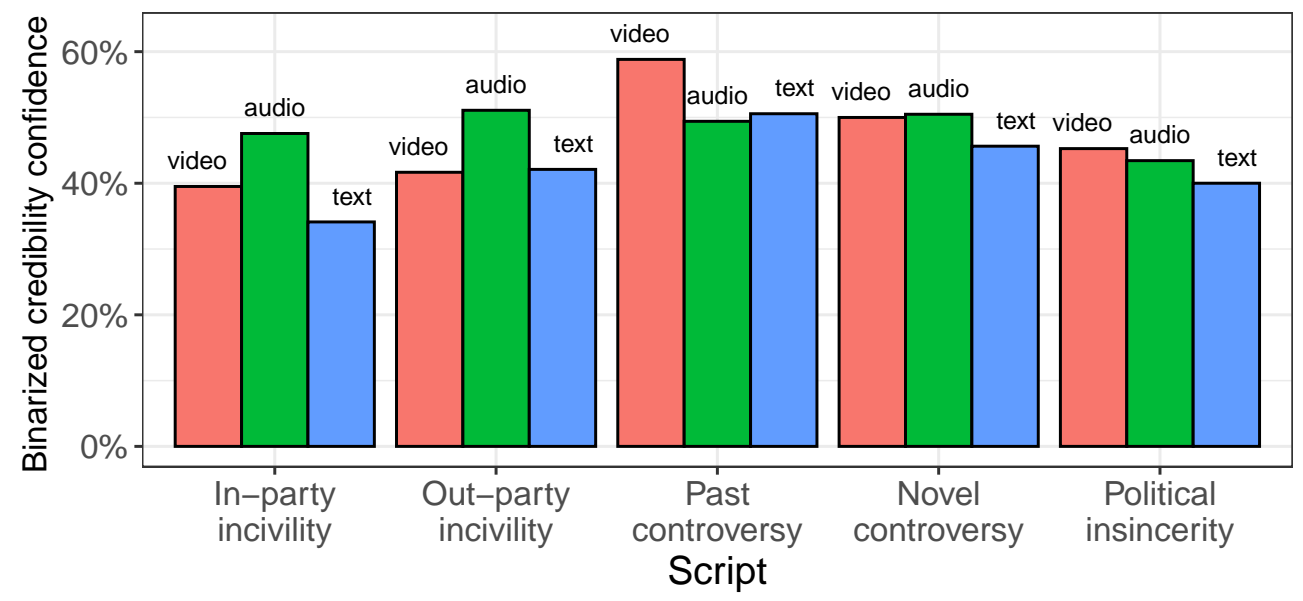

Notes: Results from the subset of respondents exposed to a scandal stimuli, not assigned an information treatment, and who provided a response to our credibility question $(n=1,848)$. To reduce the number of experimental cells, only three of five scripts were used for the skit stimuli. 
Figure G28: Other Affective Responses to First-Stage Clip
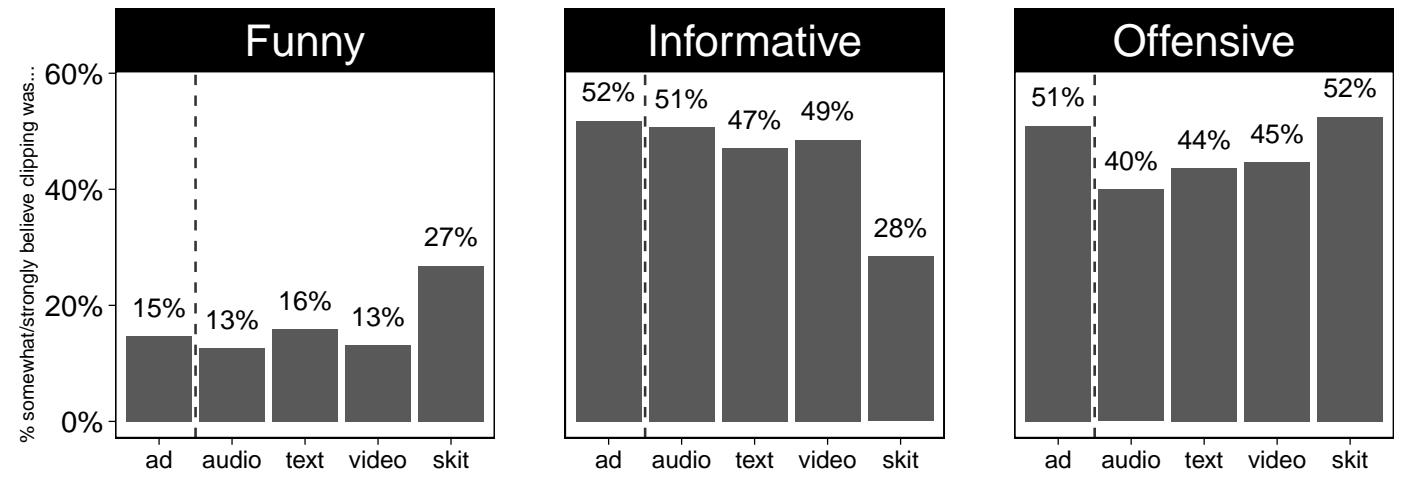

Notes: Responses evaluating whether clip was "funny," "informative," or "offensive" were solicited alongside belief that clip was not fake or doctored. The attack ad condition excluded since it is not a directly comparable clip of the scandal. 


\section{Figure G29: Detection Task Performance for Specific Clips}

(a) By Authenticity
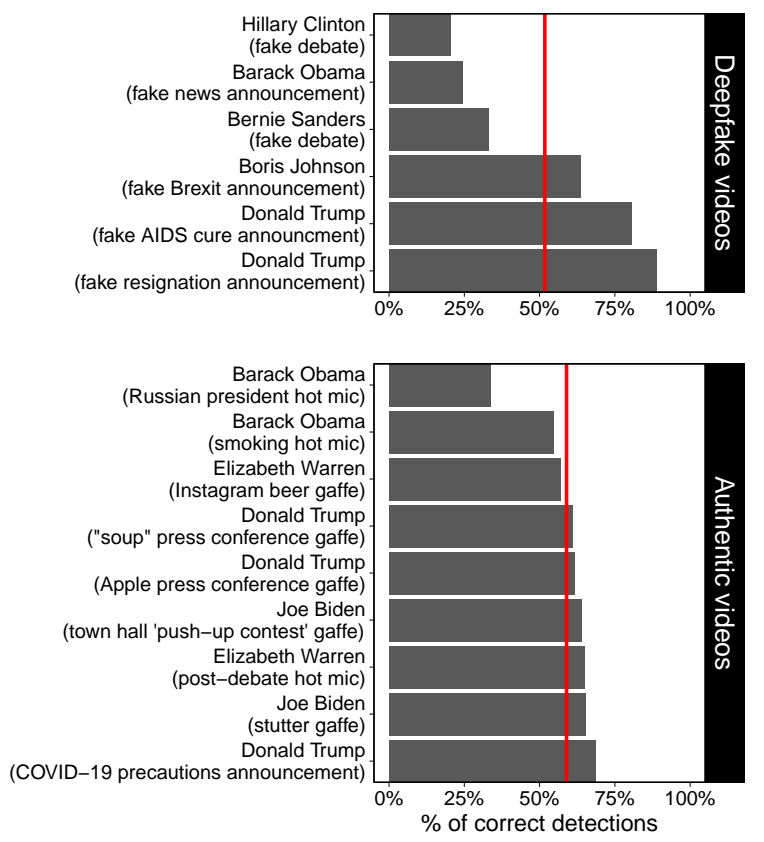

(c) Obama

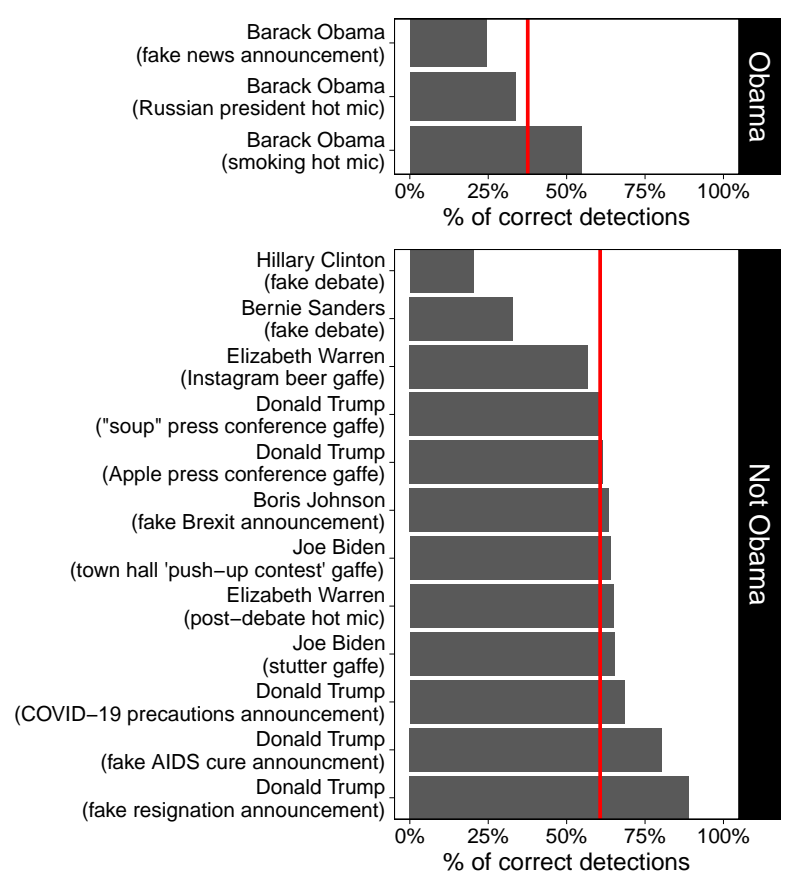

(b) By Source Cue

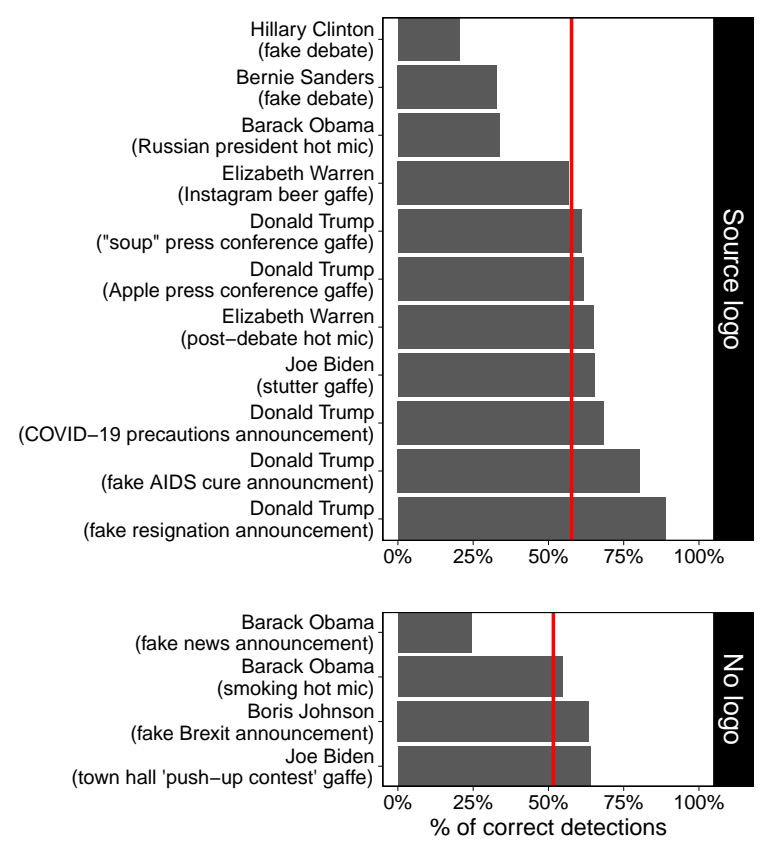

(d) Trump

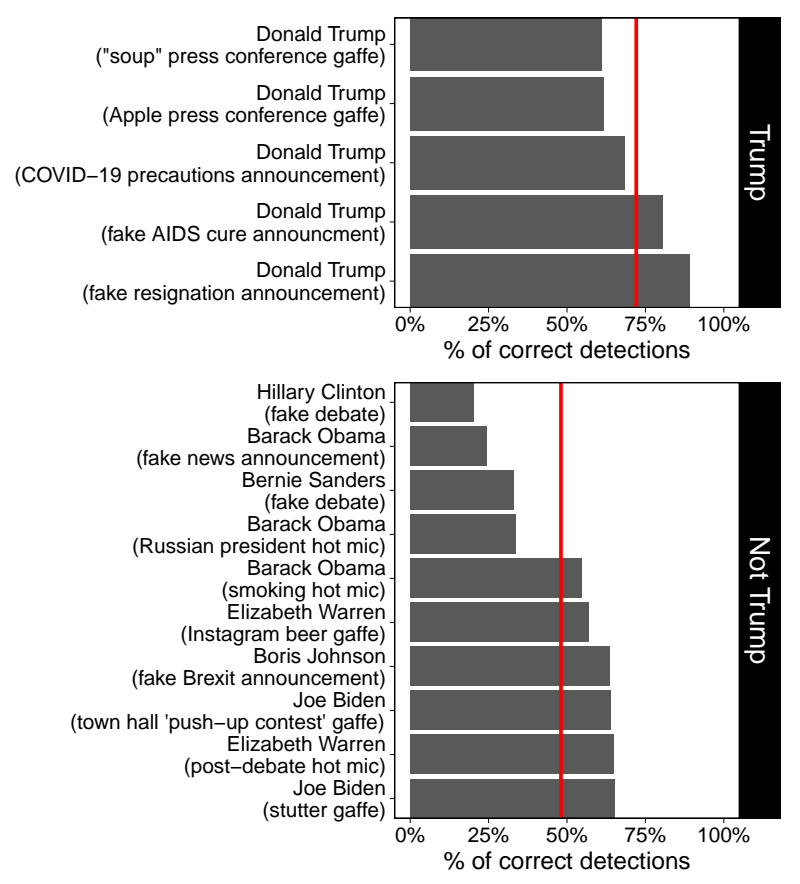

Notes: Results are for $n=5,497(99 \%)$ of respondents who provide a response to at least one video in the detection experiment. Fake clips are detected less well than real clips, but this difference $(\Delta)$ is not significant according to a $t$-test $(\Delta=-7.20 \%, t=0.57, p=0.58)$. Clips without source outlet logos are detected less well than clips with source logos, but this difference is also not significant $(\Delta=-6.03 \%, t=0.53, p=0.61)$. 


\section{Figure G30: Detection Task Performance for Specific Clips by Subgroup}

(a) By Cognitive Reflection
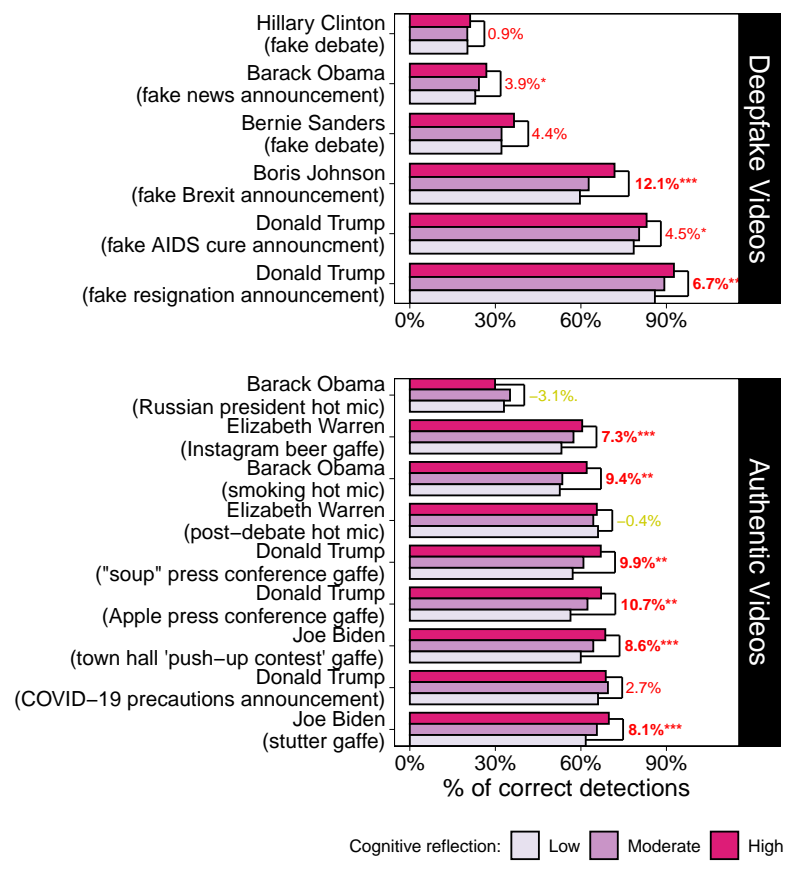

(b) By Political Knowledge
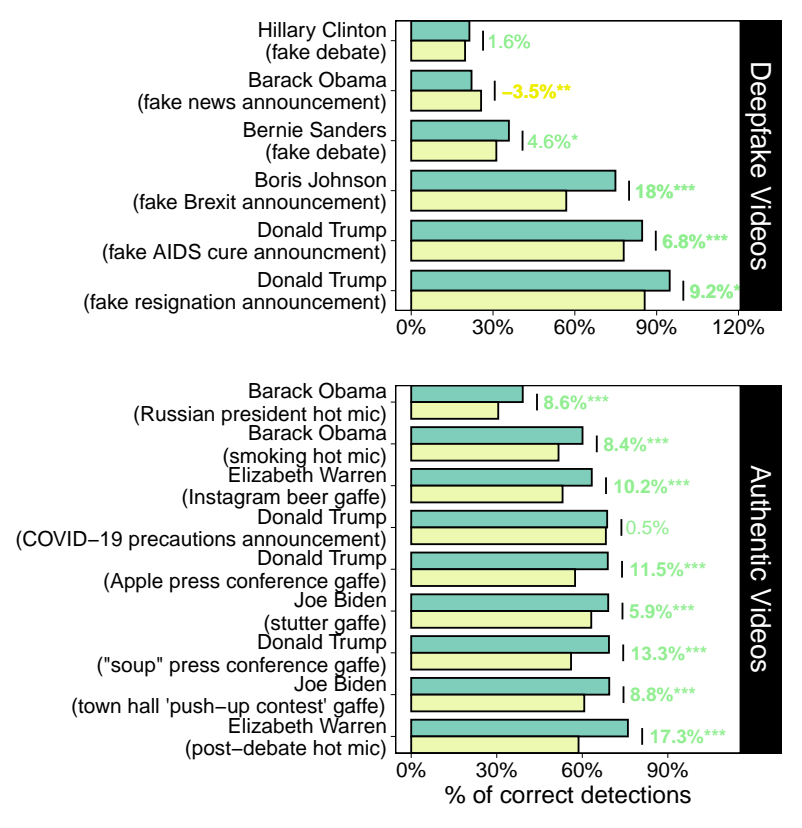

Political knowledge: $\square$ Less $\square$ More

(c) By Digital Literacy

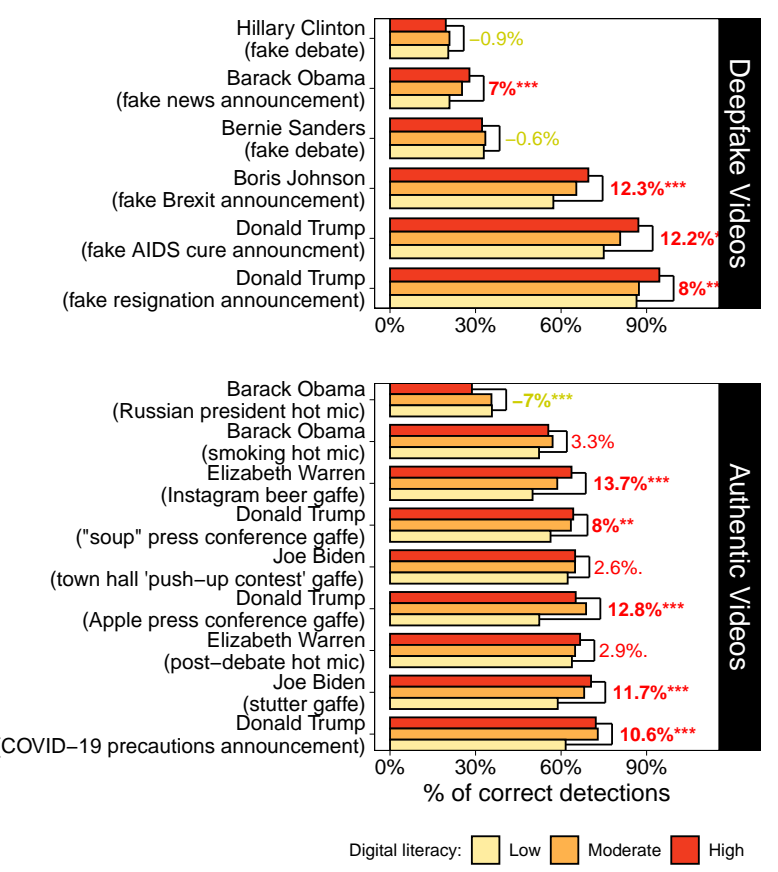

Notes: Results are for $n=5,497(99 \%)$ of respondents who provide a response to at least one video in the detection experiment. Cognitive reflection and digital literacy categories constructed as equal-sized quartiles. 


\section{Figure G31: Comparison of Partisan Group Identity Effects on Detection Task Performance}
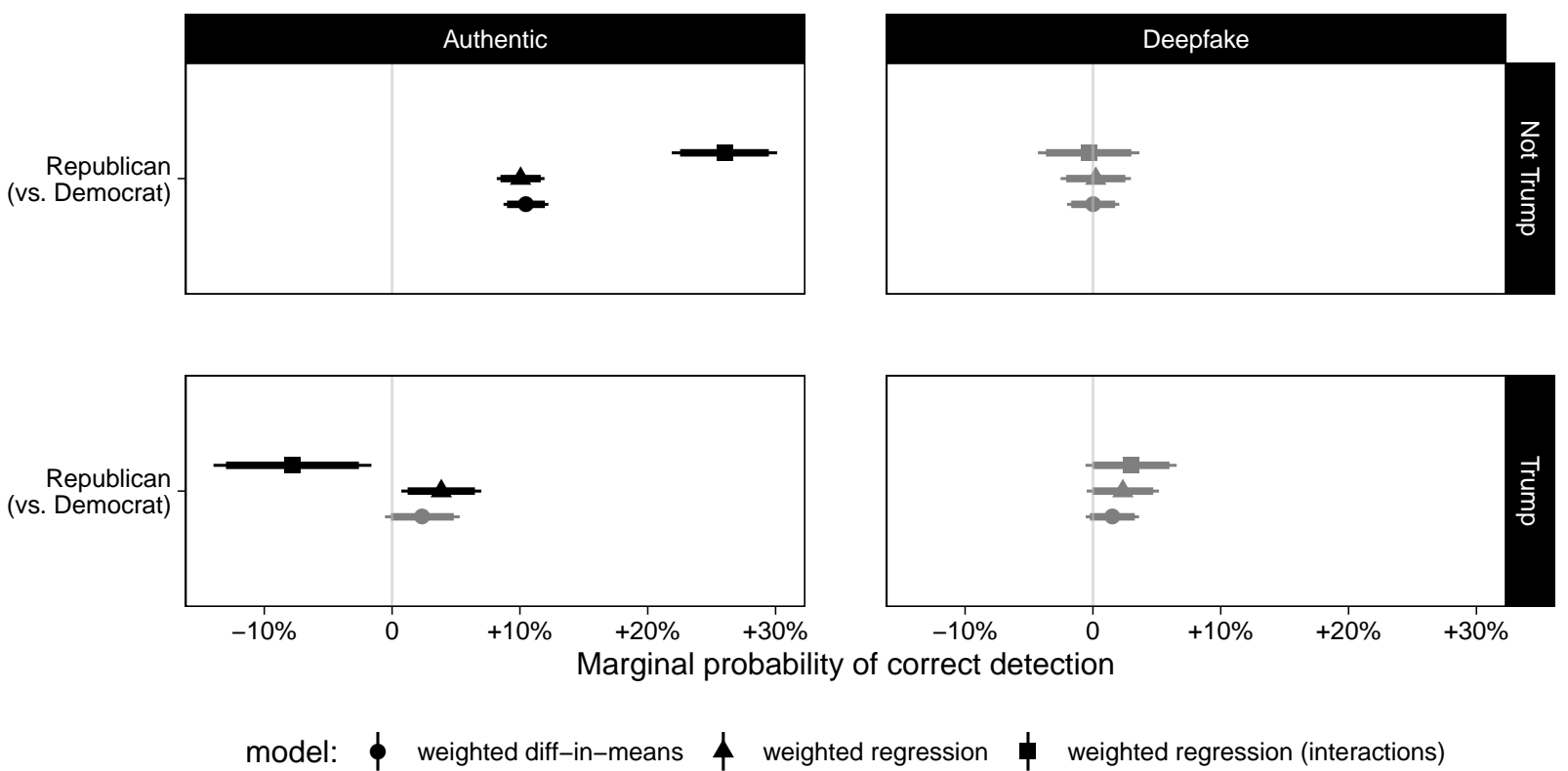

Notes: Results are for $n=5,497$ (99\%) of respondents who provide a response to at least one video in the detection experiment. All models incorporate weights from post-stratification described in Appendix E. The regression controls for the characteristics described at the start of this section as well as whether the clip contains a source logo or not. The interaction model fits an interaction term of partisanship with an indicator for particular clip within each cell. 
Figure G32: Relationship Between Credibility of Video Clip and Credibility of Event

(a) Barack Obama (Russian president hot mic)

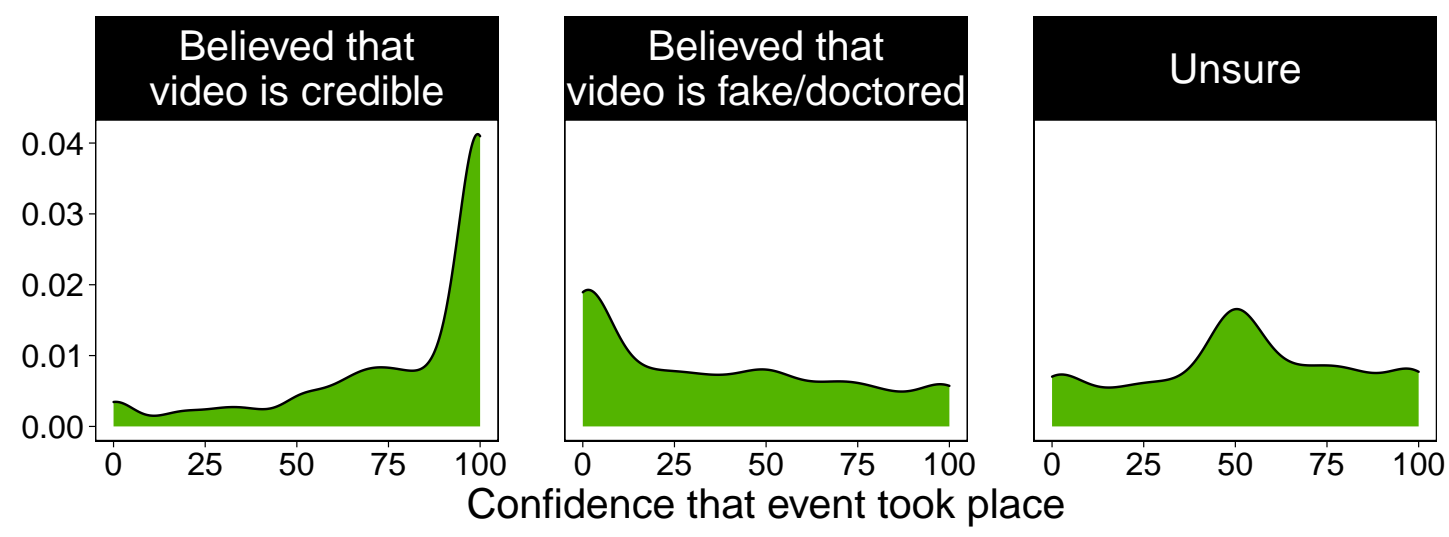

(b) Doanld Trump (COVID-19 precautions announcement)

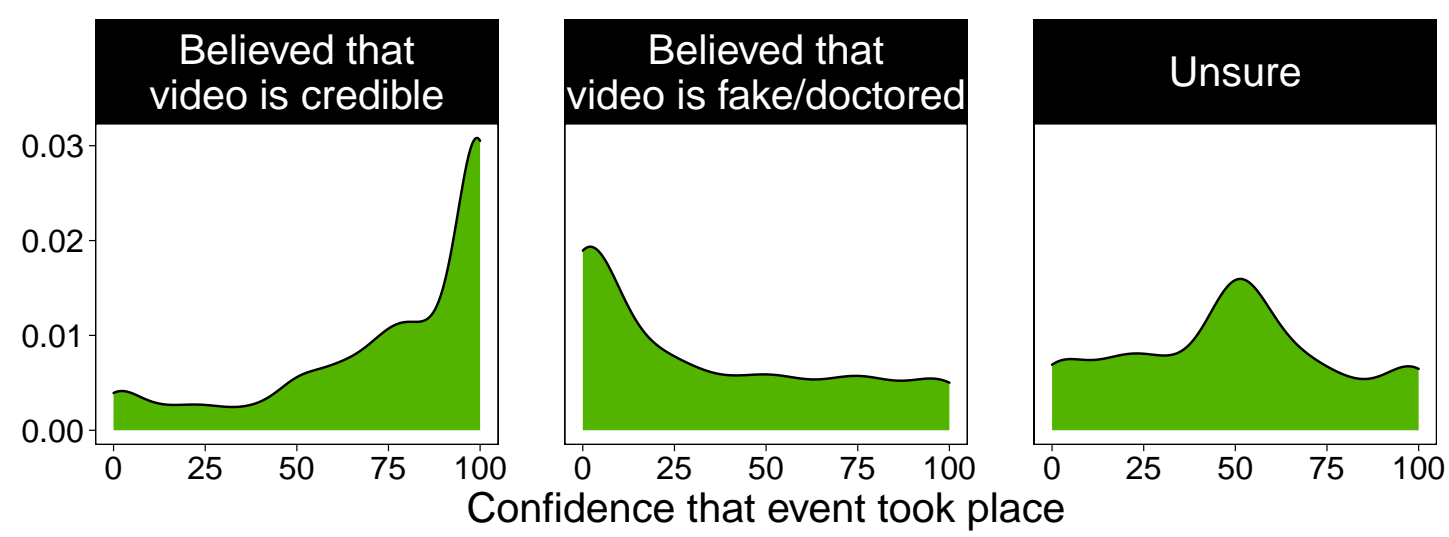

Notes: Clips (a) and (b) are real videos. Results are for $n=5,497$ (99\%) of respondents who provide a response to at least one video in the detection experiment. A variety of regression specifications estimate large, robust and statistically significant positive relationship between a respondent's belief in the video's authenticity and confidence in the depited event's occurence. 
Figure G33: Relationship Between Credibility of Video Clip and Credibility of Event by Partisanship

(a) Barack Obama (Russian president hot mic)

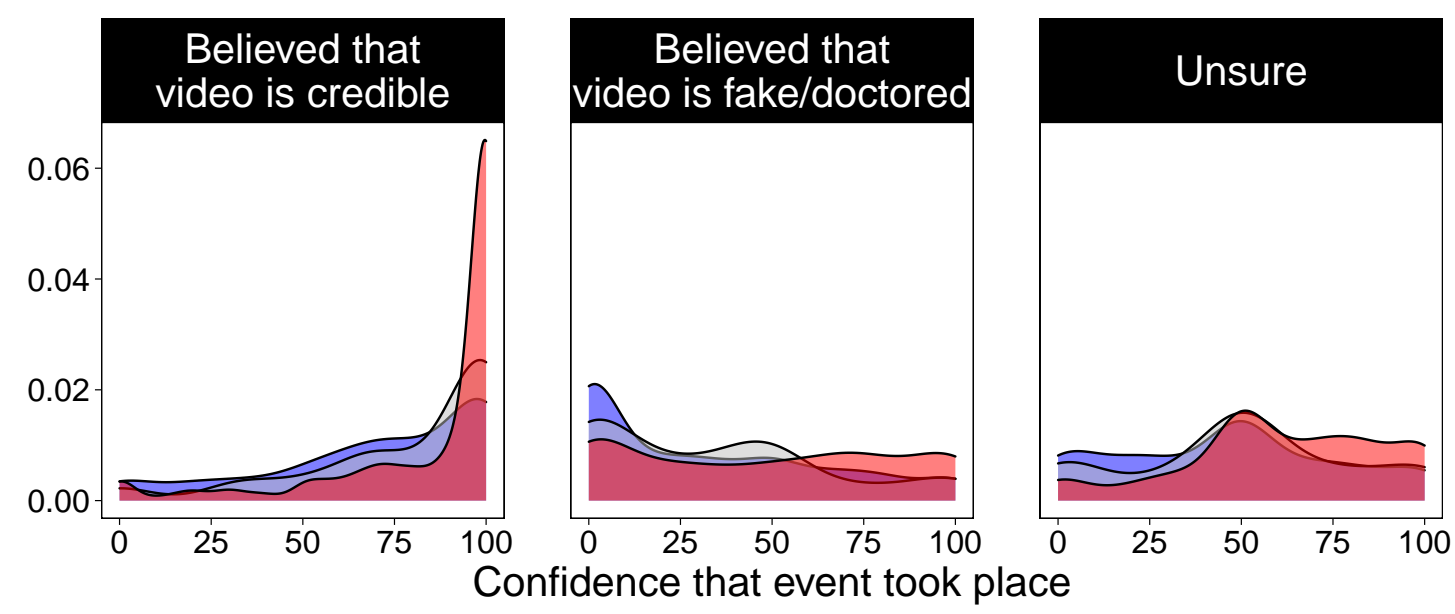

(b) Doanld Trump (COVID-19 precautions announcement)

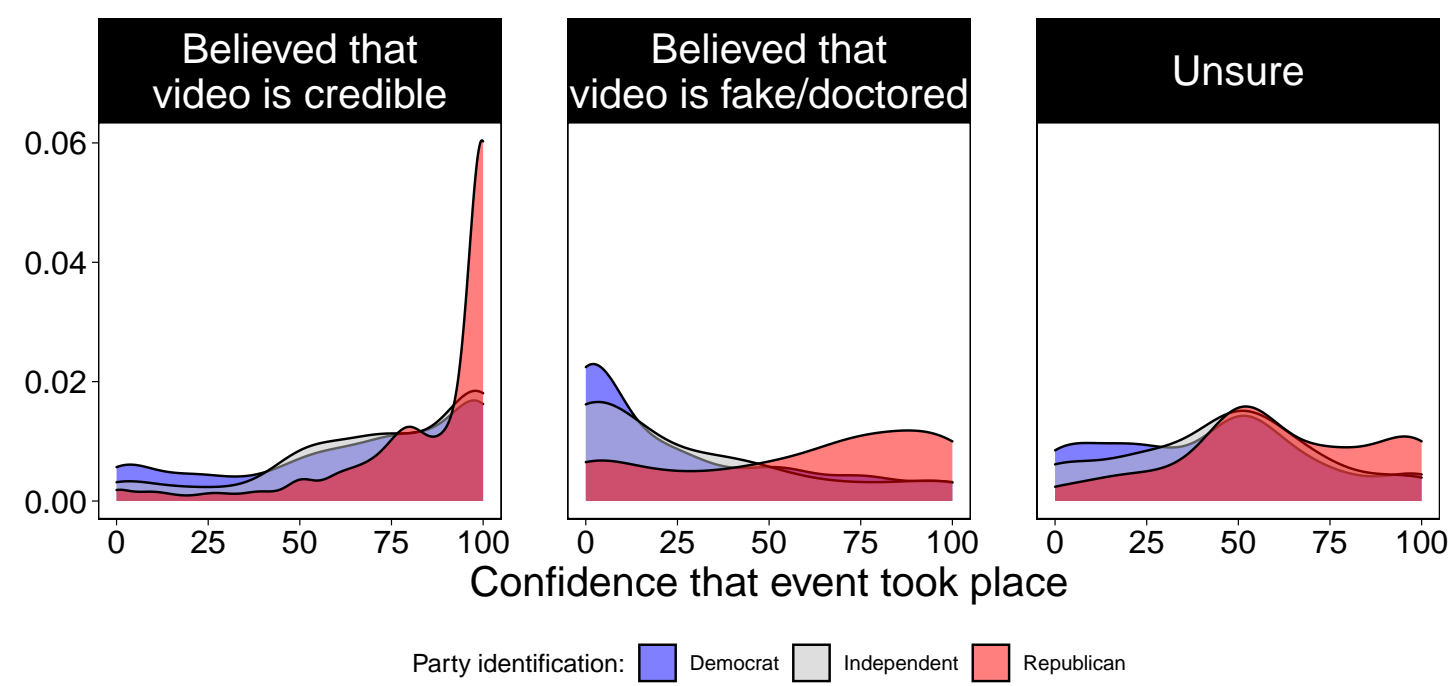

Notes: Clips (a) and (b) are real videos. Results are for $n=5,497$ (99\%) of respondents who provide a response to at least one video in the detection experiment. 